\title{
Biaxial Loading and Shallow-Flaw Effects \\ on Crack-Tip Constraint and Fracture Toughness
}

Manuscript Completed: November 1993

Date Published: January 1994

Prepared by

B. R. Bass, J. W. Bryson, T. J. Theiss, M. C. Rao

Oak Ridge National Laboratory

Managed by Martin Marietta Energy Systems, Inc.

Oak Ridge National Laboratory

Oak Ridge, TN 37831-6285

\section{DISCLAIMER}

This report was prepared as an account of work sponsored by an agency of the United States Government. Neither the United States Government nor any agency thereof, nor any of their

Prepared for

Division of Engineering

Office of Nuclear Regulatory Research

U.S. Nuclear Regulatory Commission

Washington, DC 20555-0001

NRC FIN B0119

Under Contract No. DE-ACO5-84OR21400
Government. Neither the United express or implied, or assumes any legal liability or responsibility for the accuracy, completeness, or usefulness of any information, apparatus, product, or process disclosed, or represents that its use would not infringe privately owned rights. Reference herein to any specific commercial product, process, or service by trade name, trademark, manufacturer, or otherwise does not necessarily constitute or imply its endorsement, recommendation, or favoring by the United States Government or any agency thereof. The views and opinions of authors expressed herein do not necessarily state or reflect those of the United States Government or any agency thereof.

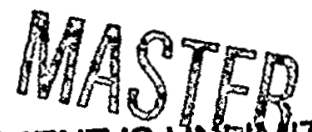




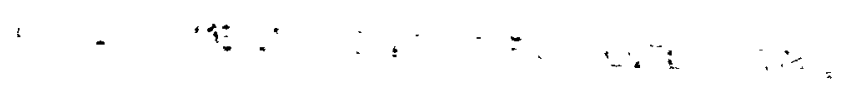




\section{DISCLAIMER}

Portions of this document may be illegible in electronic image products. Images are produced from the best available original document. 


\begin{abstract}
A program to develop and evaluate fracture methodologies for the assessment of crack-tip constraint effects on fracture toughness of reactor pressure vessel (RPV) steels has been initiated in the Heavy-Section Steel Technology (HSST) Program. Crack-tip constraint is an issue that significantly impacts fracture mechanics technologies employed in safety asséssment procedures for commercially licensed nuclear RPVs. A validated technology that incorporates constraint effects is essential to the transfer of fracture toughness data from, for example, miniature fracture toughness surveillance specimens to RPVs. The focus of studies described herein is on the evaluation of two stressed-based methodologies for quantifying crack-tip constraint (i.e., J-Q theory and a micromechanical scaling model based on critical stressed volumes) through applications to experimental and fractographic data. Data were utilized from single-edge notch bend (SENB) specimens and HSST-developed cruciform beam specimens that were tested in HSST shallow-crack and biaxial testing programs. Shallow-crack effects and far-field tensile out-of-plane biaxial loading have been identified as constraint issues that influence both fracture toughness and the extent of the toughness scatter band.
\end{abstract}

Abstract
Results from applications indicate that both the $J-Q$ methodology and the micromechanical scaling model can be used successfully to interpret experimental data from the shallow- and deep-crack SENB specimen tests. When applied to the uniaxially and biaxially loaded cruciform specimens, the two methodologies showed some promising features, but also raised several questions concerning the interpretation of constraint conditions in the specimen based on near-tip stress fields. Fractographic data taken from the fracture surfaces of the SENB and cruciform specimens are used to assess the relevance of stress-based fracture characterizations to conditions at cleavage initiation sites. Comparisons of initiation sites with near-tip stress fields from the SENB shallow-crack specimens tend to support a fracture criterion based on critical stress; however, those utilizing data from the cruciform specimens are ambiguous and require further study. Crack-tip constraint analyses of the shallow-crack cruciform specimen subjected to uniaxial or biaxial loading conditions are shown to represent a significant challenge for these methodologies. Unresolved issues identified from these analyses require resolution as part of a validation process for biaxial loading applications. This report is designated as HSST Report No. 142. 


\section{Contents}

\section{Page}

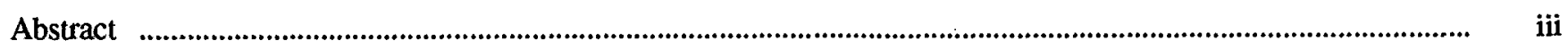

List of Figures

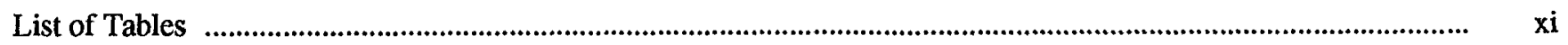

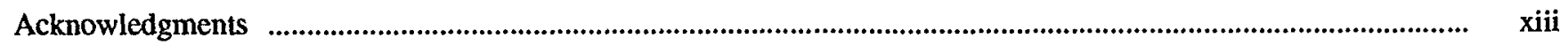

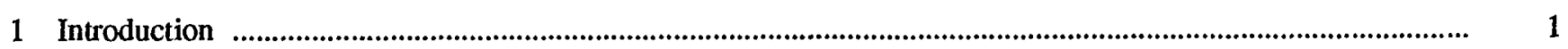

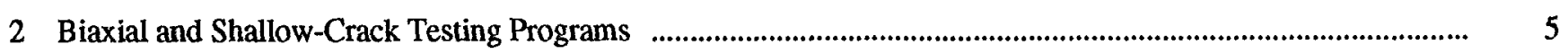

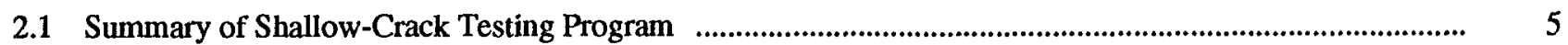

2.2 Biaxial Testing Program .................................................................................................................... 5

2.2.1 Cruciform Bend Specimen ...................................................................................................... 5

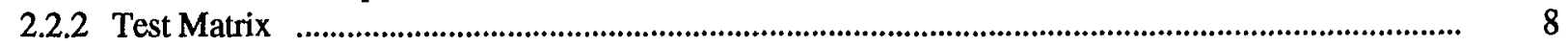

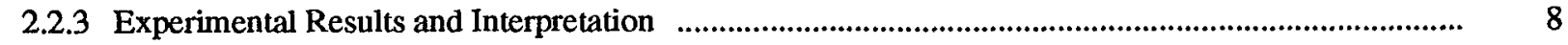

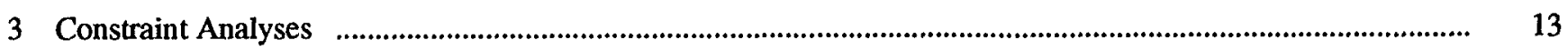

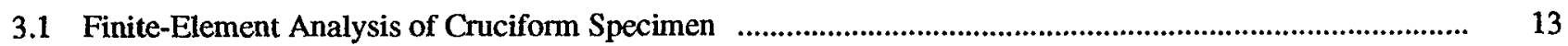

3.2 Stress Triaxiality (J-Q) Method .................................................................................................................... 20

3.2.1 Application of J-Q Method to Shallow-Crack Specimens …............................................................. 20

3.2.2 Application of J-Q Method to Cruciform Specimens .......................................................................... 21

3.3 Fracture Toughness Scaling Model (Dodds-Anderson) …......................................................................... 29

3.3.1 Application of Scaling Model to Shallow-Crack Data .......................................................................... 29

3.3.2 Application of Scaling Model to Cruciform Beam Data .................................................................... 33

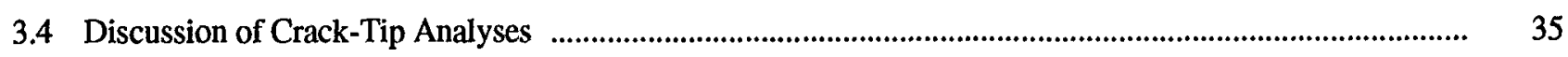

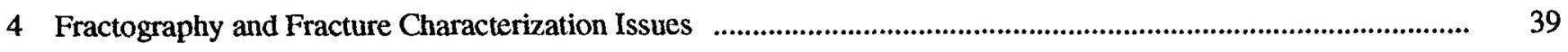

4.1 Fractographic Examinations .....................................................................................................................

4.2 Cleavage Initiation Sites and Stress-Based Fracture Characterization $\quad$............................................................ 39

4.3 3-D Interpretation of Toughness ...................................................................................................... 43

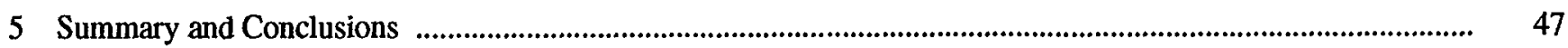

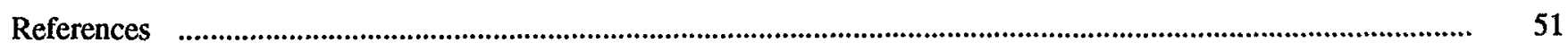

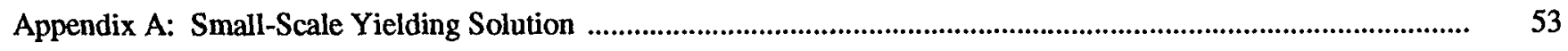

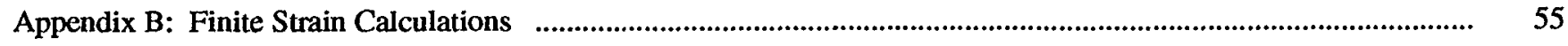




$$
\ldots \therefore \ldots
$$




\section{List of Figures}

Figure

1.1 Vessel wall biaxial far-field stresses during PTS transient with one component aligned parallel to front of longitudinal crack

1.2 Toughness $\left(\mathrm{K}_{\mathrm{Jc}}\right)$ data vs normalized temperature for shallow- and deep-crack specimens with shallow- and deep-crack lower-bound curves

2.1 Cruciform bend specimen used in HSST biaxial testing program: (a) dimensions of cruciform specimen and (b) detail of crack plane

2.2 Slot configurations used in analyses of the cruciform bend specimen: (a) uniform slots on test section boundary, (b) outer slots extended inward by $8.9 \mathrm{~mm}$ across test section boundary, (c) center slot contracted away by $5.1 \mathrm{~mm}$ from test section boundary, (d) a superposition of configurations $(b)$ and $(c)$

2.3 Biaxial and uniaxial shallow-crack toughness data as function of normalized temperature

2.4 Uniaxial and biaxial toughness data as function of crack depth at $\mathrm{T}-\mathrm{RT}$ NDT $=-10^{\circ} \mathrm{C}$

2.5 Toughness data for deep-and shallow-crack specimens as function of load ratio at $\mathrm{T}-\mathrm{RT}_{\mathrm{NDT}}=-10^{\circ} \mathrm{C}$

3.1 Definition of coordinate system and locations of interest for interpretation of finite-element results from analysis of HSST cruciform bend specimen

3.2 (a) Finite-element model for local crack-tip analyses of cruciform bend specimen, $(b)$ test section region of finite-element model for cruciform bend specimen, $(c)$ highly refined crack-tip region of finite-element model for cruciform bend specimen, and $(d)$ finite-element model with expanded region of refinement near the crack tip for analysis of uniaxially loaded cruciform specimen

3.3 Material representation for A $533 \mathrm{~B}$ steel at $\mathrm{T}=-46^{\circ} \mathrm{C}$

3.4 Comparison of calculated and measured LLD for cruciform bend specimens

3.5 Comparison of calculated and measured CMOD for cruciform bend specimens

3.6 Applied J at $\mathrm{X}=0 \mathrm{~mm}$, uniaxial and biaxial 0.6:1 loading

3.7 Applied J at $\mathrm{X}=26 \mathrm{~mm}$, uniaxial and biaxial 0.6:1 loading

3.8 Variation of $\mathrm{K}_{\mathrm{J}}$ along crack front, biaxial 0.6:1 loading

3.9 Variation of normalized $\mathrm{K}_{\mathrm{J}}$ along crack front for both uniaxial and biaxial $0.6: 1$ loading at low load and at load near failure

3.10 Distributions of opening-mode stress component for SENB specimen with a/W $=0.1$

as function of applied load up to crack initiation

3.11 Normalized opening-mode stress ahead of crack tip, $X=0 \mathrm{~mm}$, uniaxial loading

3.12 Normalized opening-mode stress ahead of crack tip, $X=0 \mathrm{~mm}$, biaxial $0.6: 1$ loading

3.13 Variation of $Q$ with normalized distance ahead of the crack tip, $X=0 \mathrm{~mm}$, uniaxial loading 
3.14 Variation of $Q$ with normalized distance ahead of the crack tip, $X=0 \mathrm{~mm}$,

biaxial 0.6:1 loading

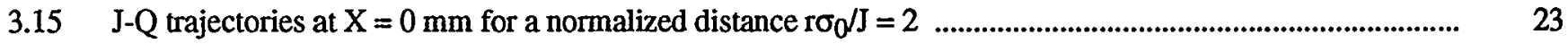

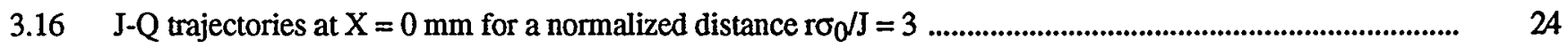

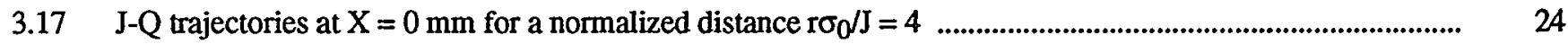

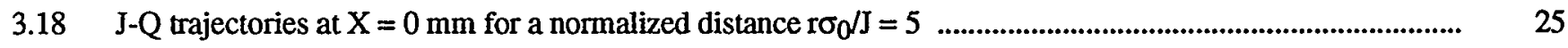

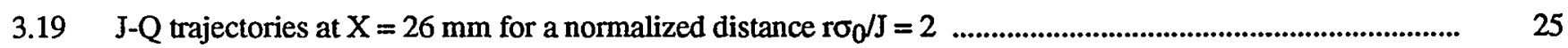

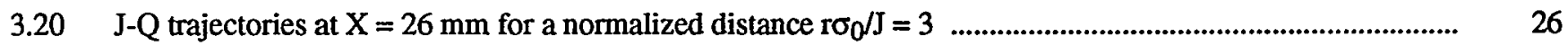

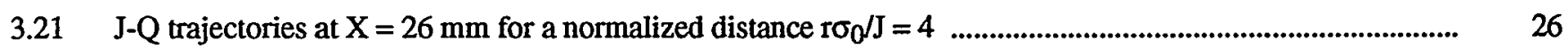

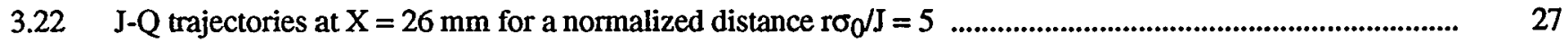

$3.23 \mathrm{~J}-\mathrm{Q}$ failure locus for $\mathrm{A} 533$ grade $\mathrm{B}$ class 1 steel at $\mathrm{T}-\mathrm{RT}_{\mathrm{NDT}}=-10^{\circ} \mathrm{C}$

3.24 HSST shallow-crack fracture toughness results as function of normalized temperature $\mathrm{T}-\mathrm{RT}_{\mathrm{NDT}}$

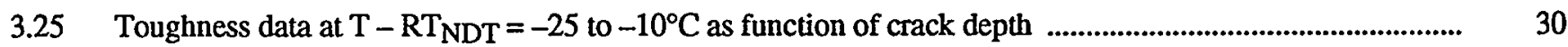

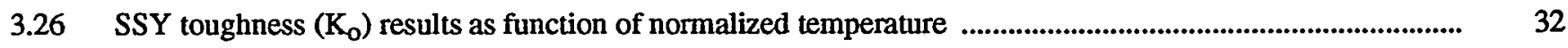

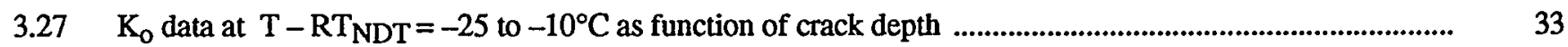

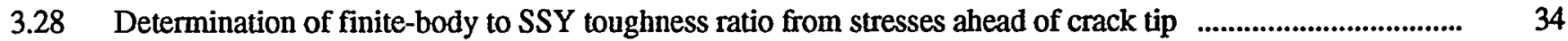

3.29 Finite-body to SSY toughness ratio as a function of normalized distance ahead of crack tip

3.30 Opening-mode stresses ahead of crack tip for the SSY solution and uniaxial and biaxial

cruciform specimens at critical values of $J$

3.31 Q-stress ahead of crack tip at critical values of $J$ for uniaxial and biaxial cruciform specimens ..................... 37

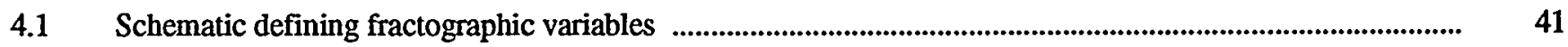

4.2 (a) Distributions of opening-mode stress component for SENB specimen with a/W $=0.1$ as function of applied load up to crack initiation; $(b)$ distribution of opening-mode stress component for biaxial shallow-crack cruciform specimen; $(c)$ toughness vs normalized distance to initiation site for shallowand deep-crack SENB specimens; and $(d)$ toughness vs normalized distance to initiation site for uniaxial and biaxial shallow-crack cruciform specimens

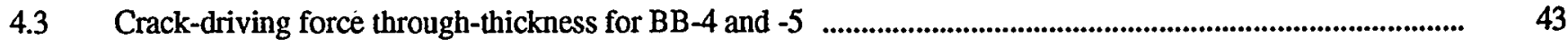

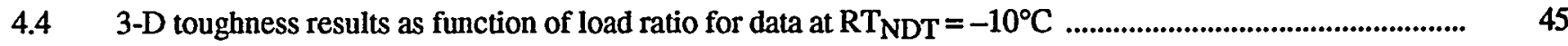

A.1 (a) Finite-element model employed to obtain SSY reference solution; (b) crack-tip region of SSY finite-element model

A.2 SSY plane strain reference fields for cruciform bend specimen

B.1 Comparison of calculated (finite strain) and measured LLD for cruciform bend specimens 
B.2 Comparison of calculated (finite strain) and measured CMOD for cruciform bend specimens

B.3 Applied J at specimen midplane $(\mathrm{X}=0 \mathrm{~mm}$ ) (finite strain) ....................................................................... 56

B.4 Normalized opening-mode stress ahead of crack tip, $X=0 \mathrm{~mm}$, uniaxial loading (finite strain) ..................... 57

B.5 Normalized opening-mode stress ahead of crack tip, $X=0 \mathrm{~mm}$, biaxial 0.6:1 loading (finite strain)

B.6 Variation of $Q$ with normalized distance ahead of crack tip, $X=0 \mathrm{~mm}$, uniaxial loading (finite strain)

B.7 Variation of $Q$ with normalized distance ahead of crack tip, $X=0 \mathrm{~mm}$, biaxial $0.6: 1$ loading (finite strain)

B.8 J-Q trajectories at $\mathrm{X}=0 \mathrm{~mm}$ for normalized distance $\mathrm{r} \sigma_{0} / \mathrm{J}=2$ (finite strain)

B.9 J-Q trajectories at $\mathrm{X}=0 \mathrm{~mm}$ for normalized distance $\mathrm{r}_{0} / \mathrm{J}=3$ (finite strain)

B.10 J-Q trajectories at $\mathrm{X}=0 \mathrm{~mm}$ for normalized distance $\mathrm{r}_{0} / \mathrm{J}=4$ (finite strain)

B.11 J-Q trajectories at $\mathrm{X}=0 \mathrm{~mm}$ for normalized distance $\mathrm{r}_{0} / \mathrm{J}=5$ (finite strain) 



\section{List of Tables}

\section{Table}

Page

$2.1 \quad$ Test matrix for development phase of biaxial testing program $\ldots$

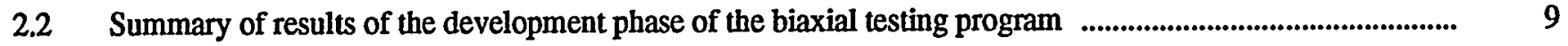

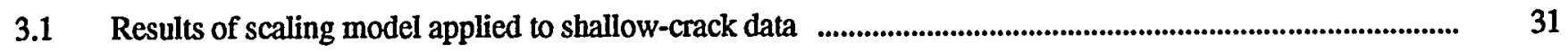

3.2 Scaling model results at distances ahead of crack tip for the uniaxial and biaxial

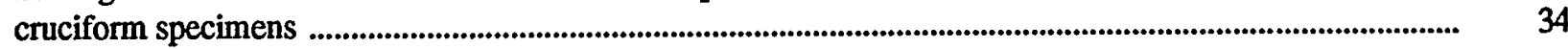

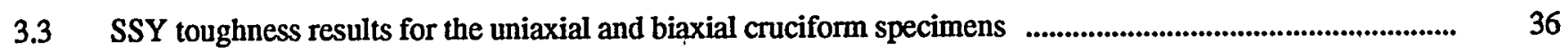

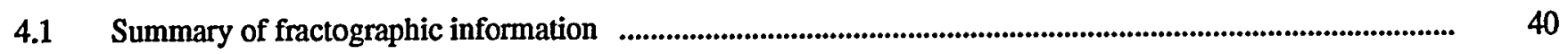

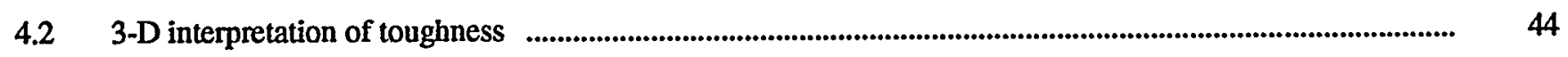



$-\cdots$ $-\cdot \cdot$ 


\section{Acknowledgments}

The authors would like to acknowledge the valuable discussions with Professor Robert H. Dodds, Jr., University of Illinois, concerning interpretations of analytical results presented in this report. We also acknowledge the contributions of Professor Stanley T. Rolfe of the University of Kansas, W.E. Pennell, D. E. McCabe, and J. A. Keeney of ORNL in reviewing this manuscript. 


\section{Introduction}

Postulated pressurized-thermal-shock (PTS) accident conditions remain an important safety assessment issue in the licensing of commercial nuclear reactor pressure vessels (RPVs), especially in the case of aging nuclear plants. The development of technology required for an accurate safety assessment of RPVs under PTS conditions is a focal point of the U.S. Nuclear Regulatory Commission (NRC)-funded Heavy-Section Steel Technology (HSST) Program. Currently, the HSST Program is seeking an improved understanding of several issues that could significantly impact the fracture mechanics technologies employed in these safety-assessment procedures. One important area of research is that of crack-tip constraint, a topic that encompasses a number of factors relating to the material fracture resistance, as well as to the transfer of fracture toughness data from small-scale specimens (i.e., surveillance specimens) to large-scale structures. Factors affecting crack-tip constraint include structural and crack geometry, loading conditions, and material properties. Within these categories, far-field, tensile out-of-plane biaxial loading conditions, and shallow-surface crack effects have been identified as issues that could significantly impact RPV safety assessments. Crack-tip constraint effects of shallow cracks and biaxial loading influence both the fracture toughness and the width of the fracture toughness scatter band (described in this report). These influences can have a substantial impact on the outcome of probabilistic PTS analyses and assessments of startup/cooldown transients for aging nuclear plants.
This report provides an overview of ongoing HSST Program research aimed at evaluating the effects of biaxial loading conditions and shallow-crack geometries on constraint conditions. A validated technology that incorporates these constraint effects is essential to the transfer of fracture toughness data to RPVs from, for example, miniature fracture toughness surveillance specimens. Consequently, development and evaluation of fracture methodologies for the quantitative assessment of crack-tip constraint effects on fracture toughness represent a major element of this research.

The motivation for the HSST biaxial fracture toughness testing program ${ }^{1}$ stems from several observations. First, startup/cooldown and PTS transients produce biaxial stress fields in an RPV wall with a significant positive out-ofplane stress aligned parallel to postulated surface cracks oriented in either the longitudinal or the circumferential direction (Fig. 1.1). Second, current RPV assessments are based on data generated from specimens that were loaded under uniaxial conditions. Furthermore, experimental evidence (see Ref. 1) of the influence of biaxial loading on fracture toughness, although scarce and difficult to interpret, indicates a decrease in toughness associated with biaxial loading. Consequently, a testing program was begun within the HSST Program to examine the influence of biaxial loads on shallow-flaw specimens under conditions prototypic of RPV service conditions.

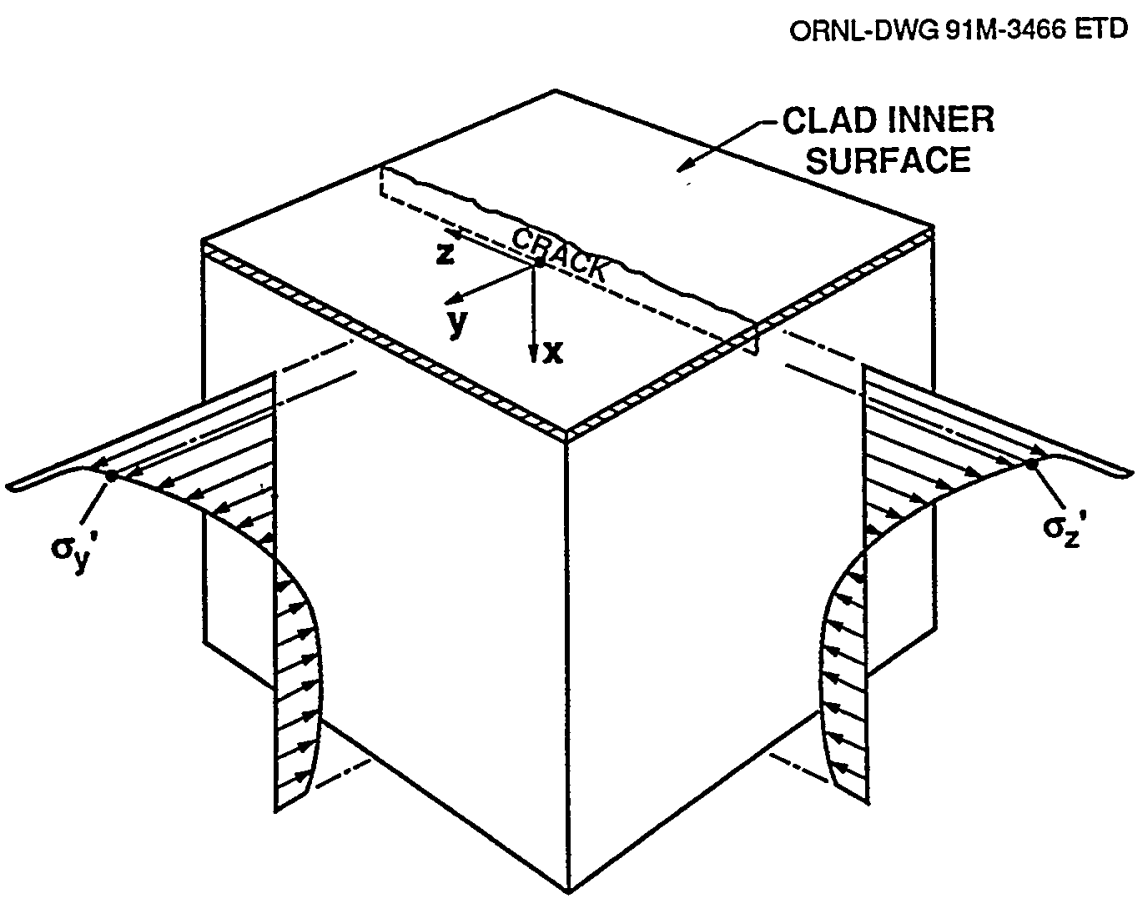

Figure 1.1 Vessel wall biaxial far-field stresses during PTS transient with one component aligned parallel to front of longitudinal crack 


\section{Introduction}

Shallow-flaw specimens were used in the biaxial testing program for several reasons. First, the probability of failure of an RPV in a PTS analysis is dominated by initiations that originate from shallow flaws $(<25 \mathrm{~mm}) .^{2-4}$ Second, recent testing 5 has shown an increase in the fracture toughness of specimens with shallow flaws compared to deepflaw specimens (see Fig. 1.2 taken from Ref. 1).

In Fig. 1.2, the increase in toughness for shallow-crack beams is quantified in terms of a temperature shift. The shallow-crack lower-bound curve for essentially one crack depth was estimated by using the deep-crack lower-bound curve shifted to lower temperatures by $\mathrm{T}_{S}=35 \mathrm{~K}\left(63^{\circ} \mathrm{R}\right)$. This temperature shift, which is crack-depth dependent, could be greater for shallower cracks that are also important in RPV analysis. The shifted lower-bound curve fits the shallow-crack data well at all test temperatures. However, any increase in crack-tip constraint resulting from tensile out-of-plane biaxial stresses would act in opposition to the in-plane constraint relaxation demonstrated by the uniaxial shallow-crack data. Potentially, this could lead to a reverse temperature shift ( $\mathrm{T}_{\mathrm{B}}$ in Fig. 1.2) of the lower-bound toughness curve that offsets the uniaxial "shallow-crack" effect by an undetermined amount. The existence and magnitude of a temperature shift due to biaxial stress effects must be determined from data generated in the transition region of the fracture toughness curve.

Current pressure vessel fracture prevention technology relies on the use of fracture-correlation parameter $(\mathrm{K})$ to characterize both the applied load and the resistance of material to crack initiation. Shortcomings of these conventional one-parameter, fracture-correlation methods, which impact issues associated with the transferability of smallspecimen (i.e., surveillance-sized) toughness data to largescale RPV applications, are being addressed through evaluation of various dual-parameter fracture methodologies. These dual-parameter formulations ${ }^{6-11}$ show promise as practical means for introducing the effect of crack-tip constraint into RPV safety assessments.

The existing methodologies being investigated within the HSST Program include stress-based fracture characterizations (i.e., J-Q methodology of O'Dowd and Shih 6-8,11 combined with Ritchie-Knott-Rice (RKR) fracture criteria ${ }^{12}$ and the Dodds-Anderson constraint correction technique ${ }^{9-11}$ ) and stress-strain-based characterizations (i.e., plane strain fracture ductility techniques of Clausing, ${ }^{13}$ Barsom, ${ }^{14}$ Merkle, ${ }^{15}$ and other researchers). Determinations are being made concerning the bounds of

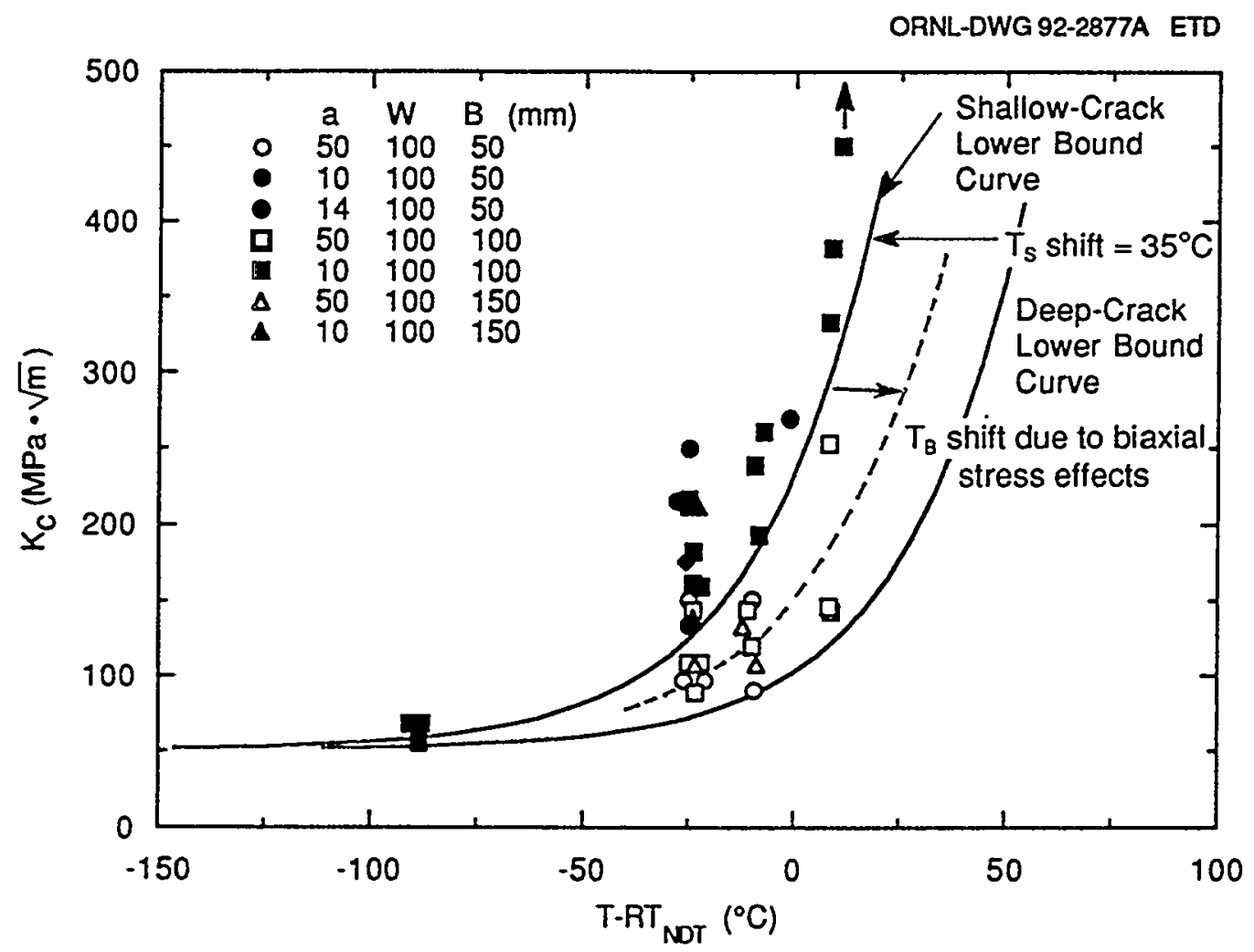

Figure 1.2 Toughness $\left(\mathrm{K}_{\mathrm{Jc}}\right.$ ) data vs normalized temperature for shallow- and deep-crack specimens with shallowand deep-crack lower-bound curves 
applicability of the existing constraint effects correlation methodologies (i.e., how effective are they in matching existing data?). If the existing methodologies are found to be deficient, determinations will be made concerning whether or not they can be modified to make them work. If necessary, alternative constraint methodologies will be developed and validated.

The following chapters describe applications of the stressbased constraint characterizations developed by ODowd and Shih ${ }^{6-8,11}$ and by Dodds and Anderson ${ }^{9-11}$ to experimental and fractographic data obtained from conventional single-edge notch bend (SENB) ${ }^{5}$ and cruciform beam ${ }^{1}$ specimens tested in the HSST Program. Chapter 2 provides summaries of the HSST testing programs 1,5 that utilized conventional shallow- and deep-crack SENB specimens and cruciform specimens tested under uniaxial and biaxial loading, respectively. Chapter 3 describes the effect of loading conditions (biaxial vs uniaxial) on crack-tip stress triaxiality in the cruciform beam specimen, based on applications of J-Q methodology. Also, results from applications of the Dodds-Anderson (D-A) fracture toughness scaling model to data from both conventional SENB and cruciform beam specimens are presented. Fractographic data taken from the fracture surfaces of the beam specimens are described in Chap. 4; also, some fracture characterization issues arising from comparison of analysis predictions with fractographic data are discussed. Finally, a summary and interim conclusions are provided in Chap. 5. 


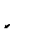




\section{Biaxial and Shallow-Crack Testing Programs}

\subsection{Summary of Shallow-Crack Testing Program}

The HSST Shallow-Crack Fracture Toughness Testing Program has been ongoing since FY 1990, producing data by testing $100-\mathrm{mm}$-deep SENB specimens. Results from the testing portion of the program have been reported previously.5 A summary of the findings from the shallowcrack fracture toughness testing program are included here for completeness.

1. Thirty-eight relatively large ( $\mathrm{W} \sim 100 \mathrm{~mm}$ deep) laboratory beam specimens were tested to compare the behavior of specimens with shallow flaws to that of specimens with deep flaws.

2. The results showed conclusively that shallow-flaw beam specimens of A 533 B material have a significant increase in crack-tip-opening displacement (CTOD) or $\mathrm{J}_{\mathrm{c}}$ toughness $(-150 \%)$ and $\mathrm{K}_{\mathrm{Jc}}$ toughness $(-60 \%)$ over deepcrack specimens in the transition region of the toughness curve. All specimens were $100 \mathrm{~mm}$ deep (W). Shallowcrack beams had crack depths ranging from 9 to $14 \mathrm{~mm}$ (a/W 0.1 to 0.14 ), while deep-crack beams had $50-\mathrm{mm}$ deep cracks $(\mathrm{a} / \mathrm{W} \sim 0.5)$.

3. There is little or no difference in toughness between deep-and shallow-flaw specimens on the lower shelf where linear-elastic conditions exist.

4. Varying the beam thickness from 50 to $150 \mathrm{~mm}$ had little or no influence on the toughness in both the shallowand deep-crack specimens in spite of the fact that the American Society for Testing and Materials (ASTM) E-399 requirement for valid plane strain results were not met. This observation suggests that plane strain behavior for steels of this strength level differ from ASTM E399.

5. In the transition region of the fracture toughness curve, the increase in shallow-flaw toughness compared with deep-flaw toughness appears to be well characterized by a temperature shift of about $35^{\circ} \mathrm{C}$. This temperature shift, which is crack-depth dependent, could be greater for shallower cracks that are also important in RPV safety assessments.

6. Posttest 2-D plane strain analyses were performed on both shallow- and deep-flaw specimens. The analytical
J-integral results were consistent with experimental $\mathrm{J}$-integral results, confirming the validity of the $\mathrm{J}$-estimation schemes used and the effect of flaw depth on fracture toughness.

7. The two-parameter J-Q analysis methodology was used as a means of quantifying the effect of flaw depth on constraint and fracture toughness. Analysis results appear to support the utility of the J-Q concept and interpretation method to characterize the crack-tip fields up to the onset of crack initiation in specimens with either deep or shallow flaws. At J-critical (onset of cleavage initiation) for the deep-flawed specimens, the Q-stress was about zero, indicating small-scale yielding (SSY) conditions. At J-critical for the shallow-flawed specimens, the Q-stress was about -0.7 . This negative $Q$-stress indicates a significant loss of constraint.

8. The observation that the two-parameter J-Q approach correlated with the loss of constraint with decreasing crack depth indicates that a J-Q analysis of actual reactor vessels may give more accurate failure predictions than current analyses.

Results (figures, tables, etc.) from the shallow-crack program have been combined with the biaxial testing program results ${ }^{1}$ and are presented as necessary. Fracture toughness determinations are based on the use of the area under the load vs the crack-mouth-opening-displacement (CMOD) curve method described in Ref. 1.

\subsection{Biaxial Testing Program}

Results of the development phase of the Oak Ridge National Laboratory (ORNL)/HSST biaxial testing program were reported previously in Ref. 1. A description of the cruciform bend specimen and a summary of results from the program are included here for completeness.

\subsubsection{Cruciform Bend Specimen}

The configuration of the cruciform bend specimen used in the testing program is depicted in Fig. 2.1. The specimen has a cruciform-shaped geometry with a cross section with dimensions of $91 \times 102 \mathrm{~mm}$ and a straight through-crack of uniform depth of $10 \mathrm{~mm}$ in the test section. The total length of this specimen in the longitudinal or transverse direction, including the test section and the loading arms, is $610 \mathrm{~mm}$. Three slots are machined into each arm to minimize diffusion of the load around the test section 


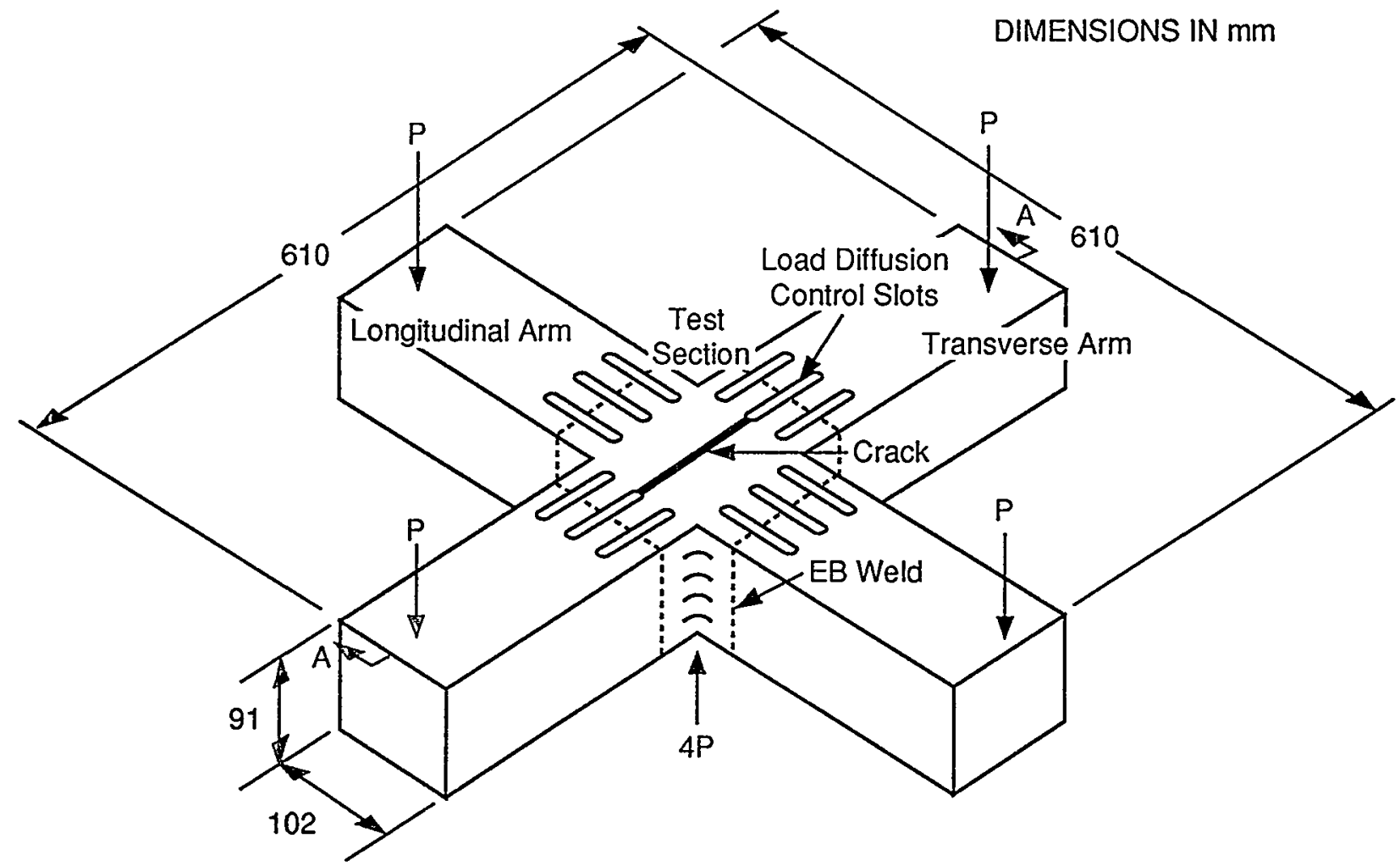

(a)

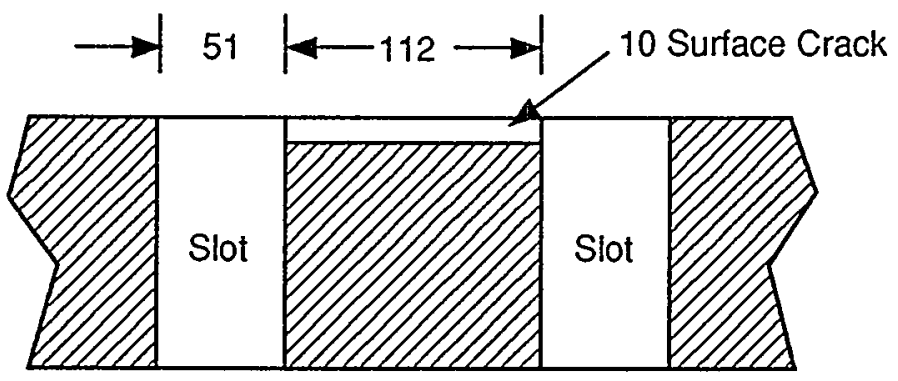

(b)

Section A-A

Figure 2.1 Cruciform bend specimen used in HSST biaxial testing program: (a) dimensions of cruciform specimen and (b) detail of crack plane

containing the through-crack. The crack is cut between two opposite central load diffusion control slots to produce a two-dimensional (2-D) shallow crack with no singularity on the surface. Figure 2.1(b) shows the profile of the crack and the intersection of the crack and the central slot.

The test section of the specimen is fabricated from A 533 grade B class 1 steel plate previously employed in the HSST wide-plate ${ }^{16,17}$ and shallow-crack ${ }^{5}$ testing programs. The specimen is notched and precracked after the two longitudinal arms are electron-beam (EB) welded to the test section. EB welding is employed to ensure minimal distortion in the specimen and a relatively small heataffected zone. The distance from the weld to the crack is sufficiently large that residual stresses at the crack tip are low. Following precracking, a machining operation is performed to remove an embrittled layer of material thickness $(-0.38 \mathrm{~mm})$ at the root of each central load-diffusion control slot where it intersects the crack. The embrittled layers are introduced into the specimen by an electro-discharge machining process used to cut the slots. Then the transverse arms are EB welded to the specimen. 
Instrumentation is placed on the specimen to monitor CMOD, load-line displacement (LLD), surface strain, and temperature at various locations. A special load reaction system has been constructed for applying bending loads (P) to the arms of the specimen in a statically determinant manner. Loading is applied at midspan to the specimen using a square, flat seat having rounded edges and the same planar dimensions as the test section. The test section bends into two orthogonal surfaces that contact the seat along the outer edges, resulting in eight-point bending (or four-point bending for the uniaxial case). Additional details concerning instrumentation and the specially designed loading system for the cruciform specimen are given in Ref. 18.

An important element in the design of the cruciform specimen concerns the optimal positioning of the center loaddiffusion control slots to minimize peak $\mathrm{K}_{\mathrm{I}}$ values and stress concentrations at the end of the crack. Results from 2-D and three-dimensional (3-D) finite-element analyses (described in Ref. 1) indicate that locating the center and outer load-diffusion control slots at different distances from the specimen midplane can be effective in controlling these peak $K_{I}$ values. Figure 2.2 illustrates different slot configurations that were analyzed to demonstrate the techniques. In Fig. 2.2(a), the edge of the center slot is positioned at the boundary of the specimen test section. In Fig. 2.2(b), the outer slot extends inward across the test section boundary for a distance of $8.9 \mathrm{~mm}$ and toward the specimen centerline. Figure 2.2(c) shows a configuration from which the center slot is located away from the test section boundary a distance of $5.1 \mathrm{~mm}$ and away from the specimen centerline. The slot configuration of Fig. 2.2(d) represents a superposition of the shift in the outboard slots of Fig. 2.2(b) and of the center slot in Fig. 2.2(c), which yields a cumulative slot differential of $14 \mathrm{~mm}$. The common factor of configurations $(b)-(d)$ in Fig. 2.2 is that the outer slots project farther in toward the specimen centerline than does the center slot. Slot configuration $(d)$ essentially eliminates stress concentrations that are present at the ends of the crack in configuration (c). Results for contours of von Mises effective stress (see Ref. 1) indicate a similar reduction in stress peaks at the end of the crack for configuration (d) when compared to configuration (c).

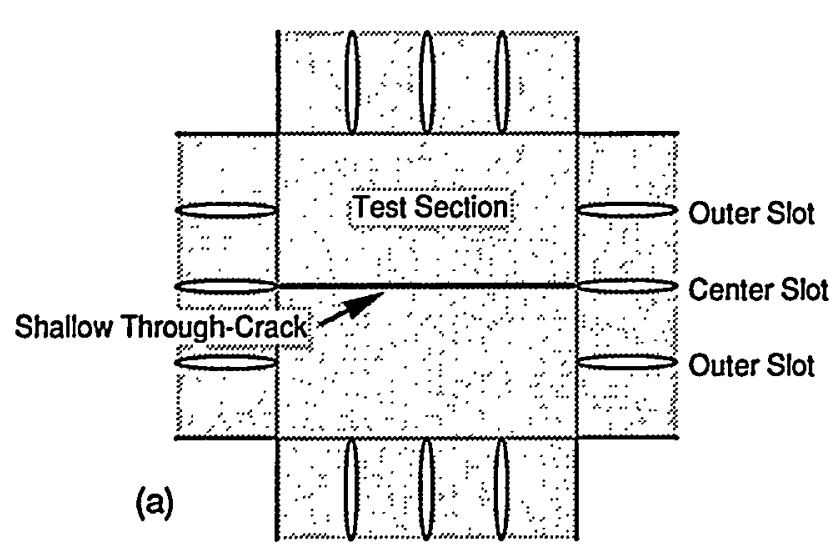

ORNL-DWG 93-2729 ETD

(b)
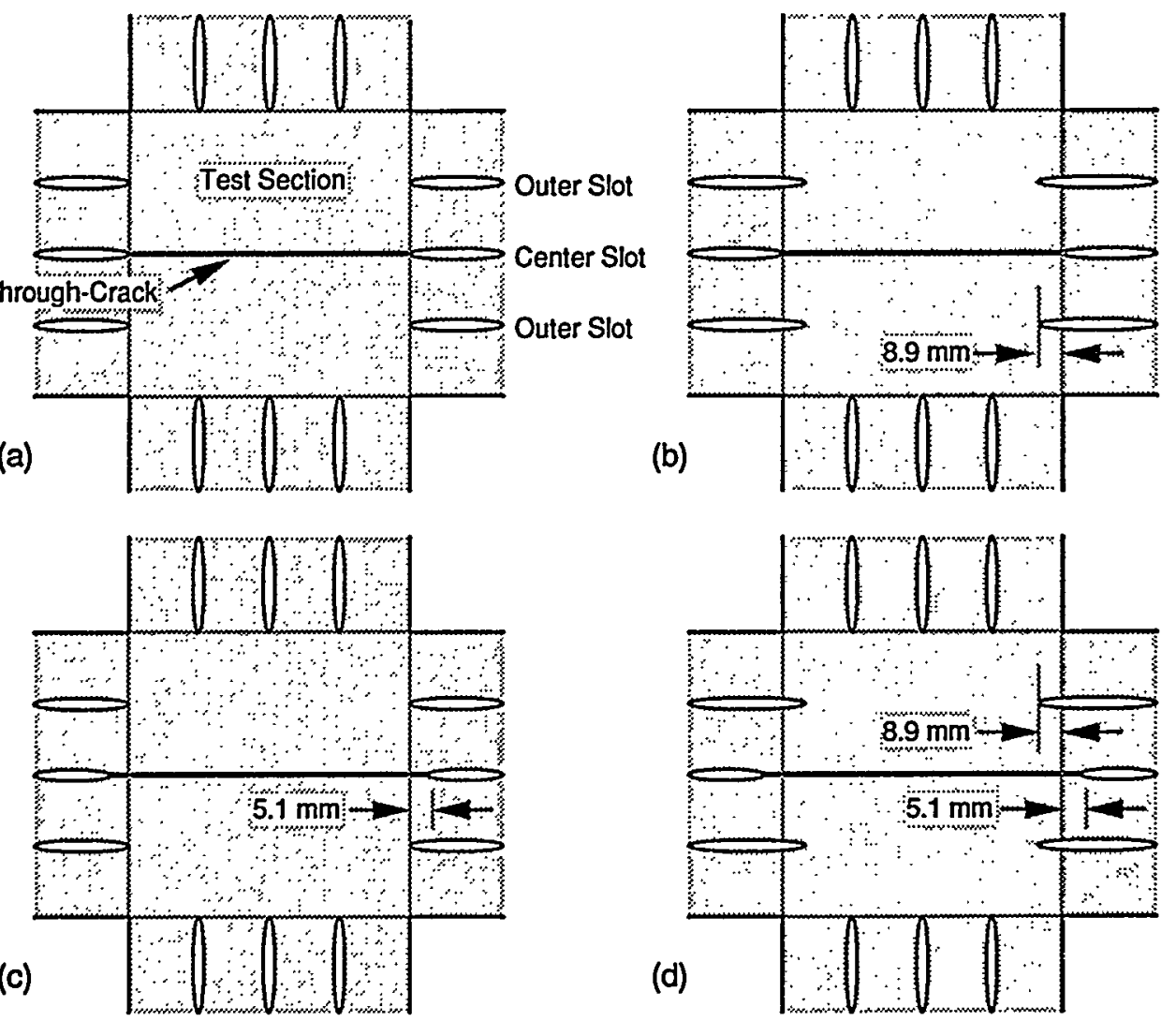

Figure 2.2 Slot configurations used in analyses of the cruciform bend specimen: $(a)$ uniform slots on test section boundary, (b) outer slots extended inward by $8.9 \mathrm{~mm}$ across test section boundary, $(c)$ center slot contracted away by $5.1 \mathrm{~mm}$ from test section boundary, $(d)$ a superposition of configurations $(b)$ and $(c)$ 


\subsubsection{Test Matrix}

The HSST Program assigned five cruciform specimens to the initial development phase of the biaxial testing program. These "development" specimens were used to evaluate the performance of the test specimen, test fixture, and procedures and to develop a test specimen geometry suitable for the generation of biaxial fracture toughness data.

Three specimen configurations having slot geometries shown in Fig. 2.2(b)-(d) were tested. As indicated in the summary of the test matrix shown in Table 2.1, configurations $(c)$ and $(d)$ represented two specimens each. In addition, to ensure that initiation did not occur at the crack-slot intersection of configuration $(d)$, each corner of the crack was blunted with a slitting saw.

Table 2.1 Test matrix for development phase of biaxial testing program

\begin{tabular}{ccc}
\hline Specimen No. & $\begin{array}{c}\text { Test section } \\
\text { configuration }\end{array}$ & Load ratio \\
\hline BB-1 & $b$ & $0.6: 1$ \\
BB-2 & $c$ & $0: 1$ \\
BB-3 & $c$ & $0.6: 1$ \\
BB-4 & $d$ & $0.6: 1$ \\
BB-5 & $d$ & $0.6: 1$ \\
\hline
\end{tabular}

Of the five development specimens, four were tested under biaxial loading, and one was tested under uniaxial loading. All biaxially loaded cruciform specimens were tested with a transverse-to-longitudinal load ratio of $0.6: 1$, as described in Ref. 1 . The uniaxially loaded cruciform specimen allows comparison with previous uniaxial shallowcrack specimens under identical test conditions (crack depth, temperature, etc.). Testing cruciform specimens in both uniaxial and biaxial loading configurations will allow toughness values to be measured with only one test condition changed, namely, the out-of-plane loading.

Test conditions were selected to facilitate comparison of data from the cruciform specimens with previous HSST shallow-crack data tested under uniaxial conditions. ${ }^{5}$ Several of the uniaxial shallow-crack tests were conducted at $\mathrm{T}-\mathrm{RT} \mathrm{T}_{\mathrm{NDT}}=-10^{\circ} \mathrm{C}$, which is in the transition region of the deep-crack toughness curve for A $533 \mathrm{~B}$ steel. The A 533 B steel used for the test section material in these tests has an $\mathrm{RT}_{\mathrm{NDT}}$ of $-35^{\circ} \mathrm{C}$. Therefore the test temperature for the cruciform specimen tests was set at $-45^{\circ} \mathrm{C}$. The cruciform specimens were $91 \mathrm{~mm}$ deep with a crack depth of $10 \mathrm{~mm}$. The beam width (W) and crack depth (a) of the cruciform specimen are approximately the same as for the HSST shallow-crack beams.

\subsubsection{Experimental Results and Interpretation}

The conditions of each specimen at failure, test temperature, and specimen geometry are tabulated in Table 2.2 (from Ref. 1). Also included in the table are the plastic component of the area under each $P$ vs LLD curve (defined as $\mathrm{U}_{\mathrm{p}}$ ) and $\mathrm{P}$ vs $\mathrm{CMOD}$ curve (defined as $\mathrm{A}_{\mathrm{pl}}$ ). Table 2.2 also lists the estimated toughness values for the tests with the parameters used to estimate the toughness. The load indicated in the table refers to the longitudinal load, that is, the total load (as measured by the load cell) divided by 1.6 for the biaxial tests. The results indicated in Table 2.2 reveal consistent, repeatable mechanical responses for the five tests.

The test results indicate that the critical load for each specimen was similar but that in the uniaxial test (BB-2) the specimen was able to withstand substantially more $(\approx 60 \%)$ deflection (LLD or CMOD) than the biaxial tests (BB-1, -4, and -5). (Strains imposed in these tests were substantially higher than any that would be produced in an RPV either from normal or accident loading; this is a consequence of testing in the transition region of the toughness curve.) In addition, the plastic "work" at the crack tip as defined by either $U_{p l}$ or $A_{p l}$ in the three biaxial tests was about one-third of the corresponding uniaxial value of $U_{p l}$ or $A_{p l}$. Furthermore, the critical displacements (LLD or $\mathrm{CMOD})$ and work performed $\left(\mathrm{U}_{\mathrm{pl}}\right.$ or $\left.\mathrm{A}_{\mathrm{p}}\right)$ were consistent for the three interpretable biaxial test results. These results indicate a pronounced reduction in the ductility of the material at fracture (as measured by critical displacement or work) due to biaxial loading.

Toughness data for the biaxial and uniaxial cruciform specimens were calculated using the techniques described in Ref. 1. The critical J-integral values were converted to critical elastic-plastic, stress-intensity factors $\mathrm{K}_{\mathrm{Jc}}$ using the plane strain formulation.* The data necessary to estimate $J$ and the resulting toughness values are tabulated in

\footnotetext{
* Some adjustment of the relationship between J and $\mathrm{K}$ may be appropriate for the positive out-of-plane strain condition generated in the biaxially loaded cruciform specimen. The form of this adjustment (if any) has not yet been investigated; however, future plans call for it to be a subject of study within the HSST Program. In this report, the plane strain conversion from $\mathrm{J}$ to $\mathrm{K}$ is employed as a matter of convention for comparison with existing data. Experimental and analytical results described herein for toughness values and crack-driving forces are generated in terms of $\mathrm{J}$ and consequently are unaffected by the conversion from $\mathrm{J}$ to $\mathrm{K}$.
} 
Table 2.2 Summary of results of the development phase of the biaxial testing program

\begin{tabular}{|c|c|c|c|c|c|c|}
\hline - & BB-1 & BB-2 & BB-3 & BB-4 & BB-5 & $\begin{array}{c}\text { Average SENB } \\
\text { data } \\
\text { (for comparison) }\end{array}$ \\
\hline $\begin{array}{l}\text { Load ratio } \\
\text { Geometry }\end{array}$ & $0.6: 1$ & $0: 1$ & $0.6: 1$ & $0.6: 1$ & $0.6: 1$ & \\
\hline $\begin{array}{l}\mathrm{B}, \mathrm{mm} \\
\mathrm{W}, \mathrm{mm} \\
\mathrm{a}, \mathrm{mm}\end{array}$ & $\begin{array}{l}102 \\
91 \\
11.1\end{array}$ & $\begin{array}{l}111 \\
91 \\
10.6\end{array}$ & $\begin{array}{l}112 \\
91 \\
8.8\end{array}$ & $\begin{array}{l}111 \\
91 \\
10.1\end{array}$ & $\begin{array}{l}111 \\
91 \\
10.0\end{array}$ & $\begin{array}{l}101 \\
102 \\
10.7\end{array}$ \\
\hline Temperature, ${ }^{\circ} \mathrm{C}$ & -45 & -41 & -47 & -46 & -44 & $-23^{a}$ \\
\hline $\begin{array}{l}\text { Failure conditions } \\
\qquad \begin{array}{l}\mathrm{P}, \mathrm{kN} \\
\mathrm{LLD}, \mathrm{mm} \\
\mathrm{CMOD}, \mathrm{mm} \\
\mathrm{U}_{\mathrm{pl}}, \mathrm{kN}-\mathrm{mm} \\
\mathrm{A}_{\mathrm{pl}}, \mathrm{kN}-\mathrm{mm}\end{array}\end{array}$ & $\begin{array}{l}784 \\
4.20 \\
0.47 \\
958 \\
168\end{array}$ & $\begin{array}{l}784 \\
8.51 \\
0.82 \\
4110 \\
455\end{array}$ & $b$ & $\begin{array}{l}818 \\
5.10 \\
0.47 \\
1523 \\
181\end{array}$ & $\begin{array}{l}751 \\
5.08 \\
0.51 \\
1501 \\
206\end{array}$ & $\begin{array}{l}763 \\
4.06 \\
0.65 \\
1163 \\
329\end{array}$ \\
\hline $\begin{array}{c}\eta \text {-factors } \\
\eta^{\ell}\end{array}$ & 0.195 & 0.117 & $b$ & 0.189 & 0.190 & 1.15 \\
\hline$\eta_{\mathrm{pl}}^{\mathrm{c}}$ & 3.53 & 2.76 & & 3.55 & 3.61 & 3.48 \\
\hline $\begin{array}{l}\text { Fracture toughness } \\
\text { Elastic component }\end{array}$ & & & $b$ & & & \\
\hline $\begin{array}{l}\mathrm{J}_{\mathrm{el}}, \mathrm{kN} / \mathrm{m} \\
\mathrm{K}_{\mathrm{I}}, \mathrm{MPa} \sqrt{\mathrm{m}}\end{array}$ & $\begin{array}{l}66.7 \\
120\end{array}$ & $\begin{array}{l}67.4 \\
120\end{array}$ & & $\begin{array}{l}72.6 \\
125\end{array}$ & $\begin{array}{l}61.2 \\
115\end{array}$ & $\begin{array}{l}67 \\
122\end{array}$ \\
\hline $\begin{array}{l}\text { P vs CMOD } \\
\mathrm{J}_{\mathrm{pl}}, \mathrm{kN} / \mathrm{m} \\
\text { Total J, kN/m } \\
\mathrm{K}_{\mathrm{Jc}}, \mathrm{MPa} \sqrt{\mathrm{m}}\end{array}$ & $\begin{array}{l}73.3 \\
140 \\
175\end{array}$ & $\begin{array}{l}141 \\
209 \\
214\end{array}$ & & $\begin{array}{l}71.8 \\
144 \\
178\end{array}$ & $\begin{array}{l}82.8 \\
144 \\
178\end{array}$ & $\begin{array}{l}125 \\
192 \\
206\end{array}$ \\
\hline $\begin{array}{l}\text { P vs LLD } \\
\mathrm{J}_{\mathrm{pl}} \\
\text { Total J } \\
\mathrm{K}_{\mathrm{Jc}}\end{array}$ & $\begin{array}{l}23.1 \\
89.7 \\
140\end{array}$ & $\begin{array}{l}54.1 \\
122 \\
163\end{array}$ & & $\begin{array}{l}32.1 \\
105 \\
151\end{array}$ & $\begin{array}{l}31.7 \\
92.9 \\
143\end{array}$ & $\begin{array}{l}145 \\
212 \\
216\end{array}$ \\
\hline
\end{tabular}

$a_{\mathrm{RT}} \mathrm{NDT}$ for this material is $-15^{\circ} \mathrm{C}$, so $\mathrm{T}-\mathrm{RT}$ NDT for these tests is the same.

$b_{\text {Not reported due to initiation in the corner. }}$

Table 2.2. The P vs CMOD method is considered the more sensitive of the techniques examined for determining fracture toughness shallow-flaw specimens and is the primary method used for the cruciform specimen analysis.

Toughness results for the SENB and cruciform specimens expressed in terms of $\mathrm{K}_{\mathrm{Jc}}$ are shown in Figs. 2.3-2.5 (taken from Ref. 1). Figure 2.3 shows the deep- and shallow-crack uniaxial toughness data as a function of normalized temperature. The data at $\mathrm{T}-\mathrm{RT}$ NDT $=-10^{\circ} \mathrm{C}$ are plotted as a function of crack depth in Fig. 2.4 and as a function of load ratio in Fig. 2.5. Examination of the data in Figs. 2.3-2.5 and Table 2.2 reveals several important points. First, biaxial loading appears to reduce the fracture toughness compared with either the uniaxial cruciform value from test
BB-2 or the SENB data. The average of the biaxial toughness is $\approx 20 \%$ less than the uniaxial cruciform value and $\approx 18 \%$ less than the average of the uniaxial SENB and cruciform results. ${ }^{*}$ Second, the uniaxial cruciform value is consistent with the SENB toughness results; this tends to validate the use of the cruciform specimen for uniaxial data generation. Third, the scatter band of the biaxial data may

\footnotetext{
* Conventional laboratory specimens have an essentially uniform crackdriving force through the thickness. Thus, toughness interpretations are based on a 2-D calculation without regard to the location of initiation sites along the crack front. The variation in crack-driving force through the thickness of the cruciform is substantially greater than that of conventional specimens. This variation, combined with fractography data on location of initiation sites, provides a basis for 3-D interpretations of fracture toughness described in Chap. 4. This 3-D interpretation tends to lower the toughness value determined from the specimen.
} 
Biaxial

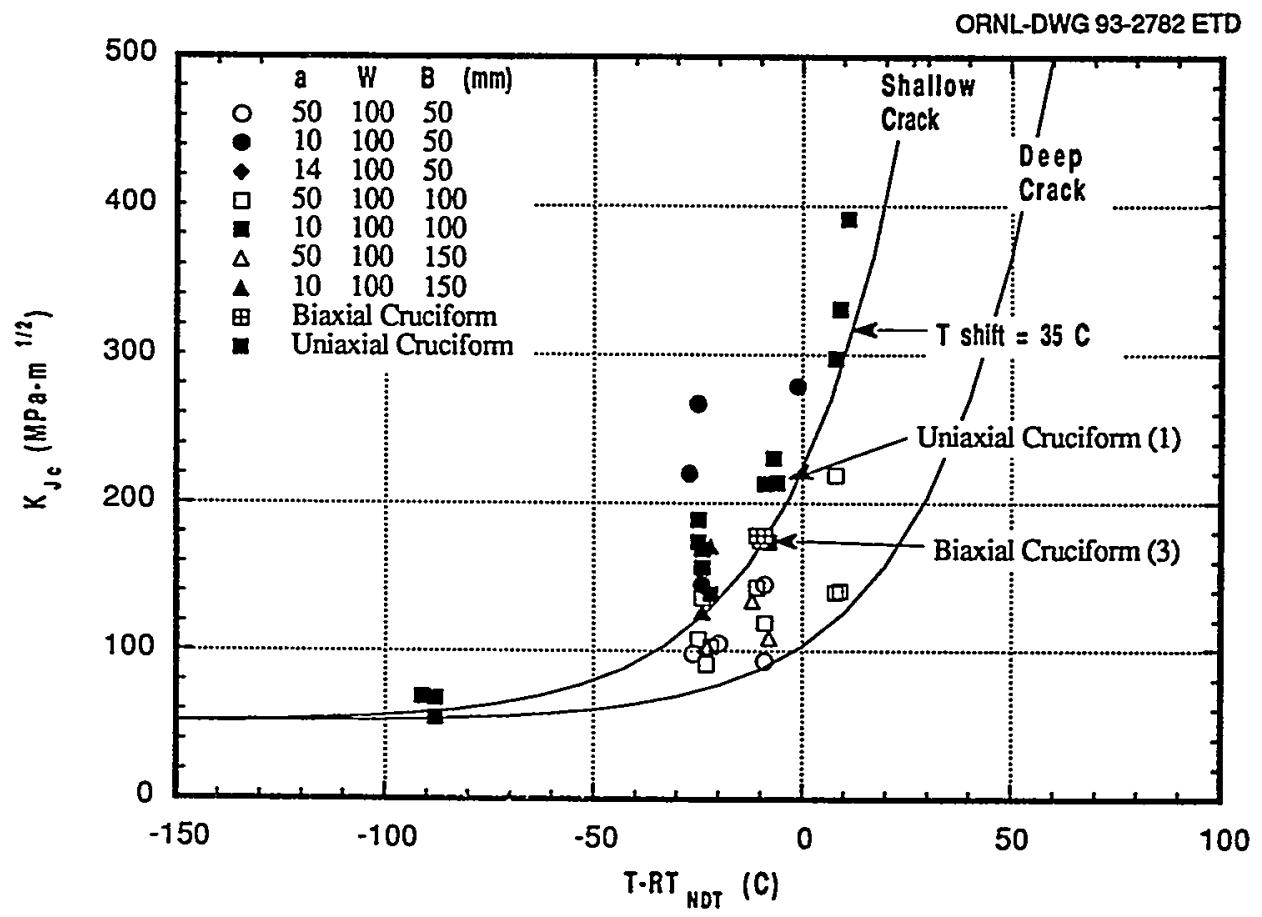

Figure 2.3 Biaxial and uniaxial shallow-crack toughness data as function of normalized temperature

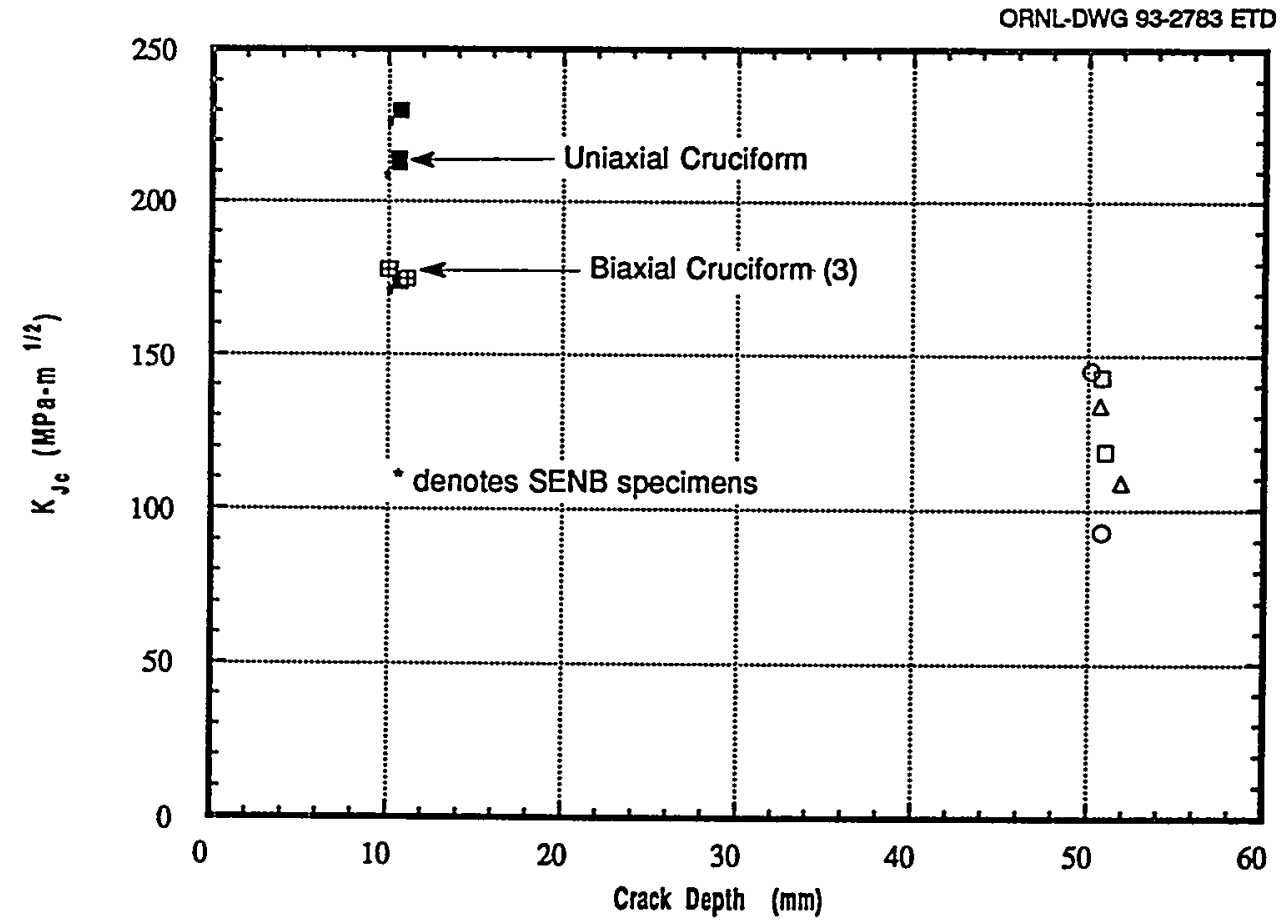

Figure 2.4 Uniaxial and biaxial toughness data as function of crack depth at $\mathrm{T}-\mathbf{R T}_{\mathrm{NDT}}=-10^{\circ} \mathrm{C}$ 


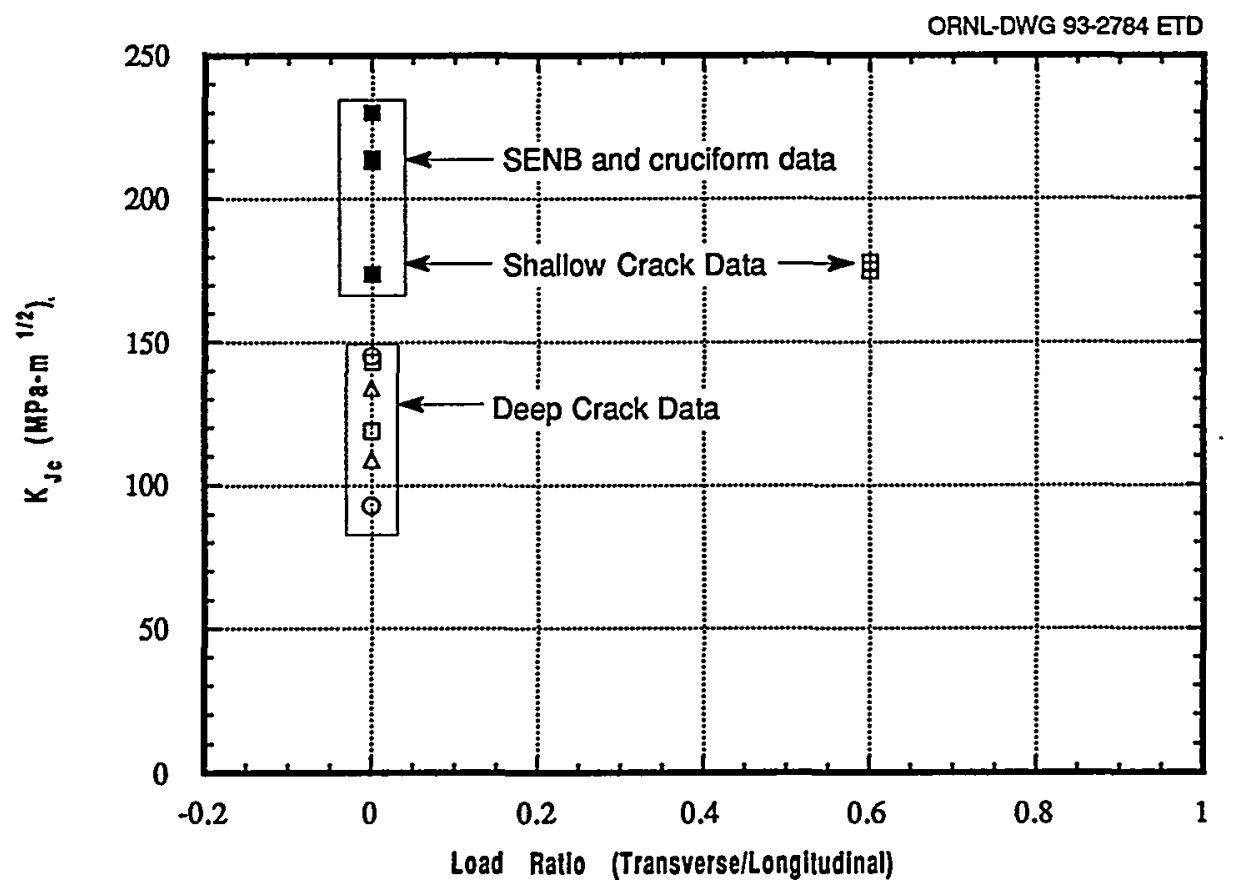

Figure 2.5 Toughness data for deep- and shallow-crack specimens as function of load ratio at $\mathrm{T}-\mathrm{RT}$ NDT $=-10^{\circ} \mathrm{C}$

be less than that associated with the uniaxial, shallowcrack data. An increase in toughness and scatter is associated with loss of constraint in laboratory specimens. Results presented in Fig. 2.4 indicate that biaxially loaded cruciform specimens yield results with reduced scatter. The trends in the biaxial and uniaxial cruciform data described here are tentative results based on very limited data. Addi- tional data are required to substantiate these trends and to provide better quantification of the effect of biaxial loading on fracture toughness. Nonetheless these initial results strongly suggest that an improved understanding of the shallow-flaw and biaxial loading effects would significantly impact the fracture mechanics technologies employed in reactor vessel failure predictions. 


\section{Constraint Analyses}

\subsection{Finite-Element Analysis of Cruciform Specimen}

Three-dimensional elastic-plastic, finite-element analyses were performed on the cruciform specimen depicted in Fig. 2.1. Local crack-tip stress fields obtained from these analyses are used in applications of stress-based constraint characterization models. The one-fourth section of the cruciform specimen depicted schematically in Fig. 3.1 is represented in the 3-D finite-element model of Fig. 3.2. The model consists of 18,650 nodes and 3,890 twenty-node isoparametric brick elements. Collapsed-prism elements arranged in a focused or centered fan configuration at the crack tip are used to produce a $1 / r$ strain singularity appropriate for inelastic analysis. Reduced integration was employed to eliminate shear locking in the elements. The cruciform specimen is assumed to be supported on a rigid plate under the test section [i.e., the area defined by $(-51 \mathrm{~mm} \leq \mathrm{Z} \leq 0,0 \leq \mathrm{X} \leq 51 \mathrm{~mm})$ in Fig. 3.1] and loaded by uniformly applied forces at the ends of the longitudinal/ transverse arms (i.e., locations $C$ and D in Fig. 3.1) to produce the uniaxial or biaxial bending conditions. The rigid support plate is incorporated into the finite-element model of Fig. 3.2 using a contact element option in the ABAQUS (Ref. 19) finite-element program.

The full geometry of the load-diffusion control slots is represented in the finite-element model [Fig. 3.2(b)]. The slot geometry incorporated in the model is represented by the configuration of Fig. 2.2(d), which was used for test specimens BB-4 and -5 . The same finite-element model was used for analysis of specimen BB-2, although the latter employed a different slot configuration [Fig. 2.2(c)]. The model also incorporated a highly refined mesh in the crack-tip region [Fig. $3.2(c)$ ] to provide resolution of stress fields over the normalized distance $2 \leq \mathrm{r} \sigma_{0} / \mathrm{J} \leq 5$ in front of the crack.

The outermost semicircular ring of nodes in the mesh of Fig. 3.2(c) has a radius of $2 \mathrm{~mm}$. This radius was extended to $4 \mathrm{~mm}$ in a second finite-element model developed for analysis of the BB-2 test [Fig. 3.2(d)]. The relatively

\section{ORNL-DWG 93M-2578A ETD}

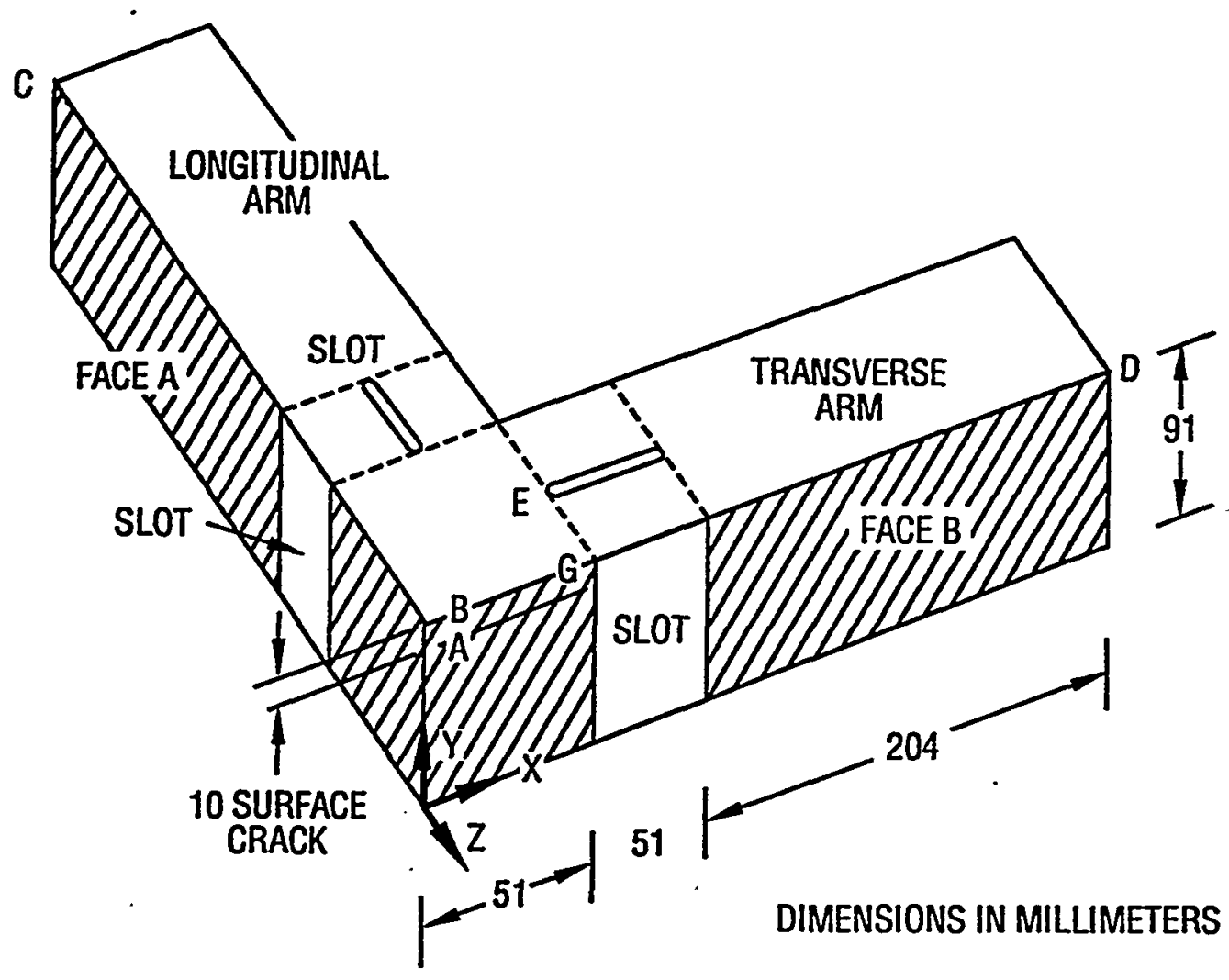

Figure 3.1 Definition of coordinate system and locations of interest for interpretation of finite-element results from analysis of HSST cruciform bend specimen 

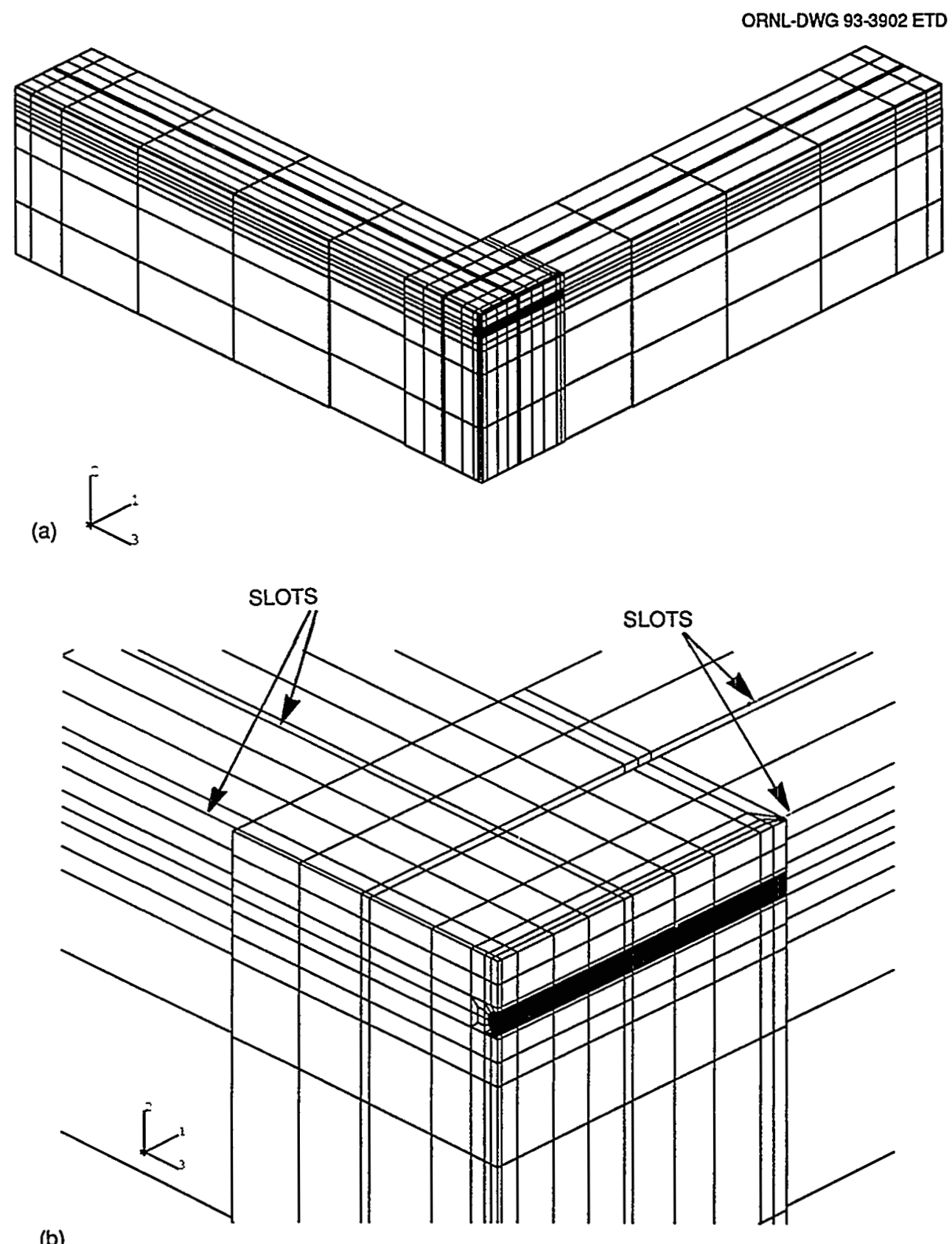

(b)

Figure 3.2 (a) Finite-element model for local crack-tip analyses of cruciform bend specimen, $(b)$ test section region of finite-element model for cruciform bend specimen, $(c)$ highly refined crack-tip region of finite-element model for cruciform bend specimen, and (d) finite-element model with expanded region of refinement near the crack tip for analysis of uniaxially loaded cruciform specimen 
Constraint

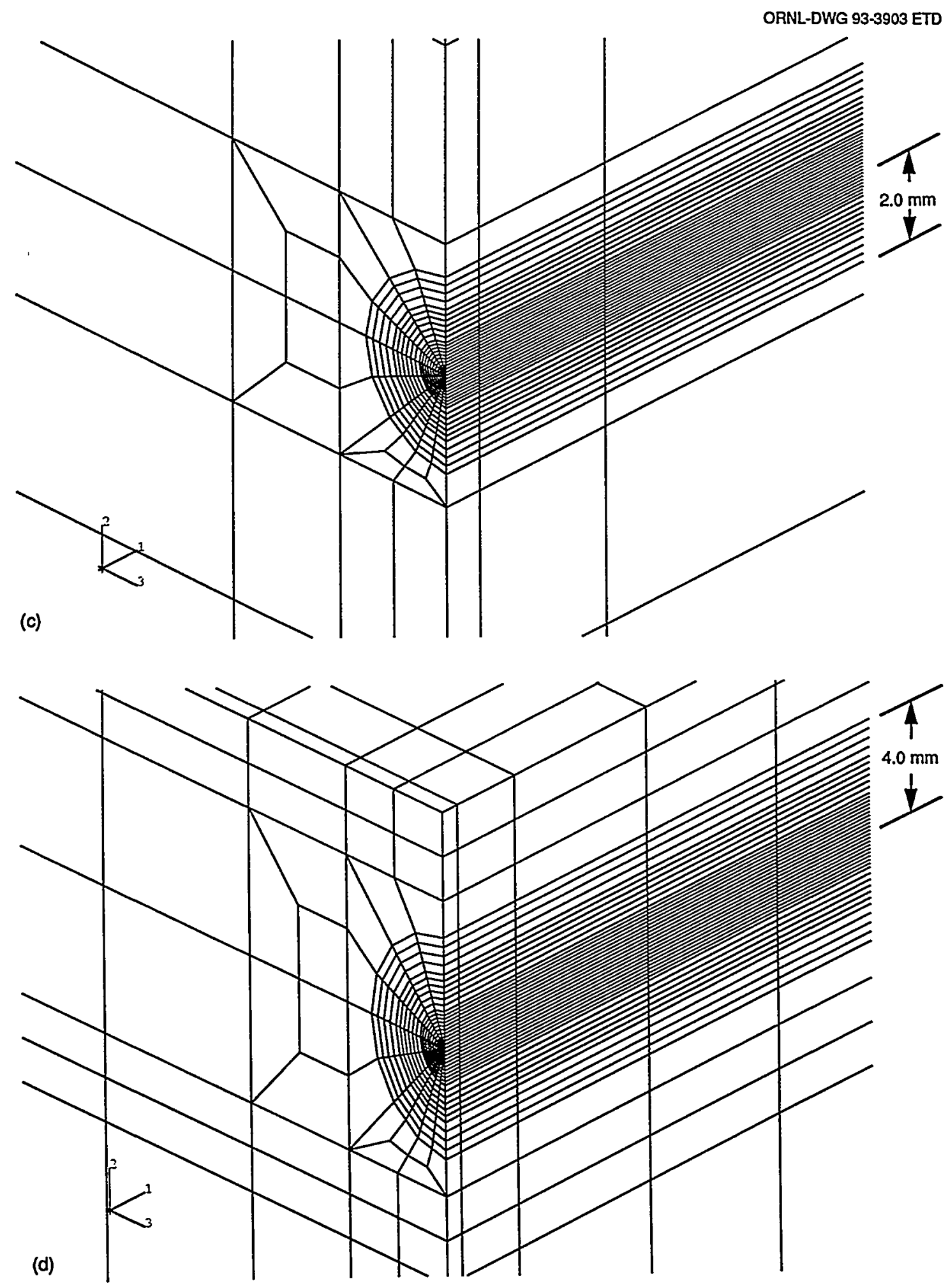

Figure 3.2 (continued) 


\section{Constraint}

higher failure load (measured in terms of $\mathrm{J}$ ) of the latter test required an expanded region of refinement to resolve the stress at a normalized distance of $r \sigma_{0} / \mathrm{J}=5$.

The material properties used for all calculations presented herein include Young's modulus $\mathrm{E}=205,170 \mathrm{MPa}$, Poisson's ratio $v=0.25$, and the piecewise linear stress strain curve depicted in Fig. 3.3. The curve in Fig. 3.3 represents a modification of material data for A 533 grade B class 1 steel taken from Ref. 17. The modification consists of an adjustment of the yield stress to produce better agreement with load vs CMOD data from the biaxial tests (described below).

Results from small-strain analyses of tests BB-2 (uniaxially loaded specimen) and BB- 4 and -5 (biaxially loaded specimens) are compared with measured data in Figs. 3.4 and 3.5. Because geometry and test conditions were essentially the same for $\mathrm{BB}-4$ and -5 , only one computation was performed for the biaxial loading case. The longitudinal-to-transverse load ratio and the load to failure for each test are given in Table 2.2. In Fig. 3.4, the calculated longitudinal load vs LLD curves (measured at point $C$ in Fig. 3.1) are compared with measured data from each of the three tests (BB-2, -4 , and -5 ). Comparisons of calculated and measured longitudinal load vs CMOD for the same tests are given in Fig. 3.5. Both Figs. 3.4 and 3.5 show good agreement between the computed and measured load vs deflection curves for the BB-2 test. Minor differences between the CMOD curves in Fig. 3.5 for BB-2 may be partly due to differences in the slot configurations in the model and in the BB-2 test specimen. The load vs deflection curves for specimens BB-4 and -5 are within the data scatter for the two tests.

The applied $\mathrm{J}$ vs longitudinal load at two positions along the crack front, $X=0$ and $26 \mathrm{~mm}$ (measured from the midplane), are given in Figs. 3.6 and 3.7 for the uniaxial and biaxial loading cases, respectively. These results illustrate the lower J-value computed for the biaxially loaded specimen at failure as compared to the uniaxial case. Figure 3.8 depicts the variation of $\mathrm{K}_{\mathrm{J}}$ along the crack front as a function of the applied loading for the biaxially loaded specimen. As the failure load is approached in Fig. 3.8, the crack-driving force remains relatively uniform across the middle half of the crack front but decreases dramatically toward the ends of the crack. The slot configuration was designed to obtain this behavior to minimize the potential for crack initiation at the ends of the slots. In Fig. 3.9, the variations of $\mathrm{KJ}_{\mathrm{J}}$ (normalized by the midplane value) along the crack front at low load and at load near failure are compared for the uniaxial and biaxial (0.6:1) loading cases. The differential placement of the outboard loaddiffusion control slots (Fig. 2.2) effectively shields the end of the crack from effects of stress concentration and development of general yielding.

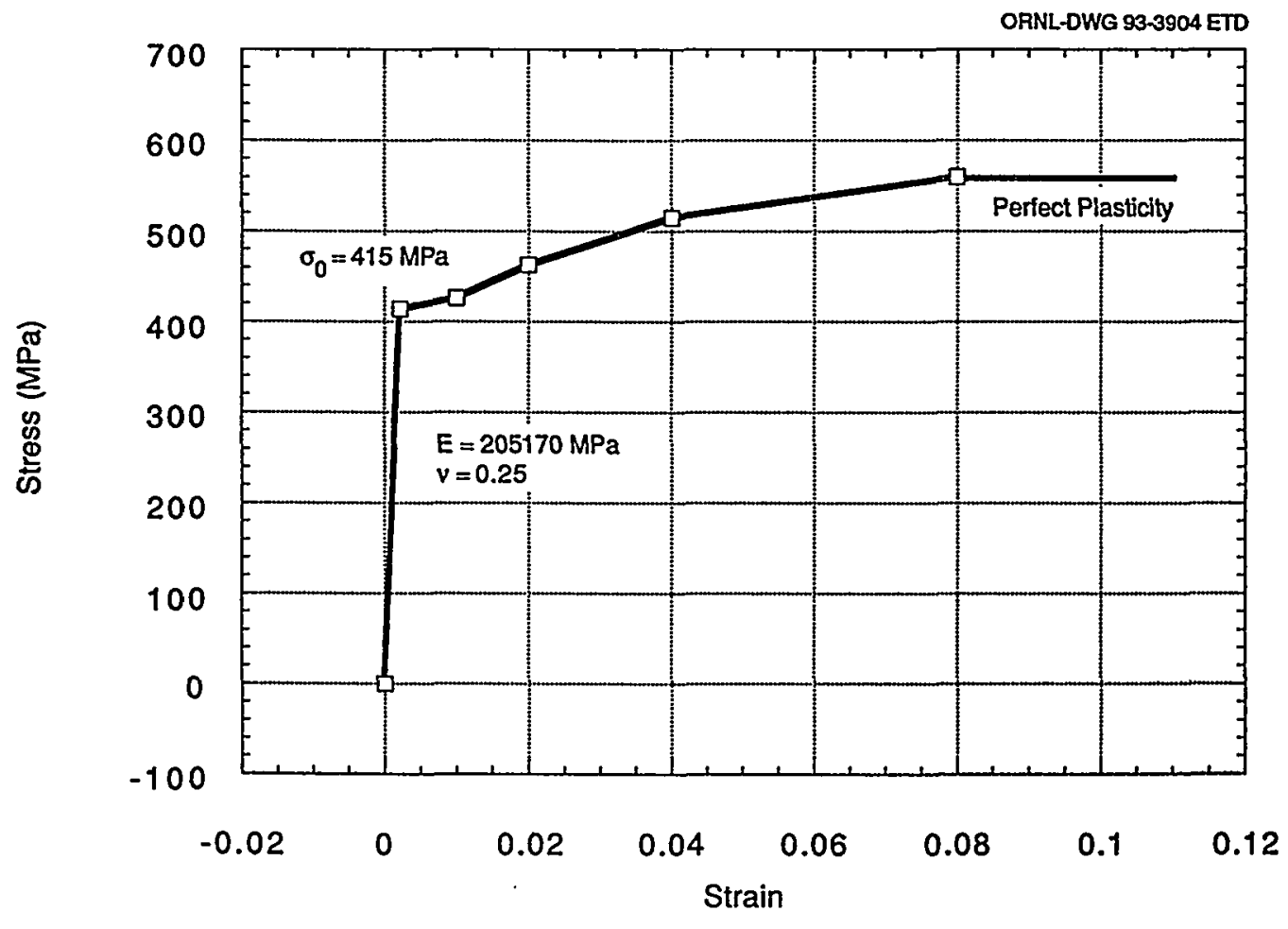

Figure 3.3 Material representation for A 533 B steel at $T=-46^{\circ} \mathrm{C}$ 


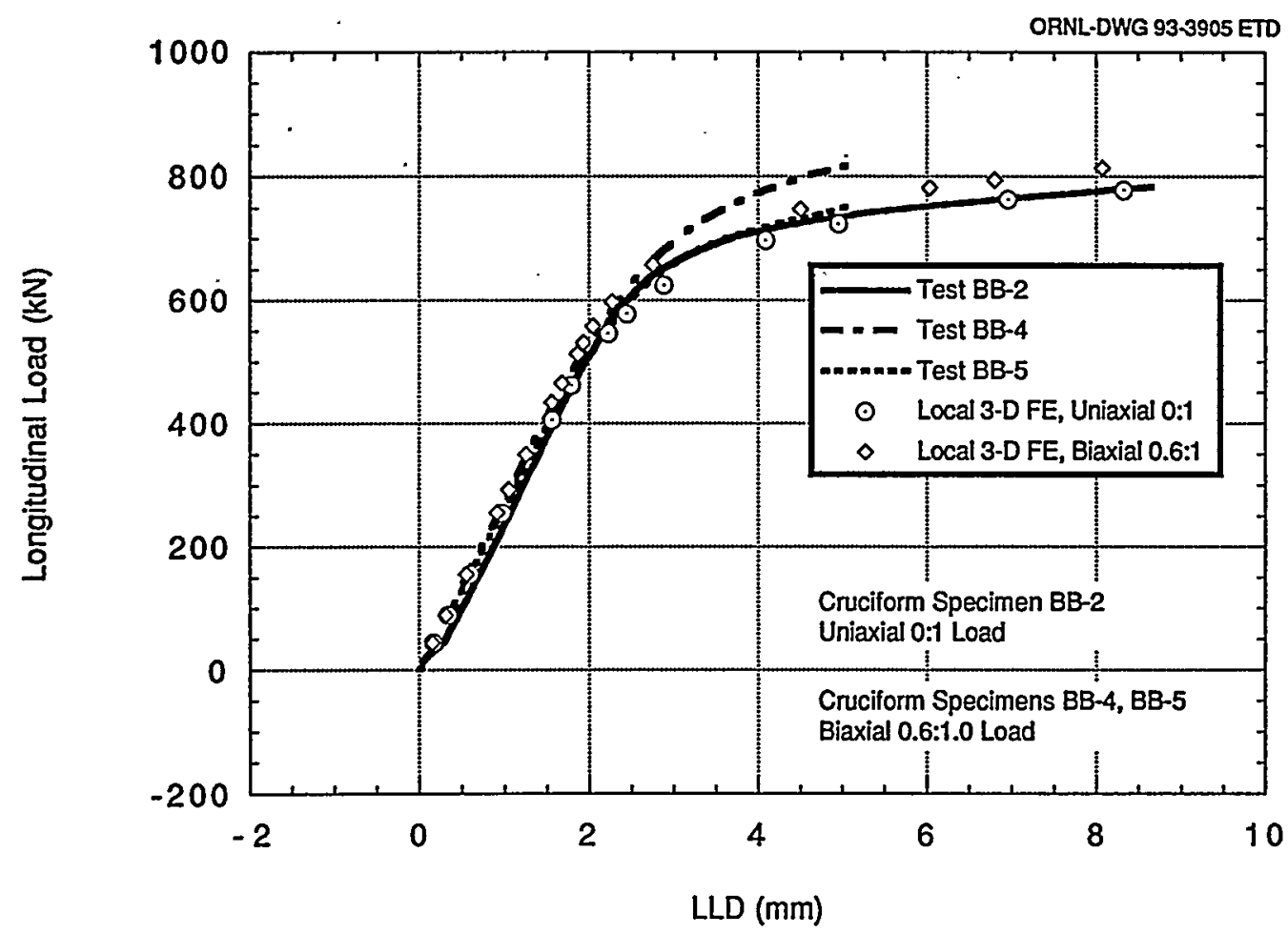

Figure 3.4 Comparison of calculated and measured LLD for cruciform bend specimens

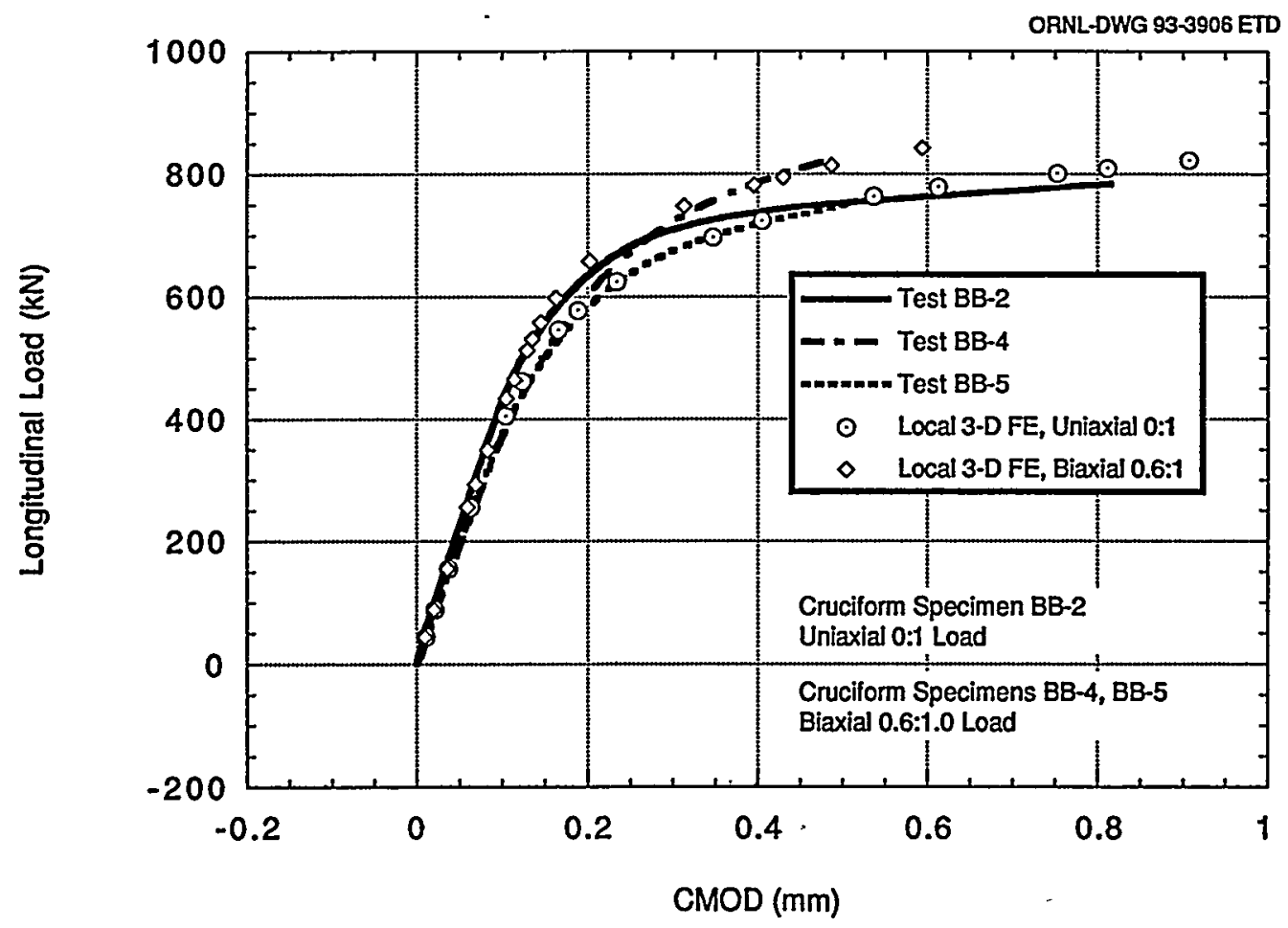

Figure 3.5 Comparison of calculated and measured CMOD for cruciform bend specimens 
Constraint

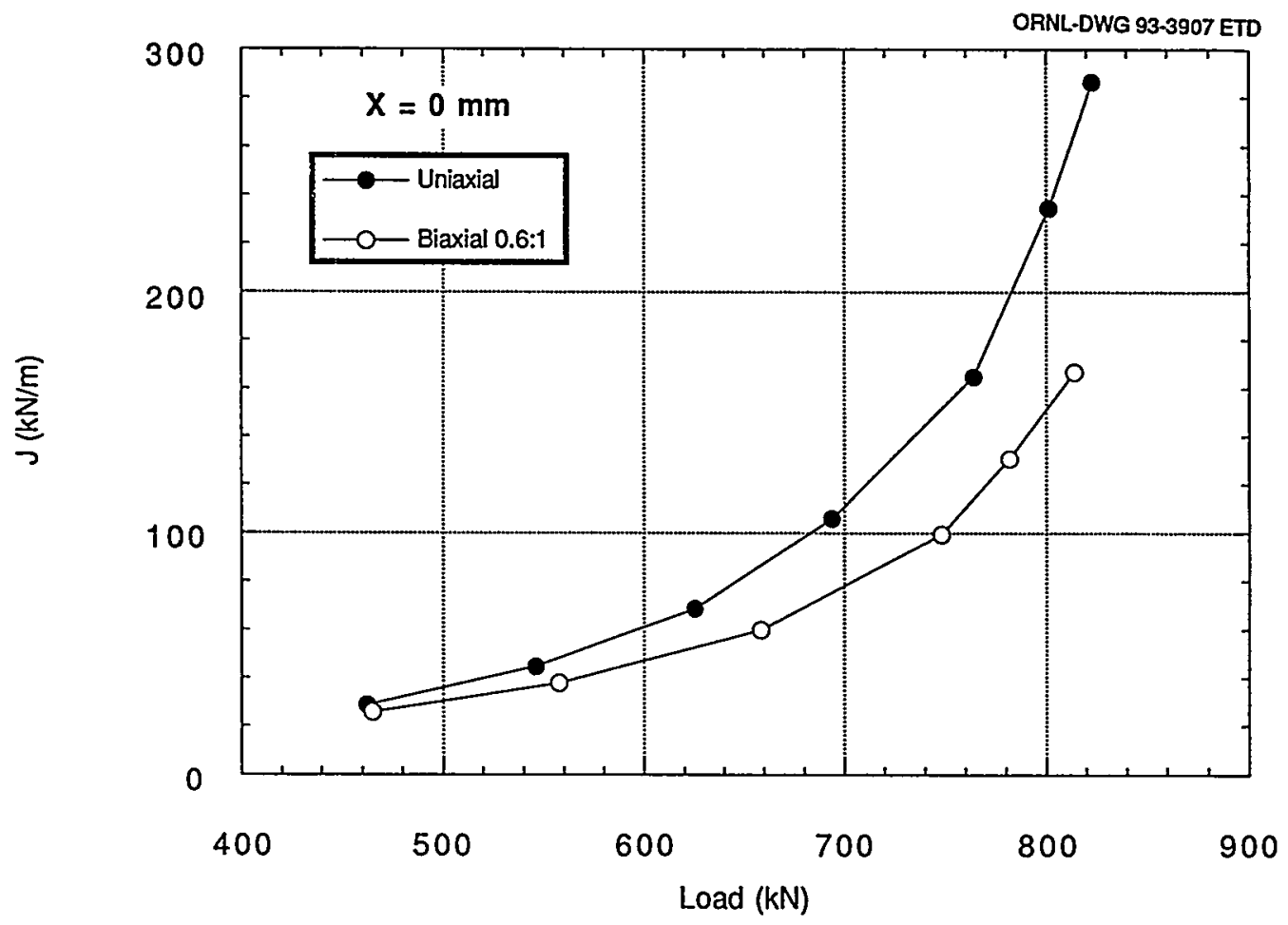

Figure 3.6 Applied $\mathrm{J}$ at $\mathrm{X}=0 \mathrm{~mm}$, uniaxial and biaxial 0.6:1 loading

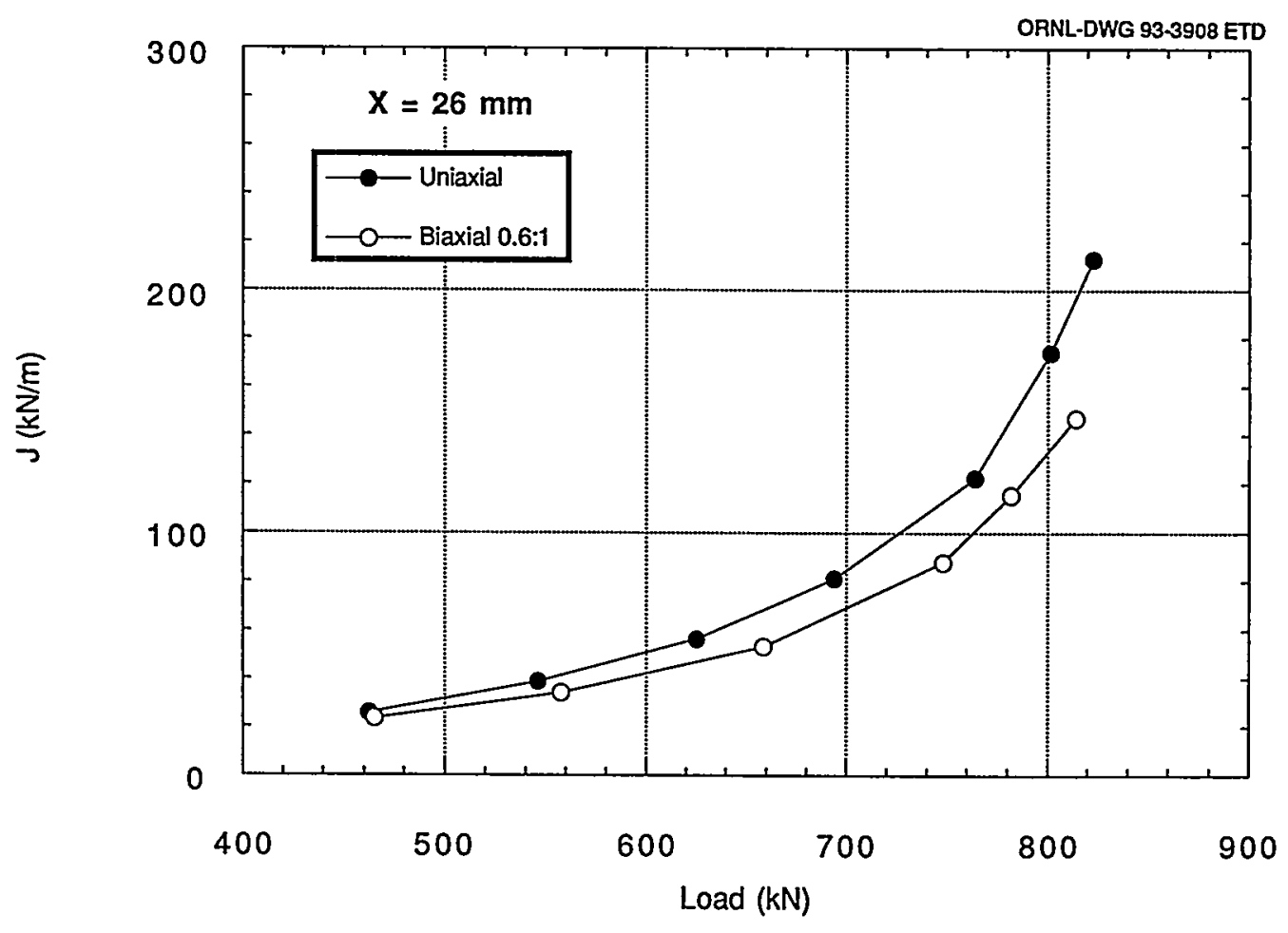

Figure 3.7 Applied $\mathrm{J}$ at $\mathrm{X}=26 \mathrm{~mm}$, uniaxial and biaxial 0.6:1 loading 
Constraint

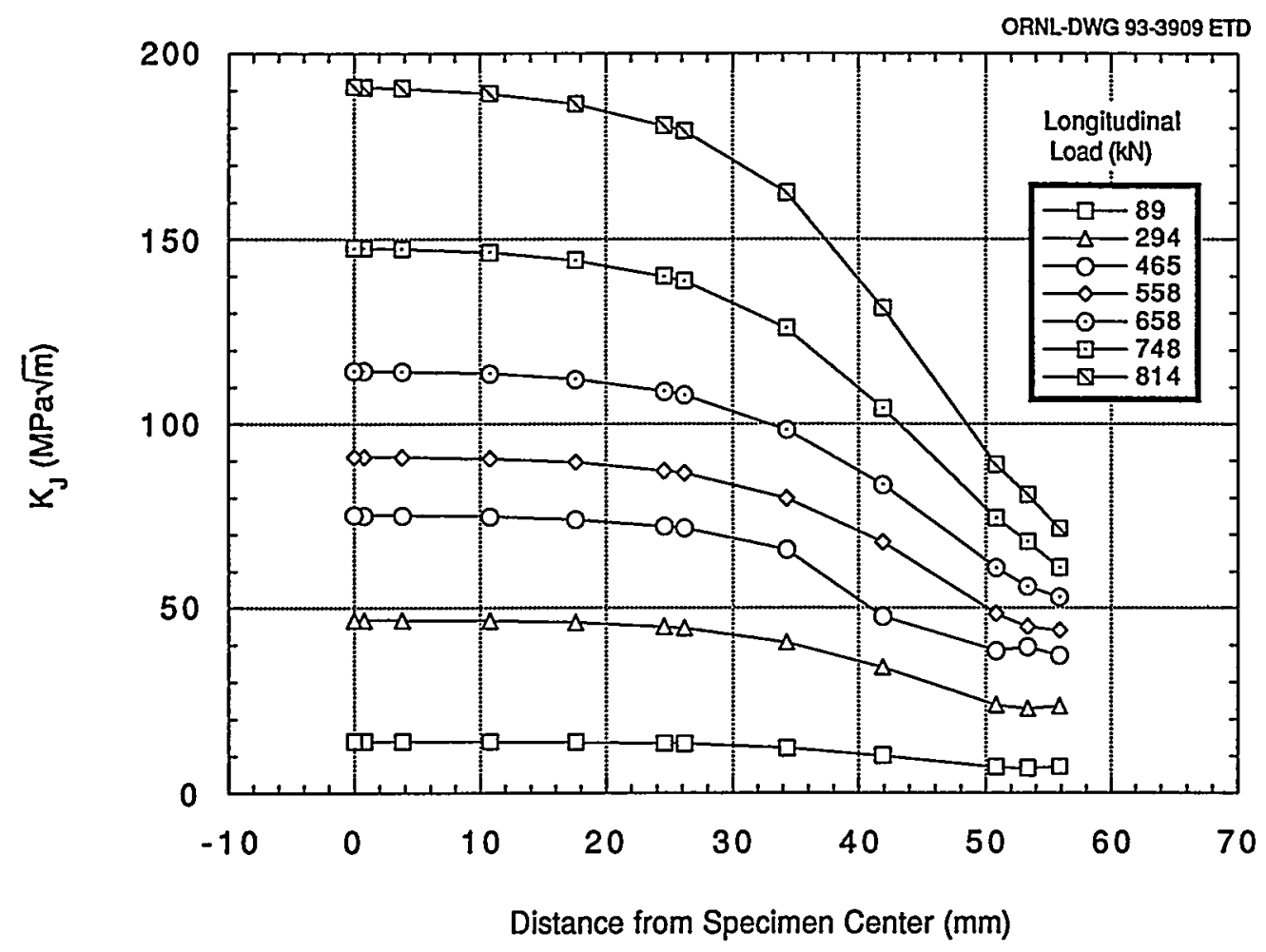

Figure 3.8 Variation of $\mathrm{K}_{\mathrm{J}}$ along crack front, biaxial 0.6:1 loading

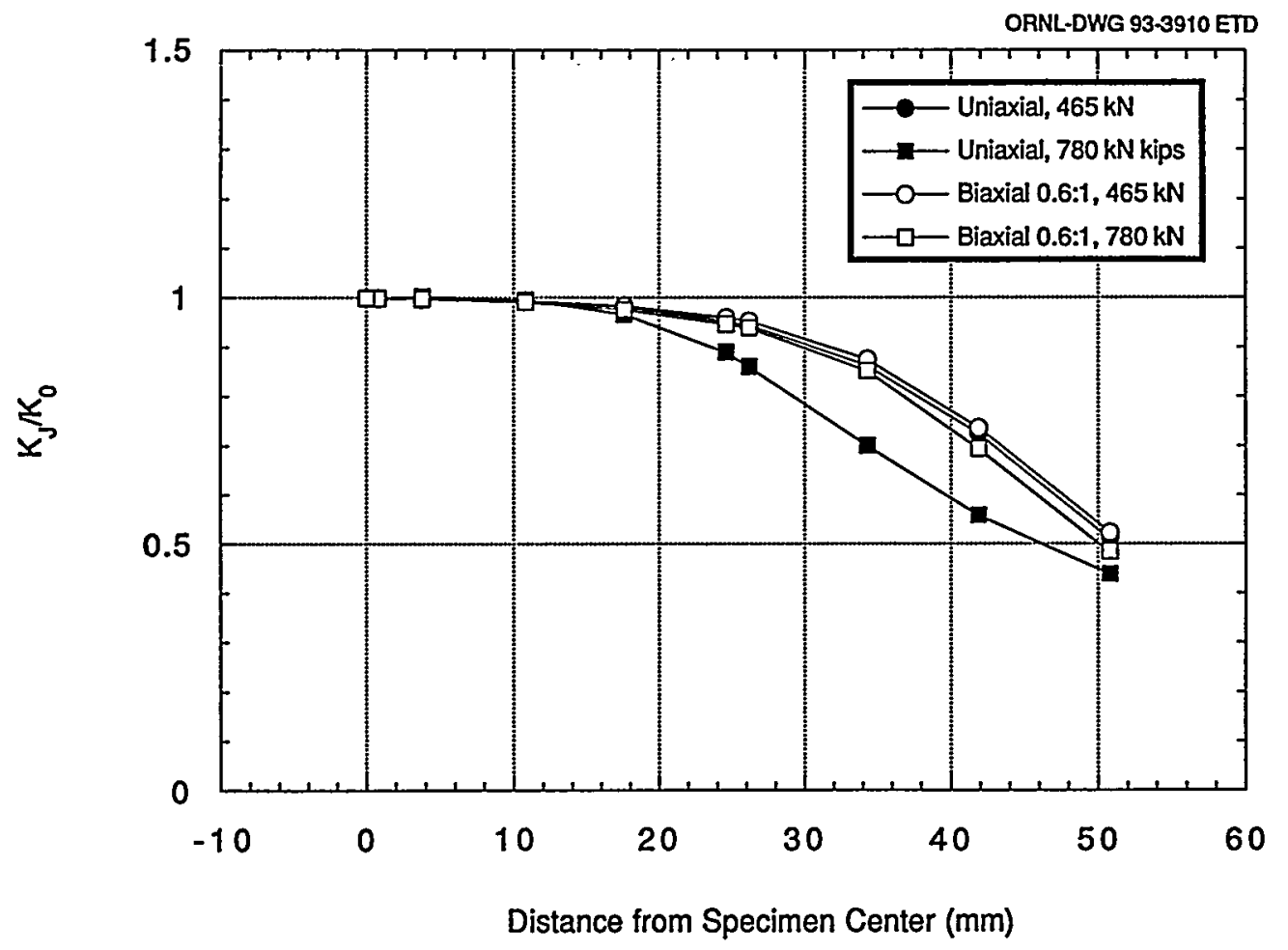

Figure 3.9 Variation of normalized $\mathrm{K}_{\mathrm{J}}$ along crack front for both uniaxial and biaxial 0.6:1 loading at low load and at load near failure 


\section{Constraint}

\subsection{Stress Triaxiality (J-Q) Method}

One of the methods used to assess the effects of shallowcrack depths and biaxial loading on crack-tip stress triaxiality is the J-Q methodology. The J-Q method was applied to the shallow- and deep-crack SENB specimens previously. ${ }^{5}$ The $\mathrm{J}-\mathrm{Q}$ method applied to the uniaxial and biaxial cruciform specimen is based on analyses described in the previous section. Results of the J-Q analyses from both test series are presented in this chapter.

The definition of Q-stress employed here is given by O'Dowd and $\mathrm{Shih}^{8}$ in the form

$$
\mathrm{Q}(\overline{\mathrm{I}})=\frac{\sigma_{\theta \theta}(\overline{\mathrm{I}})-\left[\sigma_{\theta \theta}(\overline{\mathrm{I}})\right]_{\mathrm{SSY}}}{\sigma_{0}},
$$

where $\overline{\mathrm{r}}=\mathrm{r} /\left(\mathrm{J} / \sigma_{0}\right)$ is a normalized distance measured in the crack plane ahead of the crack tip $(\theta=0)$; the $r, \theta$ polar coordinate system is centered at the crack tip such that $\theta=0$ corresponds to the crack plane ahead of the tip. In Eq. (1), the Q-stress measures the departure of the openingmode stress $\sigma_{\theta \theta}$ from the reference plane strain SSY solution, normalized by the yield stress $\sigma_{0}$.

Using a modified boundary layer (MBL) formulation, O'Dowd and Shih ${ }^{8}$ determined that the Q-stress character- izes the magnitude of a spatially uniform (approximately) hydrostatic stress state in a forward sector $(|\theta| \leq \pi / 2$ and $1 \leq \bar{r} \leq 5$ ) of the crack-tip region. The Q-stress, although found to be essentially independent of $\bar{r}$, was formally defined at $\overline{\mathbf{r}}=2$, which falls just outside the finite strain blunting zone. For conditions ahead of the crack that do not conform to a spatially uniform hydrostatic stress field, O'Dowd and Shih ${ }^{8}$ introduced Eq. (1) to emphasize the explicit dependence of $Q$ upon distance $\overline{\mathrm{r}}$. The latter definition of Q-stress is convenient for applications presented herein due to the spatial dependence of $Q$ determined for certain loading conditions applied to the cruciform specimen. Additional information concerning SSY solutions to be used in Eq. (1) are given in Appendix A.

\subsection{Application of J-Q Method to Shallow- Crack Specimens}

The J-Q method was applied to a select number of shallowand deep-crack SENB specimens as described previously. ${ }^{5}$ The Q-stress at failure for the deep-crack specimens was found to be negligible, indicating that these specimens failed under essentially SSY conditions. The shallow-crack specimens, however, were found to have a Q-stress of about -0.7 at failure, which represents a significant loss of constraint. The opening-mode stresses ahead of the crack tip for the shallow-crack specimens, shown in Fig. 3.10 from Ref. 5, exhibited a uniform deviation from the SSY solution over a distance of $2 \leq \bar{r} \leq 10$ (i.e., spatially uniform). The Q-stress was determined for these specimens

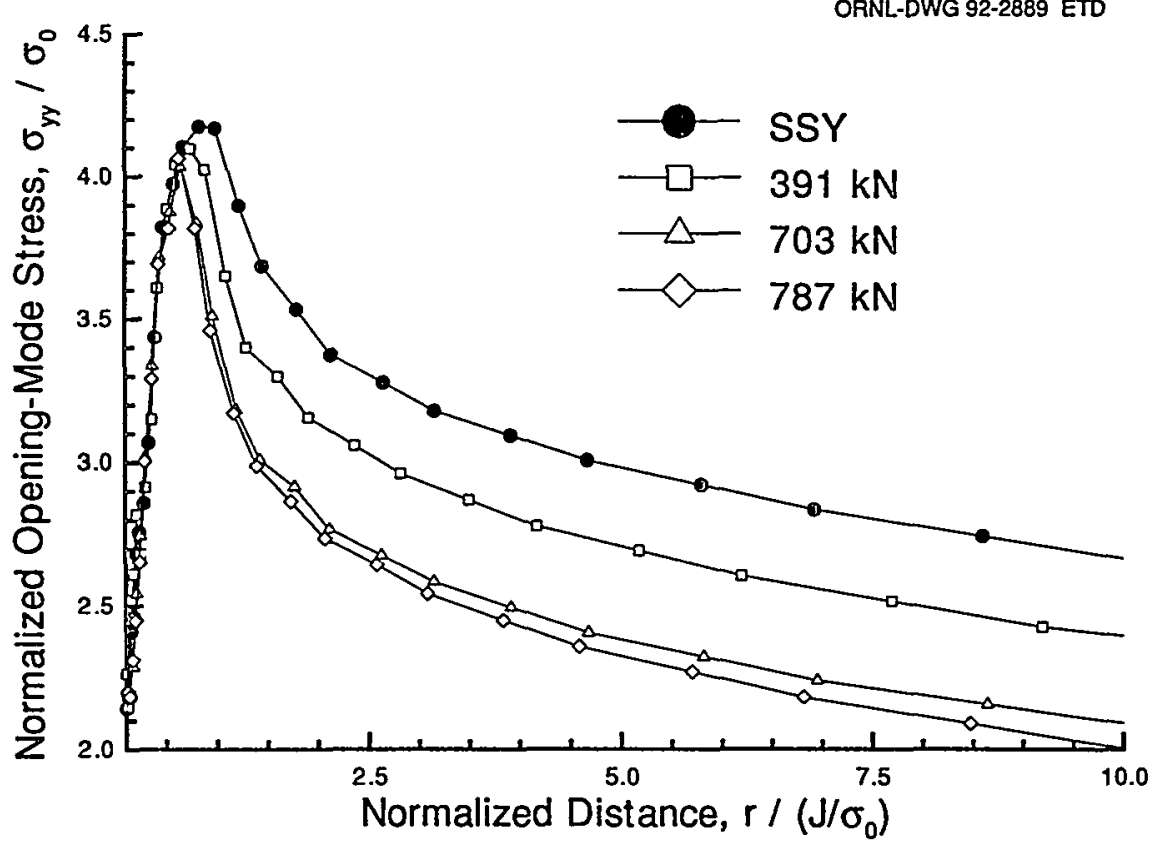

Figure 3.10 Distributions of opening-mode stress component for SENB specimen with $a / W=0.1$ as function of applied load up to crack initiation 
only at $\overline{\mathbf{r}}=2$. These specimens were used to construct a preliminary J-Q toughness locus that could be then applied to RPV analyses.

The J-Q method was used to analyze the HSST wide-plate tests, 16,17 which also had relatively shallow cracks (a/W 0.2 ) and exhibited a significant toughness increase. While the $\mathrm{J}-\mathrm{Q}$ analysis revealed a loss of constraint associated with the wide-plate tests, the J-Q locus for these tests was not in agreement with the $\mathrm{J}-\mathrm{Q}$ locus for the limited shallow-crack tests. ${ }^{20}$ This discrepancy between the shallow-crack and wide-plate $\mathrm{J}-\mathrm{Q}$ analysis is currently being investigated by reanalyzing both specimen types.* This reanalysis has generated a J-Q failure locus based on most of the shallow-crack data and several of the wideplate results. A preliminary $\mathrm{J}-\mathrm{Q}$ locus taken from this upcoming report will be presented in the next section with the cruciform data added.

\subsubsection{Application of the J-Q Method to Cruciform Specimens}

The $J-Q$ constraint analyses reported in this section are based on small strain finite-element formulations. In

*R. H. Dodds, Jr., "Constraint Analysis of the Shallow-Crack and WidePlate Test Results," to be issued as a NUREG under subcontract to the HSST Program.
Appendix B of this report, the crack-tip constraint analyses described in this section are reported using a finite strain finite-element formulation. Again, interpretations of biaxial loading effects on stress triaxiality are unchanged from the smail strain formulation. This agreement between the finite strain and small strain solutions supports conclusions in Ref. 8 that small strain formulations for J-Q analyses are generally acceptable.

Trends in the response of near-tip stress triaxiality to uniaxial and biaxial loading conditions can be interpreted from Figs. 3.11-3.23. Values of Q-stress are determined from Eq. (1) and from the distributions given in Figs. 3.11 and 3.12 of opening-mode stress in the crack plane ahead of the tip as a function of applied load for the uniaxial and biaxial specimens, respectively. The SSY distribution is taken from a boundary layer solution described in Appendix A. For the uniaxial case (Fig. 3.11), the stress distribution continues to decrease with increasing applied load, reflecting a progressive loss of stress triaxiality associated with shallow cracks in bending. In Fig. 3.12, the decrease in stress for the biaxial case relative to the SSY solution saturates as the failure load is approached, resulting in near identical stress conditions ahead of the crack for several load steps.

The variation of $Q$ with $\bar{r}$ as a function of applied load over the annulus $2 \leq \bar{r} \leq 5$ for the uniaxial and biaxial

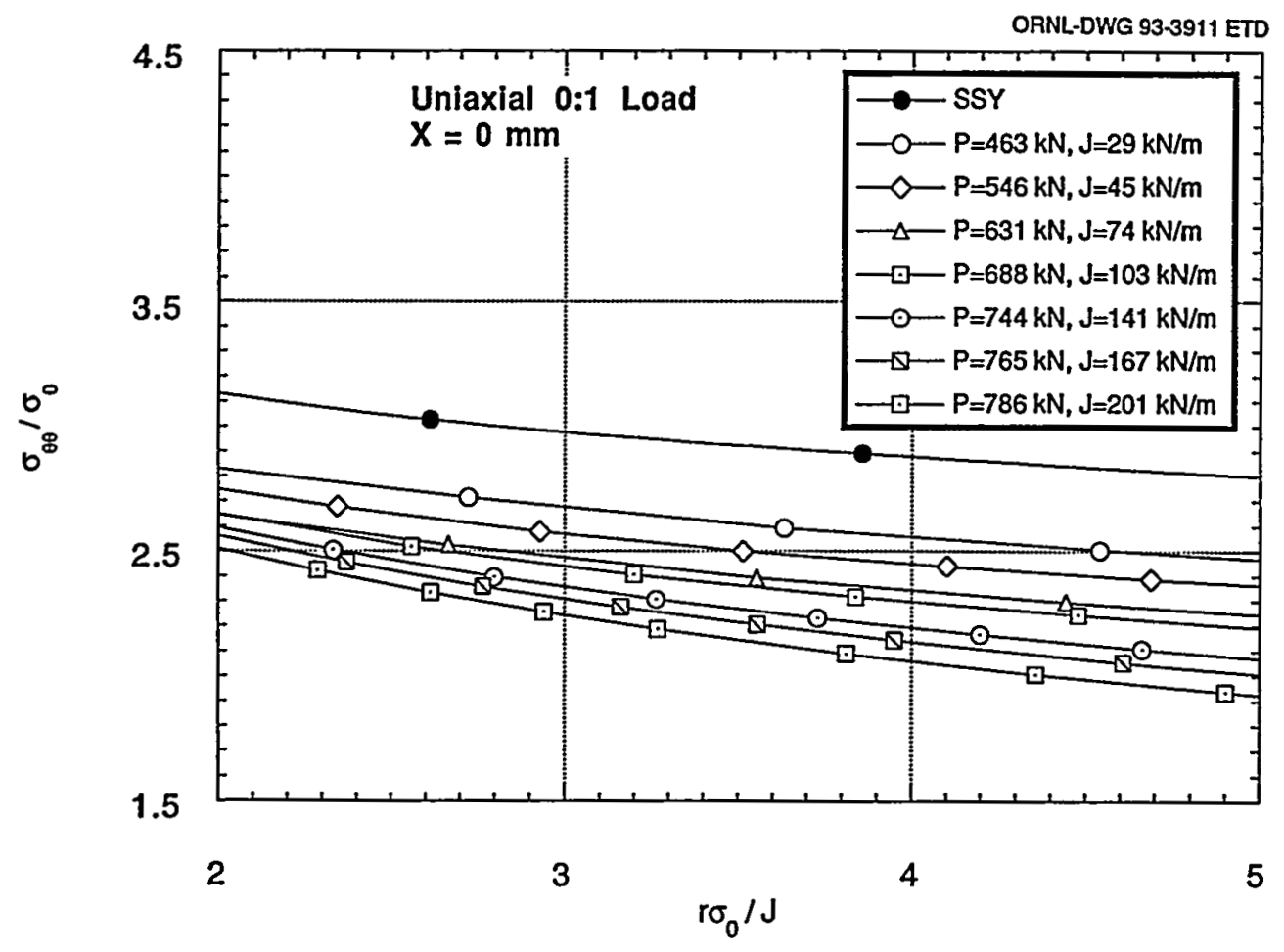

Figure 3.11 Normalized opening-mode stress ahead of crack tip, $X=0 \mathrm{~mm}$, uniaxial loading 


\section{Constraint}

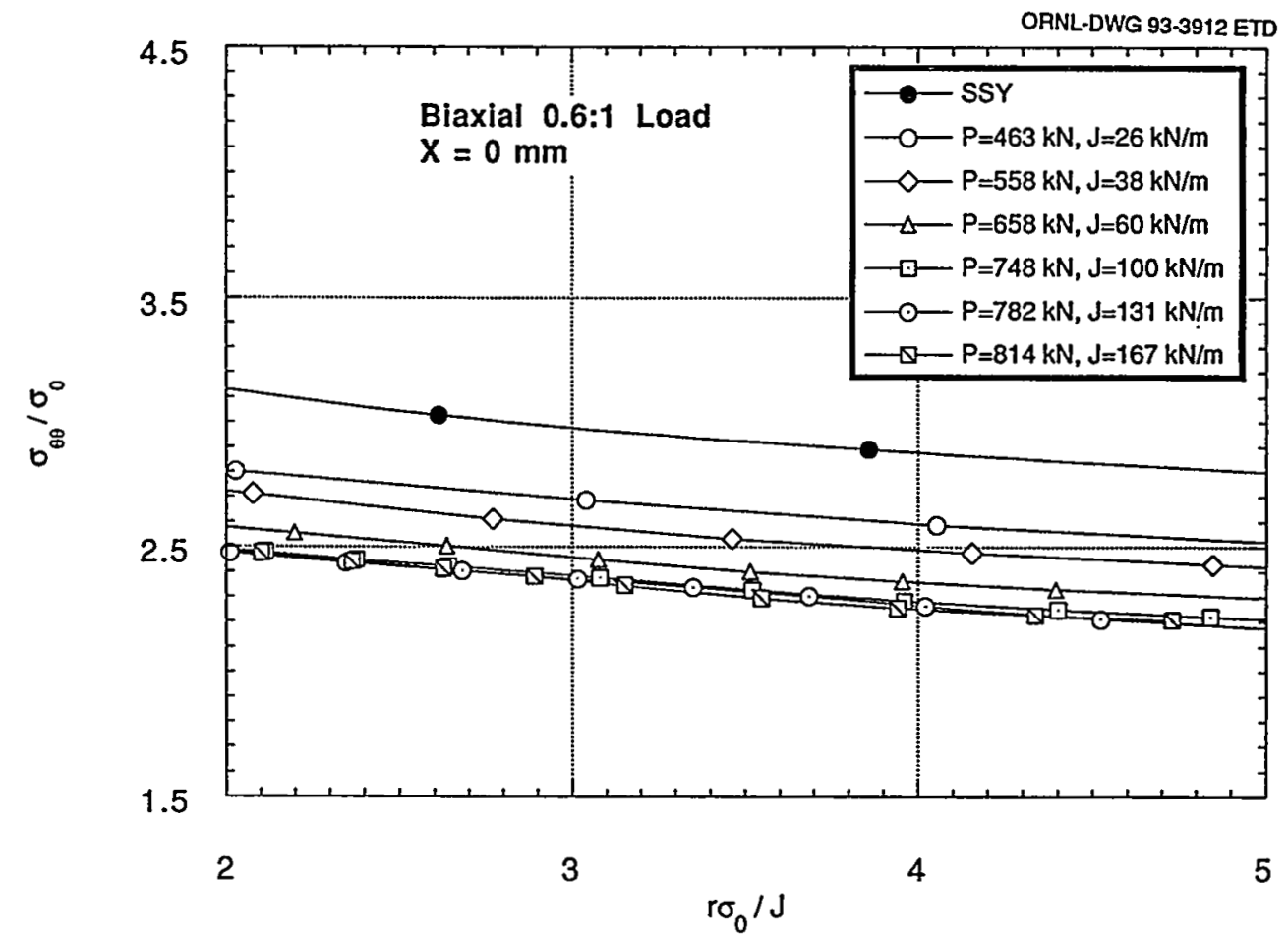

Figure 3.12 Normalized opening-mode stress ahead of crack tip, $X=0 \mathrm{~mm}$, biaxial 0.6:1 loading

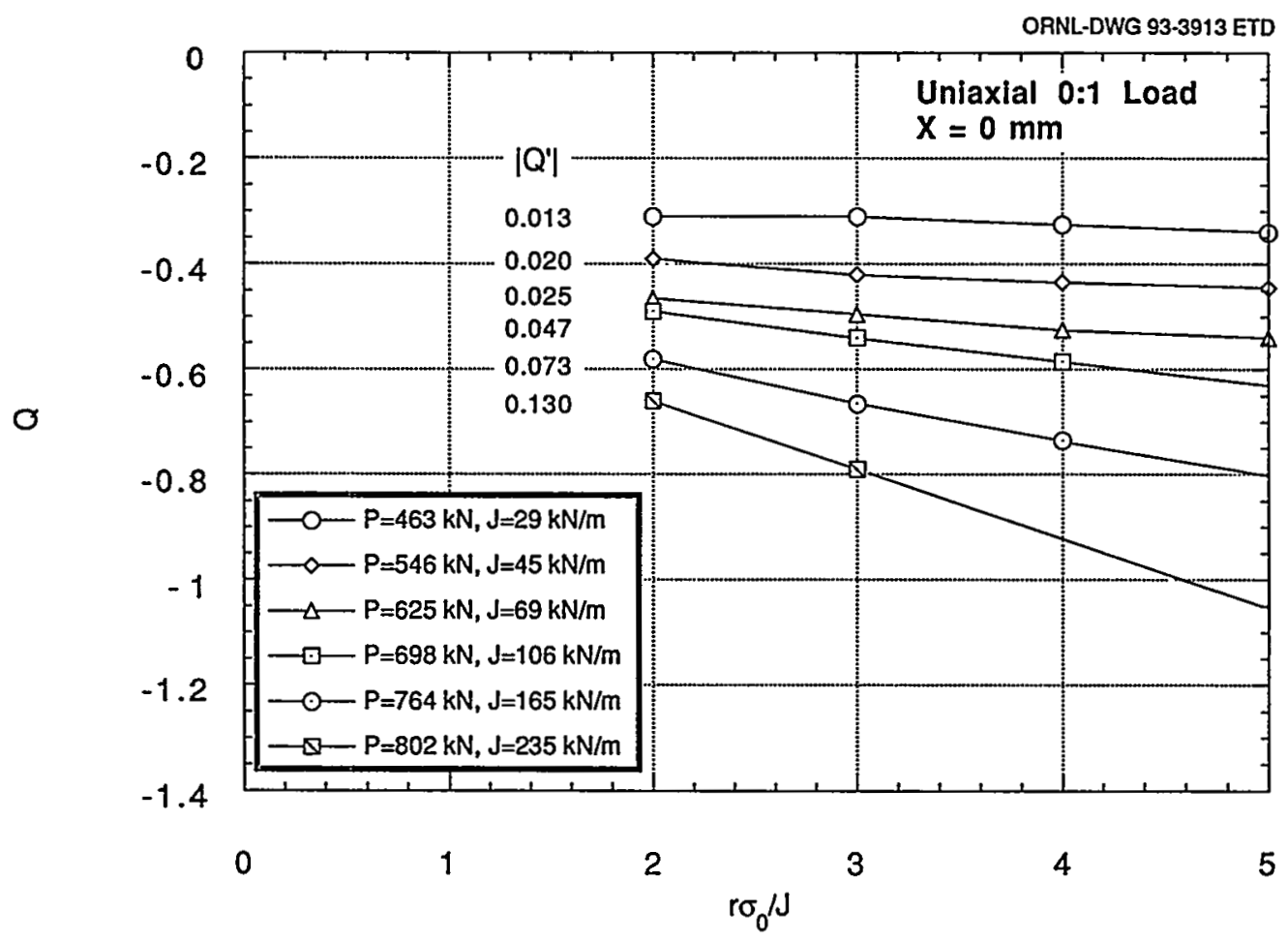

Figure 3.13 Variation of $Q$ with normalized distance ahead of the crack tip, $X=0 \mathrm{~mm}$, uniaxial loading 


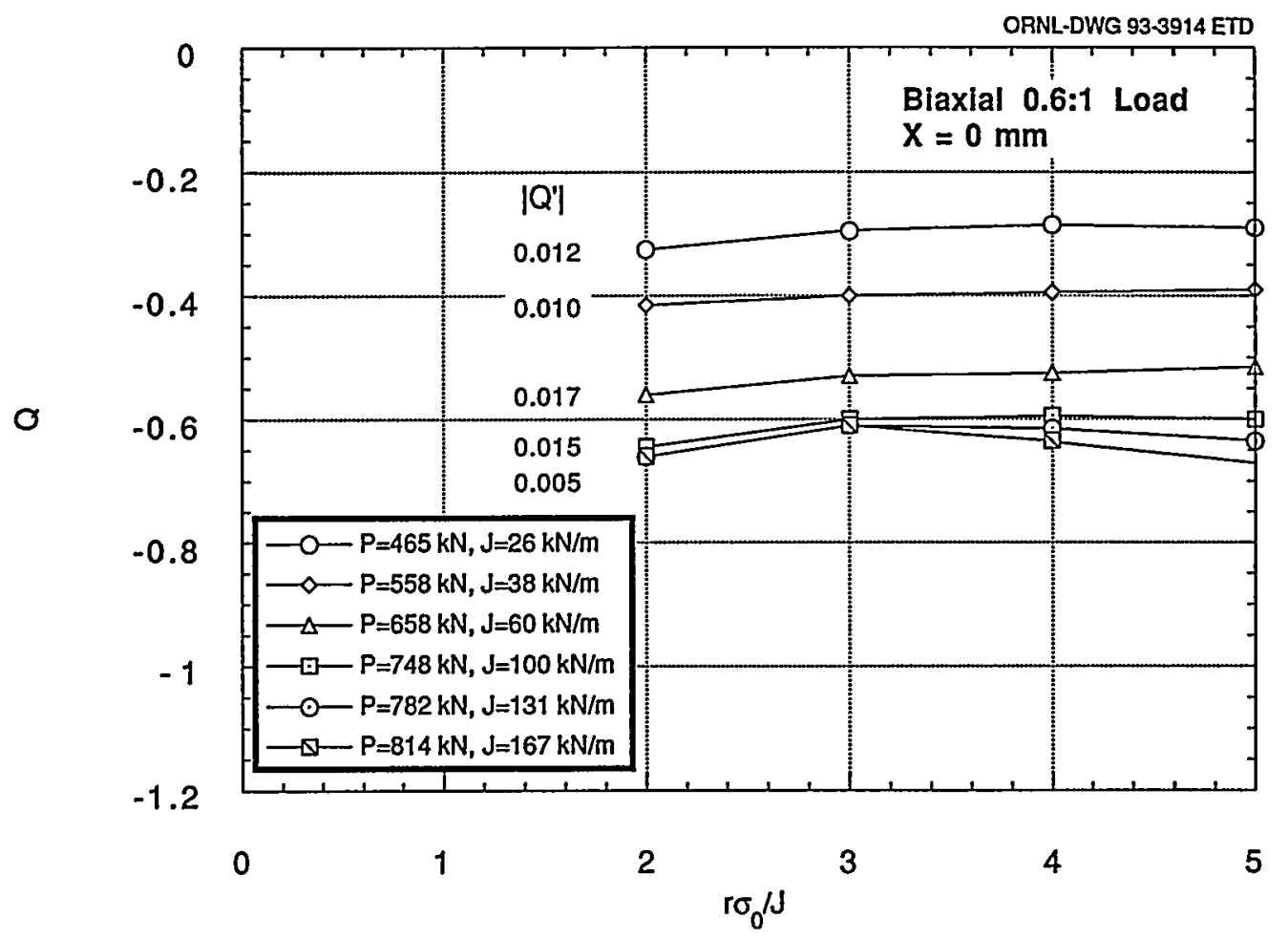

Figure 3.14 Variation of $Q$ with normalized distance ahead of the crack tip, $X=0 \mathrm{~mm}$, biaxial 0.6:1 loading

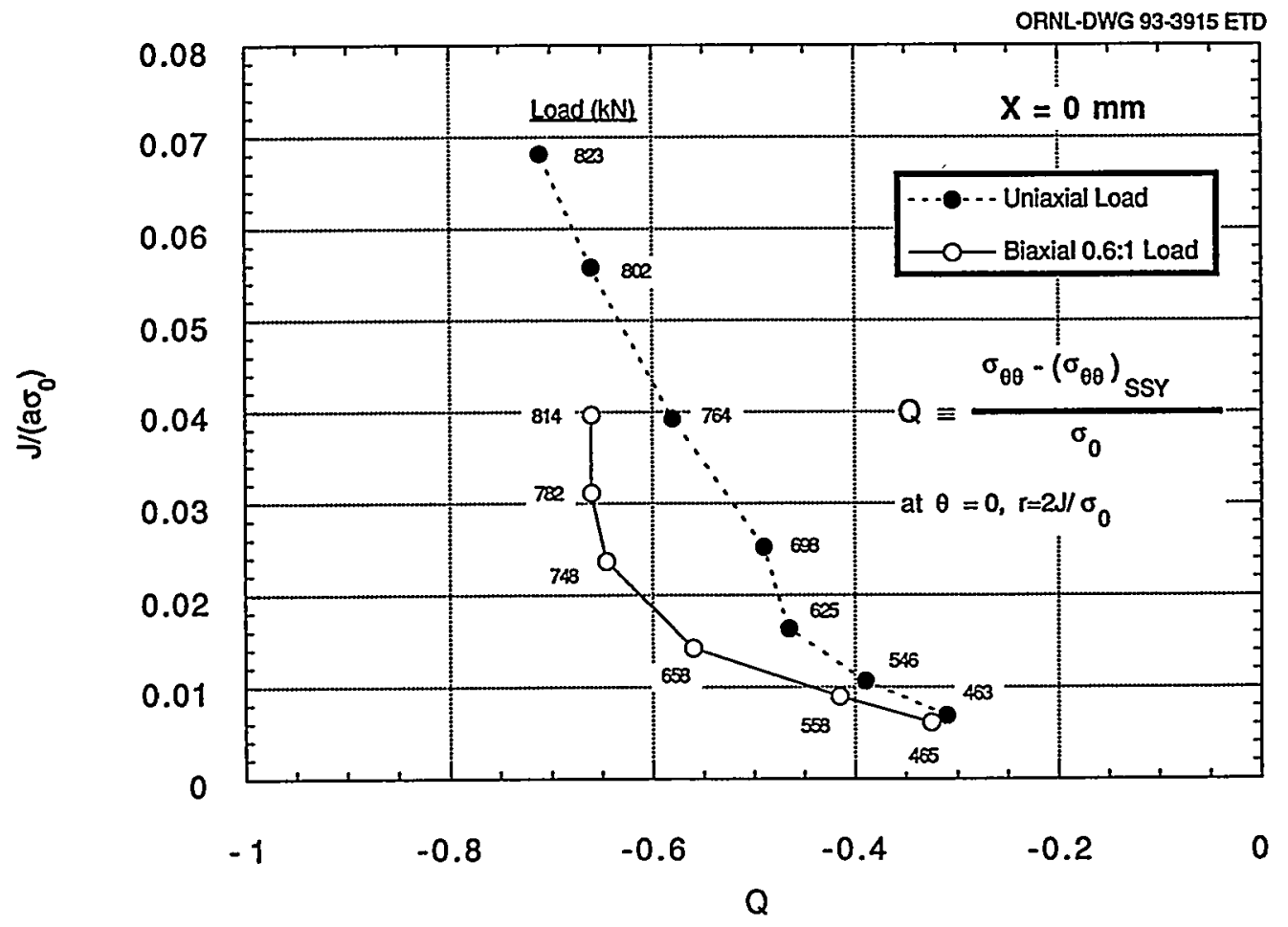

Figure 3.15 $\mathrm{J}-\mathrm{Q}$ trajectories at $\mathrm{X}=0 \mathrm{~mm}$ for a normalized distance $r \sigma_{0} J \mathrm{~J}=2$ 
Constraint

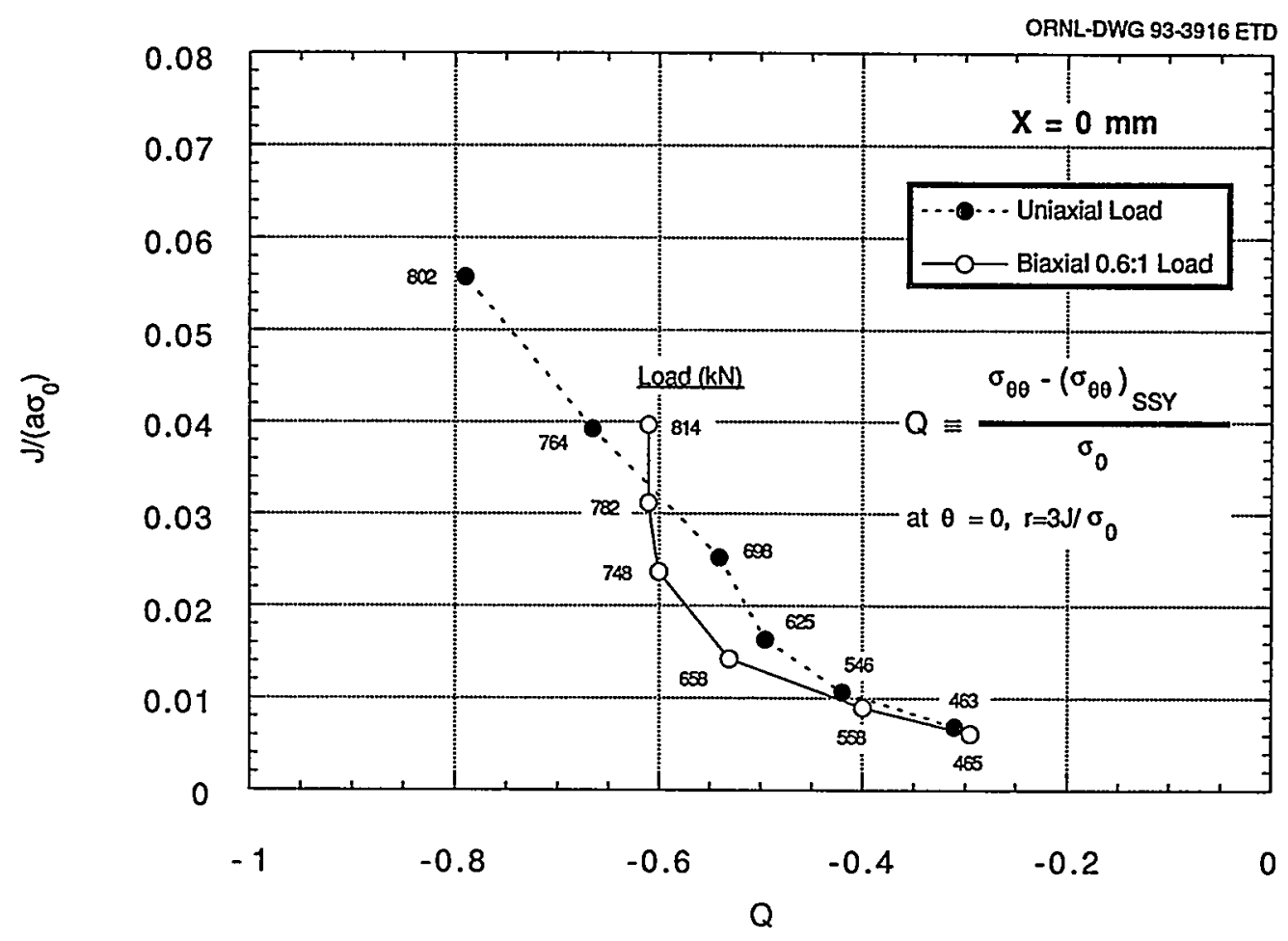

Figure 3.16 $\mathrm{J}-\mathrm{Q}$ trajectories at $\mathrm{X}=0 \mathrm{~mm}$ for a normalized distance $r \sigma_{0} / \mathrm{J}=3$

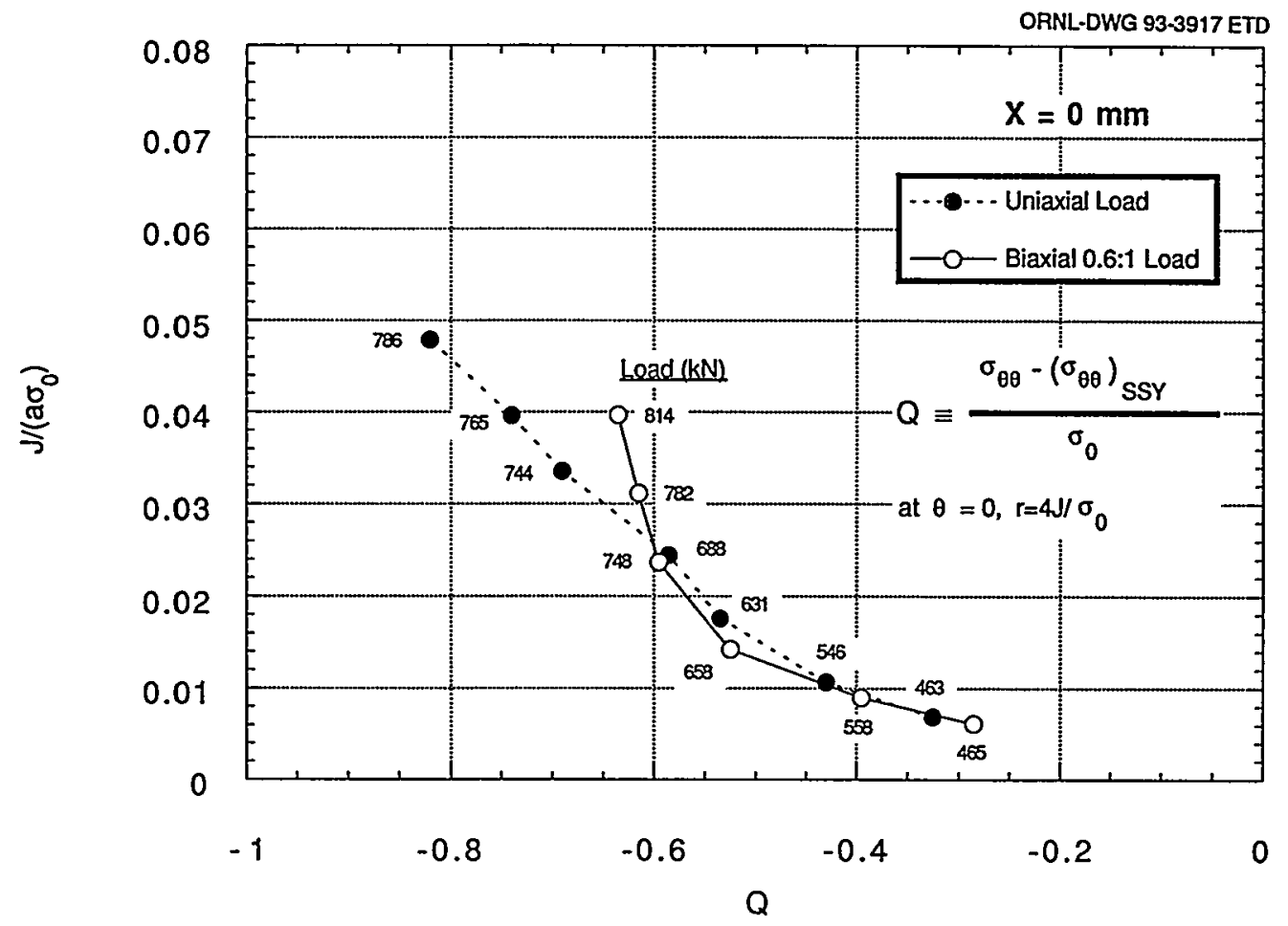

Figure 3.17 $\mathrm{J}-\mathrm{Q}$ trajectories at $\mathrm{X}=0 \mathrm{~mm}$ for a normalized distance $r \sigma_{0} / \mathrm{J}=4$ 


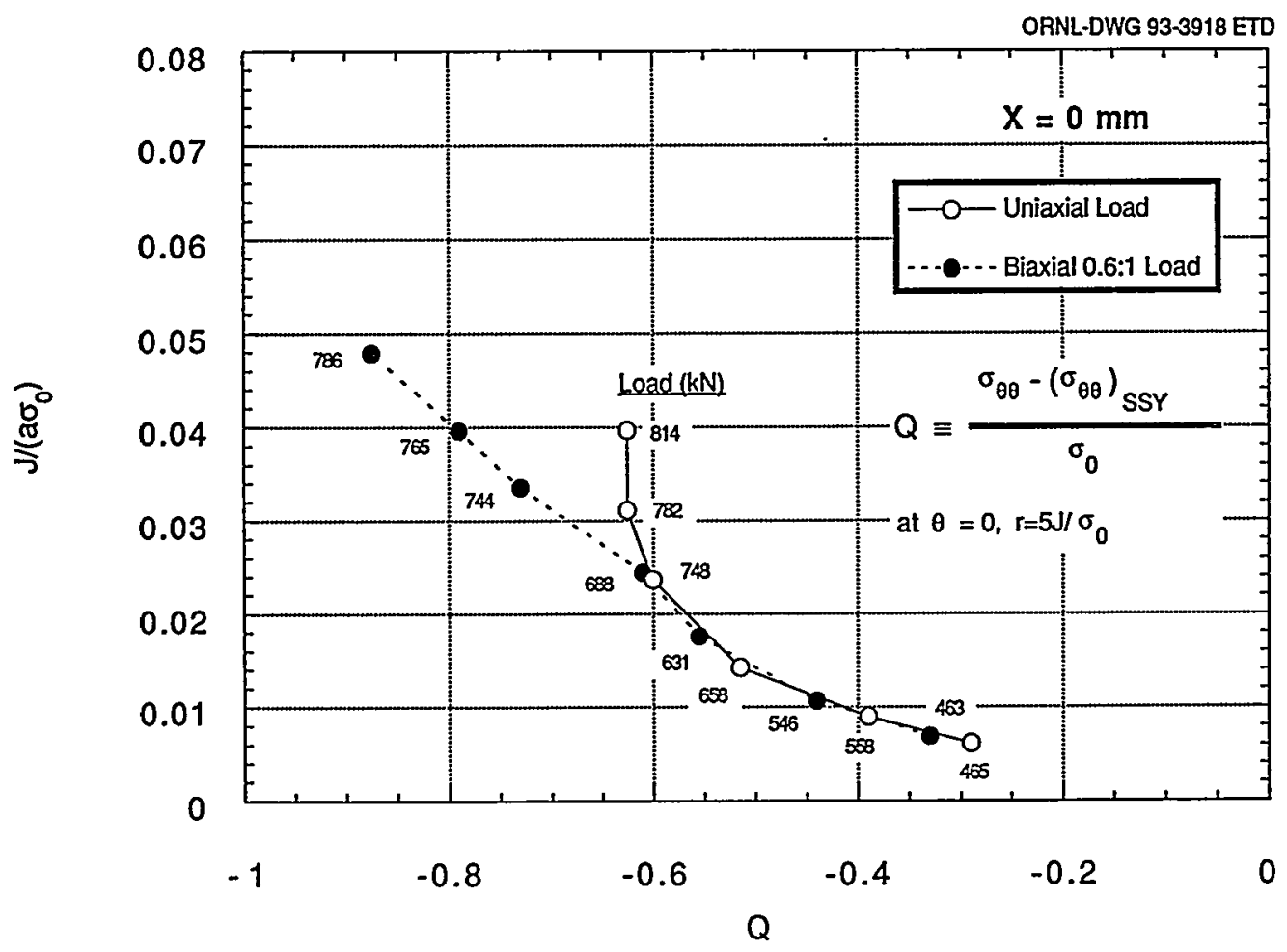

Figure 3.18 J-Q trajectories at $X=0 \mathrm{~mm}$ for a normalized distance $r \sigma_{0} / \mathrm{J}=5$

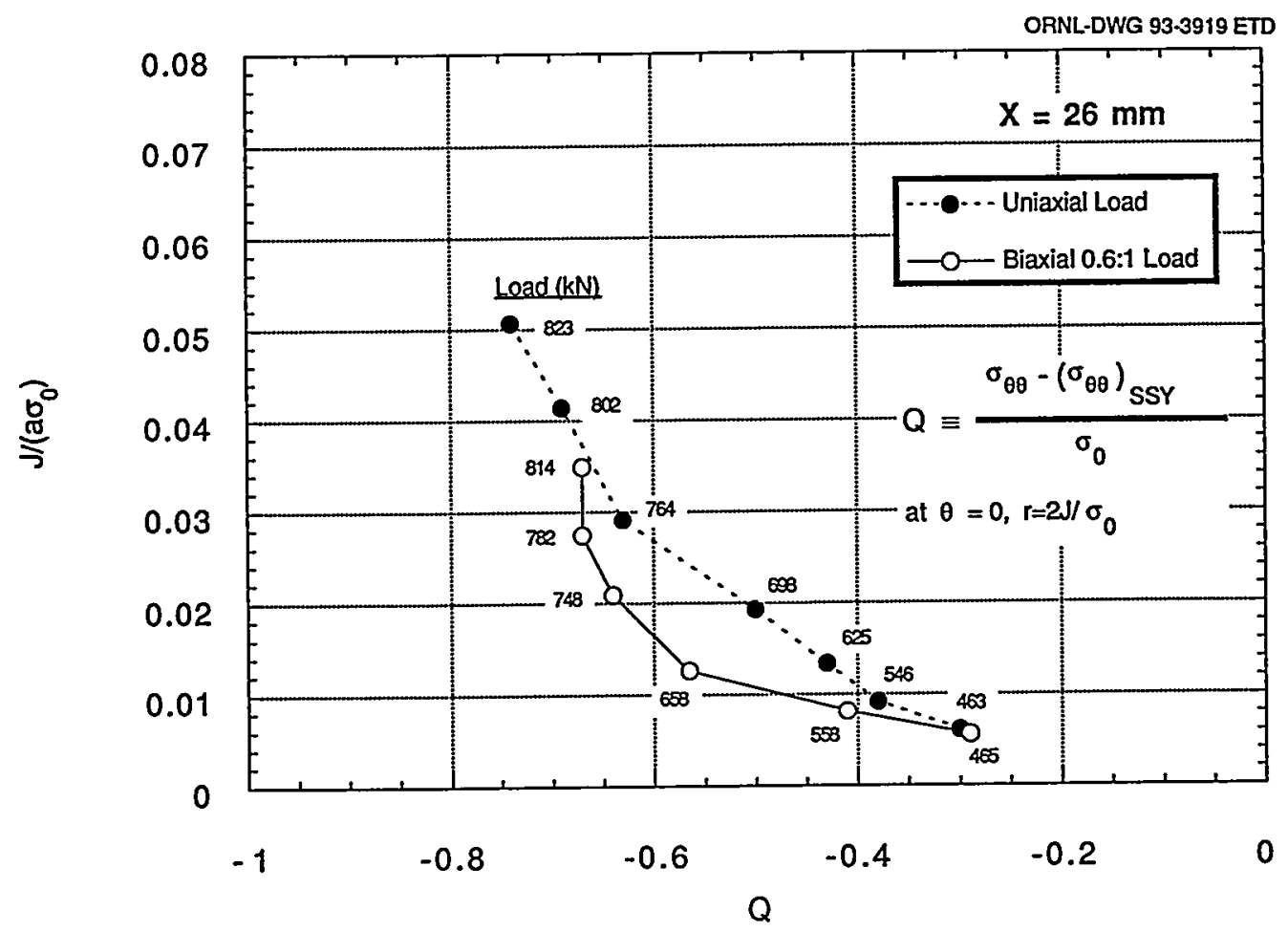

Figure 3.19 J-Q trajectories at $X=26 \mathrm{~mm}$ for a normalized distance $r \sigma_{0} / J=2$ 
Constraint

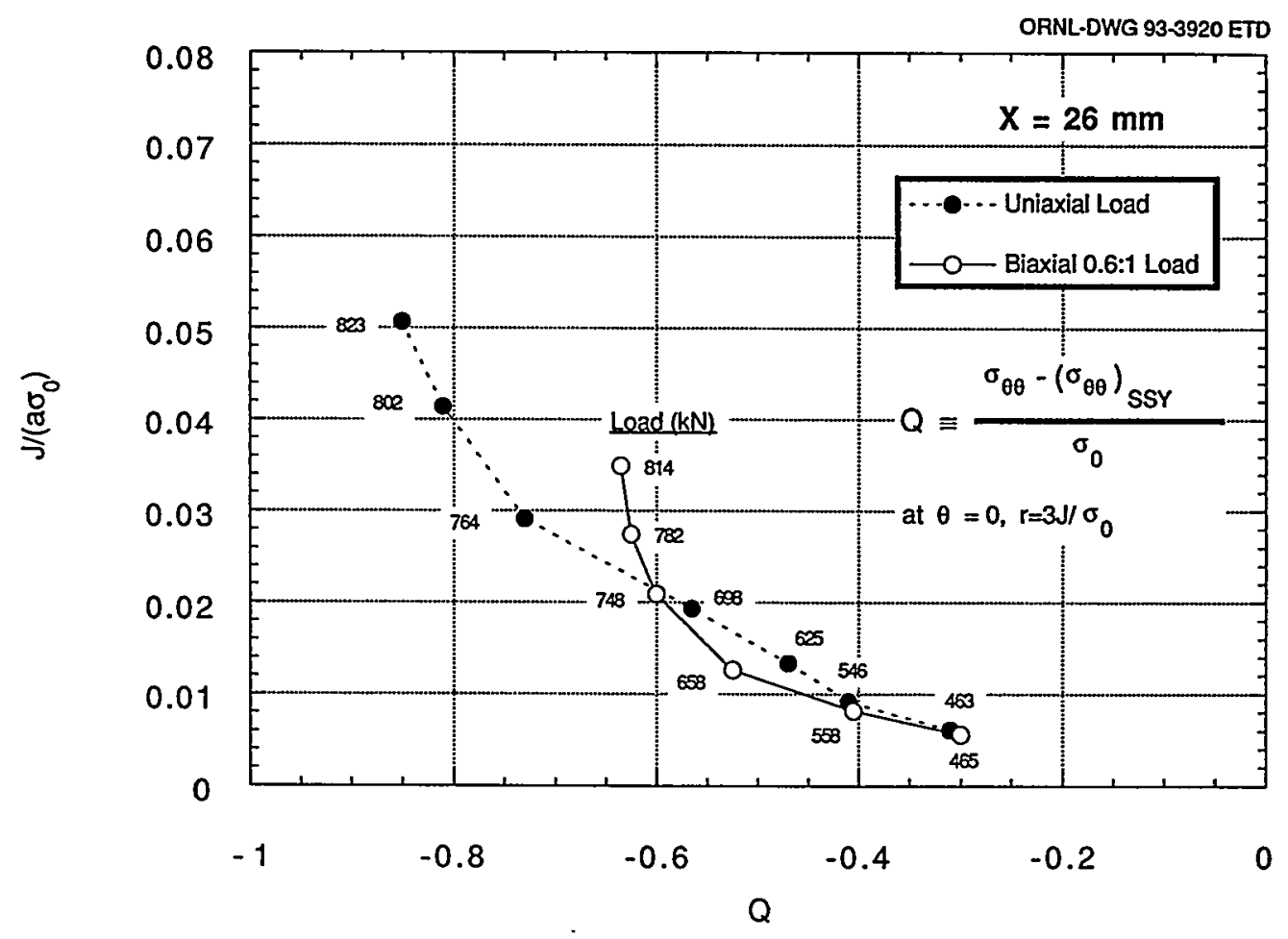

Figure 3.20 $\mathrm{J}-\mathrm{Q}$ trajectories at $\mathrm{X}=26 \mathrm{~mm}$ for a normalized distance $r \sigma_{0} / \mathrm{J}=3$

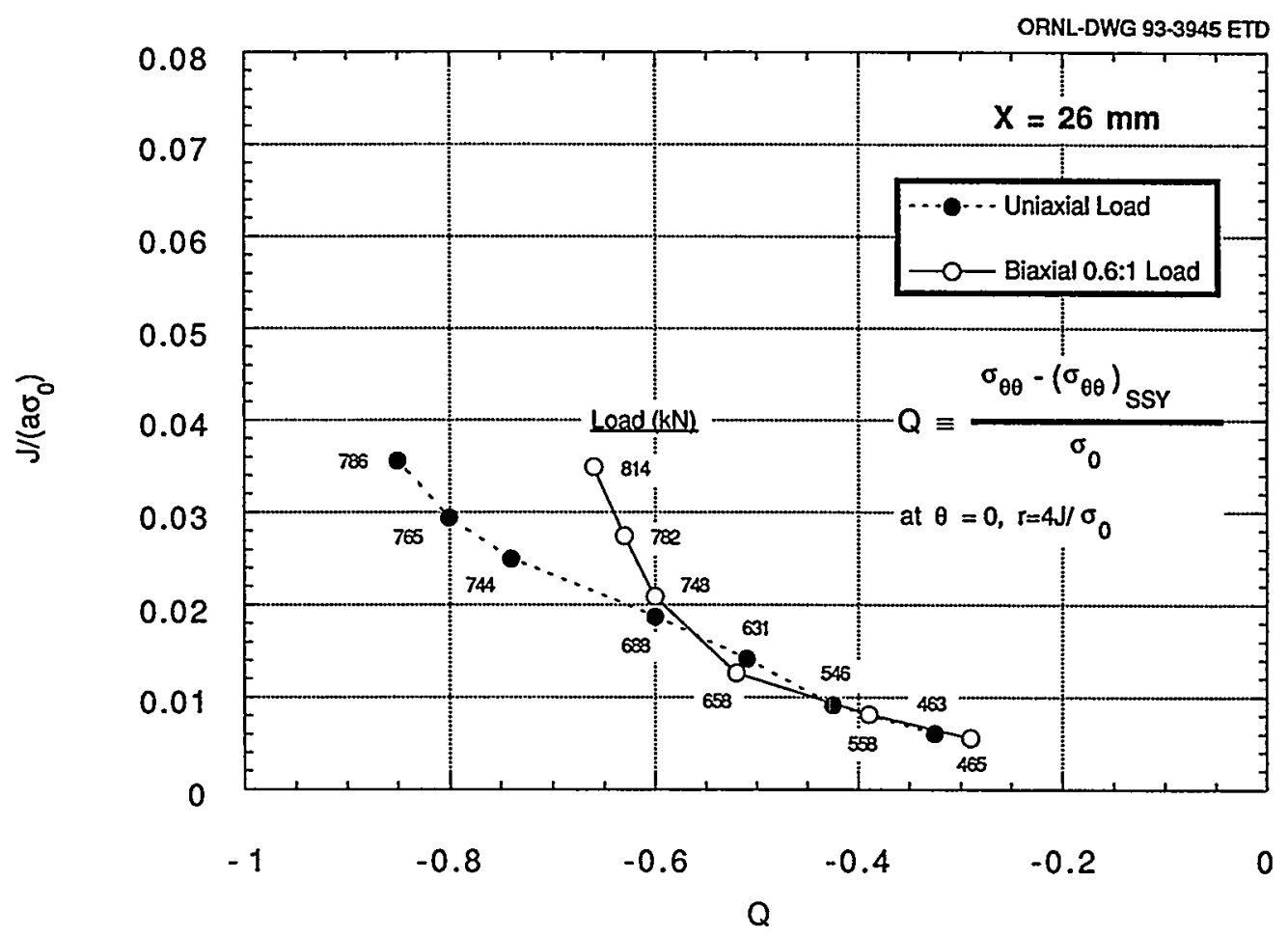

Figure 3.21 $J-Q$ trajectories at $X=26 \mathrm{~mm}$ for a normalized distance $r \sigma_{0} / J=4$ 
Constraint

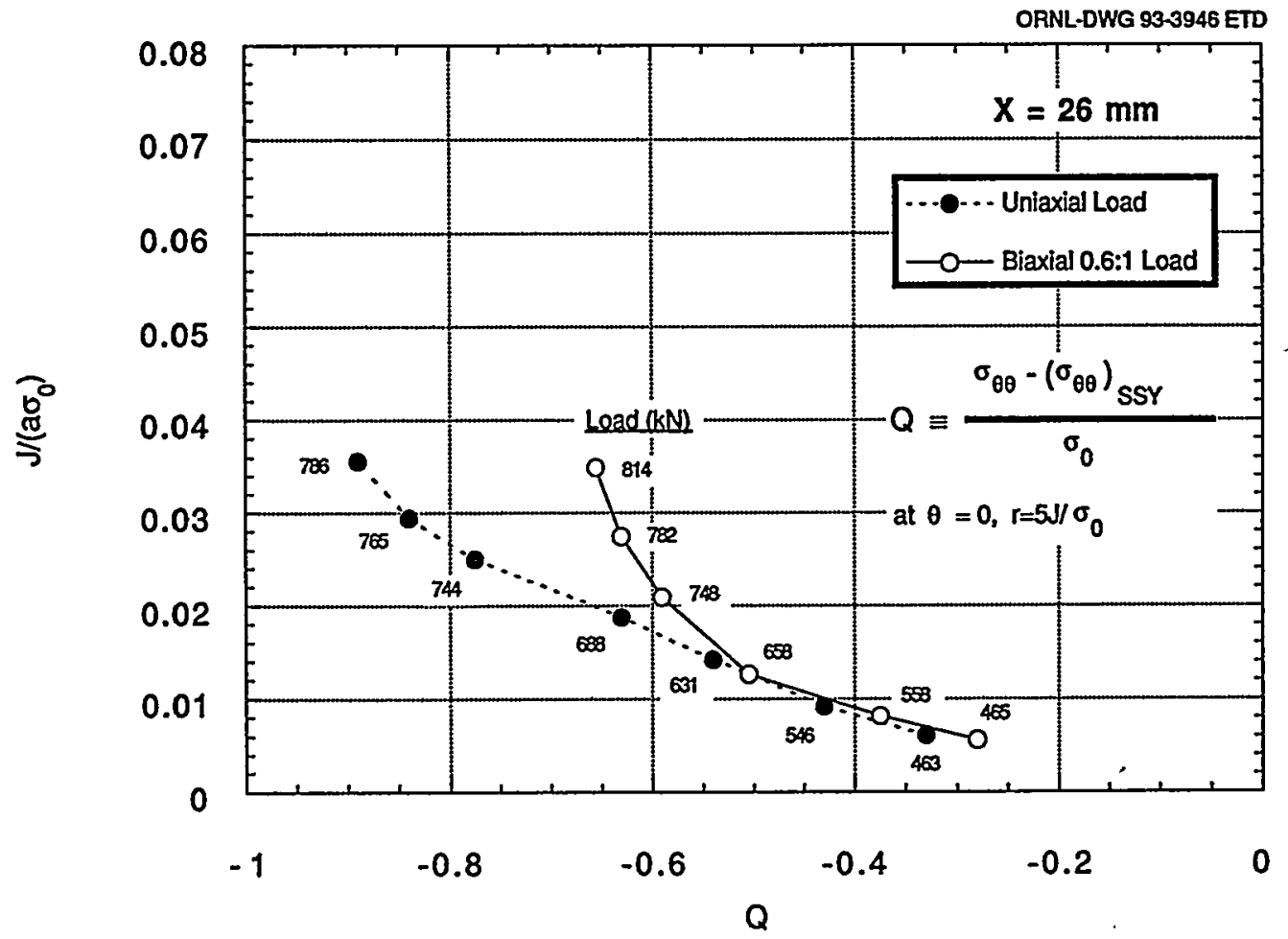

Figure 3.22 $\mathrm{J}-\mathrm{Q}$ trajectories at $\mathrm{X}=26 \mathrm{~mm}$ for a normalized distance $\sigma_{0} / \mathrm{J}=5$

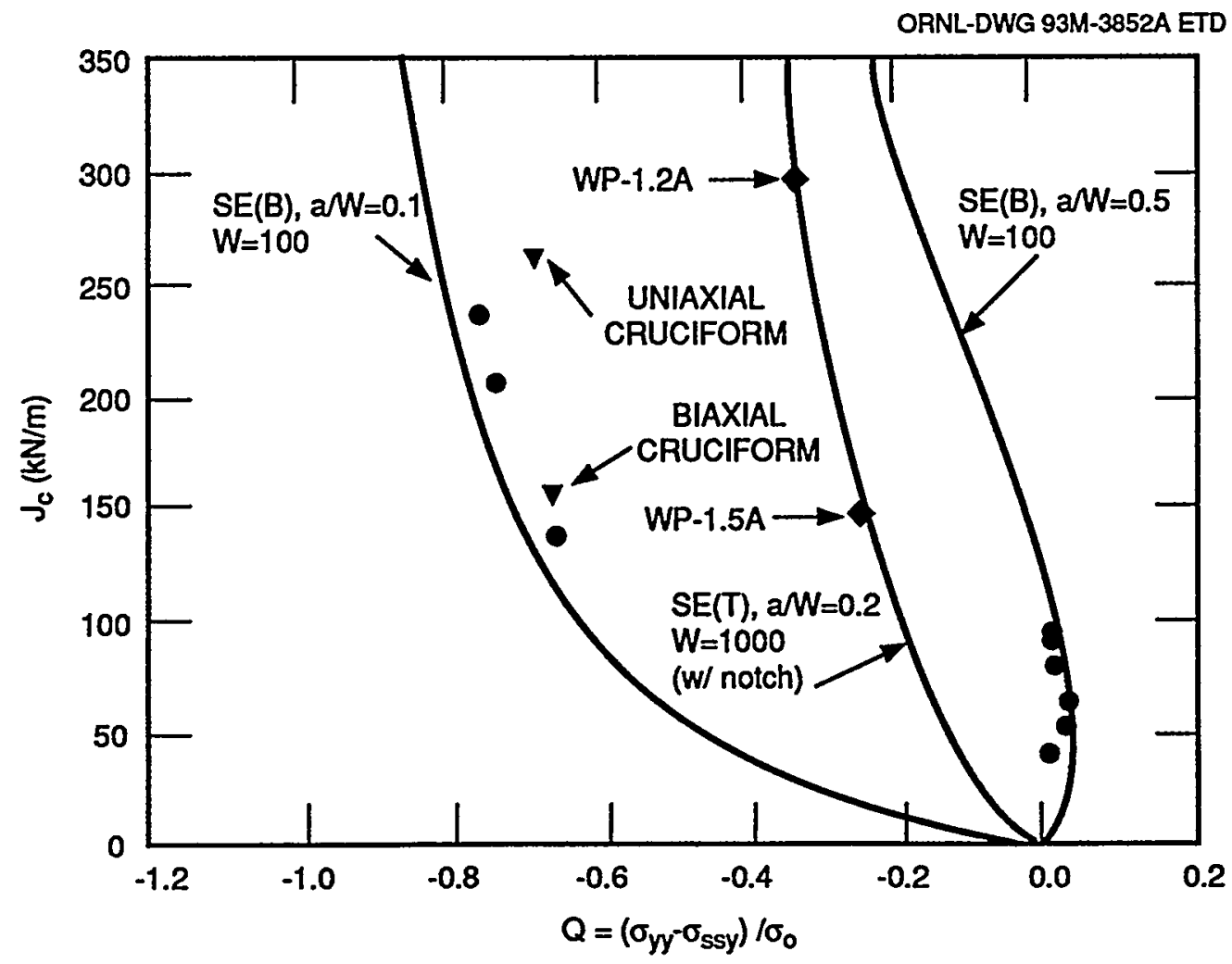

Figure 3.23 J-Q failure locus for A 533 grade $B$ class 1 steel at $T-R T_{N D T}=-10^{\circ} \mathrm{C}$ 


\section{Constraint}

loading cases is shown in Figs. 3.13 and 3.14, respectively. In Fig. 3.13, the Q-stress steadily decreases as the applied load is increased and as general yielding develops in the uniaxially loaded specimen. Also, the Q-stress exhibits a dependence on radial distance with increasing load, an effect previously observed in Fig. 3.11. The bending field imposed on the beam by the applied loads progressively impinges on the near crack-tip field within the region defined by $\bar{r} \leq 5$, producing an essentially linear dependence of $Q$ upon $\bar{r}$ at higher J values.

To quantify changes in the stress triaxiality from a spatially uniform hydrostatic field ahead of the crack, O'Dowd and $\mathrm{Shih}^{8}$ defined the mean gradient of $\mathrm{Q}$ over the annulus $1 \leq$ $\overline{\mathbf{r}} \leq 5$ :

$$
Q^{\prime}=\frac{Q(\bar{r}=5)-Q(\overline{\mathrm{r}}=1)}{4} .
$$

The criterion of $\left|Q^{\prime}\right|<0.1$ was proposed by O'Dowd and $\mathrm{Shih}^{8}$ as an indication that the Q-stress field is essentially constant over the annulus $1<\overline{\mathrm{r}}<5$. The $Q^{\prime}$ function was used in Ref. 8 to assess the dependence of $Q$ upon $\overline{\mathrm{r}}$ in analyses of three-point bend bar specimens for a range of crack depths. Values of $\left|Q^{\prime}\right|>0.1$ were computed at higher loads for deep-crack geometries in these analyses, reflecting the interaction of far-field bending stresses with the near-tip field. (This spatial dependence of Q-stresses was not evident in the HSST shallow-crack SENB analyses of Fig. 3.10.)

Previous discussion of Fig. 3.13 noted that the far-field bending stresses impact stress fields on the annulus $2<\overline{\mathrm{r}}<$ 5 at higher values of uniaxial loading applied to the cruciform specimen. For this specimen, Fig. 3.13 indicates that the criterion $\left|Q^{\prime}\right|<0.1$ is not satisfied on the annulus $2<$ $\overline{\mathbf{r}}<5$ as failure load is approached. The $Q^{\prime}$ criterion based on a maximum of 0.1 appears to permit a large variation in Q-stress over the crack-tip annulus. In this case, the variation in $\mathrm{Q}$ over the crack-tip annulus is greater than the difference between calculated Q-stress values for uniform and biaxial loading cases. Thus, it remains difficult to support the quantification of crack-tip constraint based on stress conditions in this annulus that are so heavily influenced by the far-field stresses. Consequently, application of the Q-stress methodology under conditions represented by the uniaxially loaded specimen at failure appears to be problematic. Further discussion of this issue is provided in subsequent sections in the context of J-Q trajectories and fractographic data concerning cleavage initiation sites.

The effect on variation of Q-stress vs $\overline{\mathbf{r}}$ due to addition of the out-of-plane bending load is illustrated by results from the biaxial case given in Fig. 3.14. For this case, $Q$ varies negligibly with $\bar{r}$ (i.e., $\left|Q^{\prime}\right| \sim 0.01$ ) over the annulus $2 \leq \overline{\mathrm{r}} \leq 5$ for the full range of loading. The Q-stress steadily decreases to a value of -0.6 , where it remains (approximately) constant until failure conditions are reached. This value of Q-stress agrees well with the Q-stress determined at failure for the shallow-crack SENB specimens. Comparison of these results with the uniaxial case in Fig. 3.13 indicates that biaxial loading produces a higher stress triaxiality (as quantified by $Q$ ) at failure conditions and a hydrostatic stress field that is more spatially uniform over the annulus $2 \leq \bar{r} \leq 5$. The interaction of the local stress field and the far-field bending stresses in the uniaxially and biaxially loaded cruciform specimens is discussed further in Sect. 3.4.

The evolution of the J-Q loading path at the midplane of the cruciform specimen for the uniaxial and biaxial loading cases is depicted in Figs. 3.15-3.18. The Q-stress is evaluated at distances ahead of the crack given by $\overline{\mathrm{r}}=2,3,4$, and 5 in Figs. 3.15-3.18, respectively. The J-Q loading path for the biaxial case is essentially the same at $\bar{r}=3,4$, and 5. The Q-stress reaches a constant value of approximately -0.6 as the loading path turns sharply upward and failure conditions are approached. For the uniaxial case, the J-Q path is sensitive to the choice of $\bar{r}$ (i.e., $Q$ becomes more negative with increasing $\bar{r}$ ), as would be expected from results shown previously in Fig. 3.13. Response of the cruciform specimen in terms of measured P, LLD, and CMOD data (Figs. 3.4 and 3.5) indicated no significant biaxial loading effects for contained yielding conditions. Similar behavior between the uniaxial and biaxial cases for the $\mathrm{J}-\mathrm{Q}$ trajectory is demonstrated only for values of $\bar{r} \geq 4$. For this case, the uniaxial $J-Q$ loading path follows the biaxial path up to a value of $\mathrm{J} /\left(\mathrm{a} \sigma_{0}\right)=0.24$ (which corresponds to $\mathrm{J} \sim 100 \mathrm{kN} / \mathrm{m}$ or $\mathrm{K}_{\mathrm{J}} \sim 150 \mathrm{MPa} \sqrt{\mathrm{m}}$ ) and then diverges from the biaxial case as yielding increases in the specimens. In Fig. 3.18, the uniaxial and biaxial paths diverge at a $Q$-stress value of -0.6 , a condition that represents substantial loss of triaxiality.

Several observations can be made concerning the J-Q trajectories computed at selected locations ahead of the crack tip in Figs. 3.15-3.18. Given the similarity of the uniaxial and biaxial P-CMOD responses at low loads, the expectation is that the J-Q trajectories for the uniaxial and biaxial specimens would exhibit similar behavior. Figure 3.15 depicts the $J-Q$ trajectories computed at $\overline{\mathbf{r}}=2$, that is, at the location formally defining the Q-stress. The trajectory for the uniaxial case exhibits a significantly higher constraint condition (i.e., higher Q-stress) than the biaxial case for almost the entire loading path. This analytical result is at odds with experimental results that imply the biaxially loaded specimen is the more highly constrained specimen. 
At failure conditions, however, the uniaxial Q-stress is slightly more negative than the biaxial Q-stress, which is consistent with expected behavior. With increasing distance from the crack tip, the J-Q trajectory for the uniaxial case translates in the direction of decreasing triaxiality (i.e., more negative Q-stress values). For points in that portion of the annulus defined by $\overline{\mathrm{r}} \geq 4$, the uniaxial and biaxial trajectories are very similar for $Q>-0.6$ (see Figs. 3.17 and 3.18). However, there is no rationale for quantifying constraint at distances relatively far removed from the crack tip in an annulus where far-field stresses have a strong influence as in the uniaxial case. Fractographic examination of the test specimens (described in Chap. 4) showed no evidence of cleavage initiation sites in the annulus under consideration. Therefore, the cruciform specimens will be interpreted in terms of J-Q trajectories defined at $\overline{\mathrm{r}}=2$, despite the previously observed inconsistencies between the uniaxial and biaxial trajectories at lower load.

Corresponding results for the $\mathrm{J}-\mathrm{Q}$ loading paths for the uniaxial and biaxial cruciform specimen computed at a point on the crack front located $26 \mathrm{~mm}$ from the midplane are given in Figs. 3.19-3.22. These results show stress triaxiality effects similar to those determined for the midplane of the specimen. In Fig. 3.22, the J-Q trajectories for the uniaxial and biaxial loading cases diverge at $Q \sim-0.5$, which is somewhat higher than the corresponding midplane value of -0.6 (see Fig. 3.18)

A J-Q failure locus for A 533 grade B class 1 steel at one temperature is schematically constructed in Fig. 3.23. This failure locus utilizes $\mathrm{J}-\mathrm{Q}$ trajectories from analyses of shallow- and deep-crack SENB and HSST wide-plate data performed by Dodds.* The estimated J-Q toughness values for the uniaxially and biaxially loaded cruciform specimen at $\overline{\mathrm{r}}=2$ are also included. Figure 3.23 depicts the scatter for a toughness locus corresponding to these J-Q trajectories. The toughness locus implies that reduced stress triaxiality (as reflected in more negative values of $Q$ ) is associated with increases both in apparent fracture toughness and in data scatter. The trajectories for the cruciform specimens fall well within the scatter of the failure locus. Also, the tendency for the biaxially loaded specimen trajectory to saturate at a higher stress triaxiality (i.e., less negative Q-stress) and turn abruptly upward suggest that biaxial loading could produce less data scatter in shallow-crack geometries than the uniaxial case.

\footnotetext{
*R. H. Dodds, Jr., "Constraint Analysis of the Shallow-Crack and WidePlate Test Results," to be issued as a NUREG under subcontract to the HSST Program.
}

\subsection{Fracture Toughness Scaling Model (Dodds-Anderson)}

The Dodds-Anderson (or D-A) scaling model ${ }^{10}$ analyzes constraint conditions by determining the area (or volume when considering a 3-D geometry) within a particular stress contour for a finite-body geometry and scaling that area (or volume) with an equivalent SSY solution. The SSY state is then considered to yield true fracture toughness results completely independent of specimen size or loading and is comparable to a specimen of infinite size. The scaling model has been successfully applied to fracture toughness results exhibiting either a loss of in-plane constraint (i.e., shallow cracks) or out-of-plane constraint (i.e., thickness effects). ${ }^{10}$ The scaling model assumes that the volume of critically stressed material surrounding the crack tip is the same in different specimens with different constraint conditions. As a result, the SSY critical fracture toughness can be determined in a high-constraint geometry and then applied to a low-constraint geometry or vice versa.

\subsubsection{Application of Scaling Model to Shallow-Crack Data}

The D-A scaling model has been used to investigate both in-plane and out-of-plane constraint loss in the HSST shallow- and deep-crack test results. The in-plane investigation is reported herein; the application of the model to out-of-plane constraint or thickness effects is the subject of a separate report. ${ }^{\dagger}$ The scaling model was applied to the shallow-crack data using information available in the literature ${ }^{21}$ without the need of additional crack-tip analysis.

The fracture toughness data from the HSST shallow-crack program are shown in Fig. 3.24 as a function of normalized temperature ( $\mathrm{T}-\mathrm{RT} \mathrm{NDT}_{\mathrm{T}}$ ). The shallow-crack toughness increase can be quantified by a temperature shift of $-35^{\circ} \mathrm{C}$. The data within the box at a normalized temperature range of approximately $-10^{\circ} \mathrm{C}$ to $-25^{\circ} \mathrm{C}$ in Fig. 3.24 are replotted in Fig. 3.25 as a function of crack depth. As expected in a low-constraint geometry, Fig. 3.25 shows both an increase in the fracture toughness values and data scatter from the shallow-crack specimens when compared with the deepcrack specimens. Figures 3.24 and 3.23 are complementary, both indicating an increase in toughness and data scatter with decreased constraint. The regression analysis shown in Fig. 3.25 indicates a mean shallow-crack

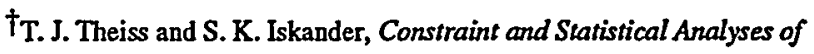
Transition Range A533 B Toughness Data, USNRC Report NUREG/CR-6106 (ORNUTM-12467), to be published.
} 


\section{Constraint}

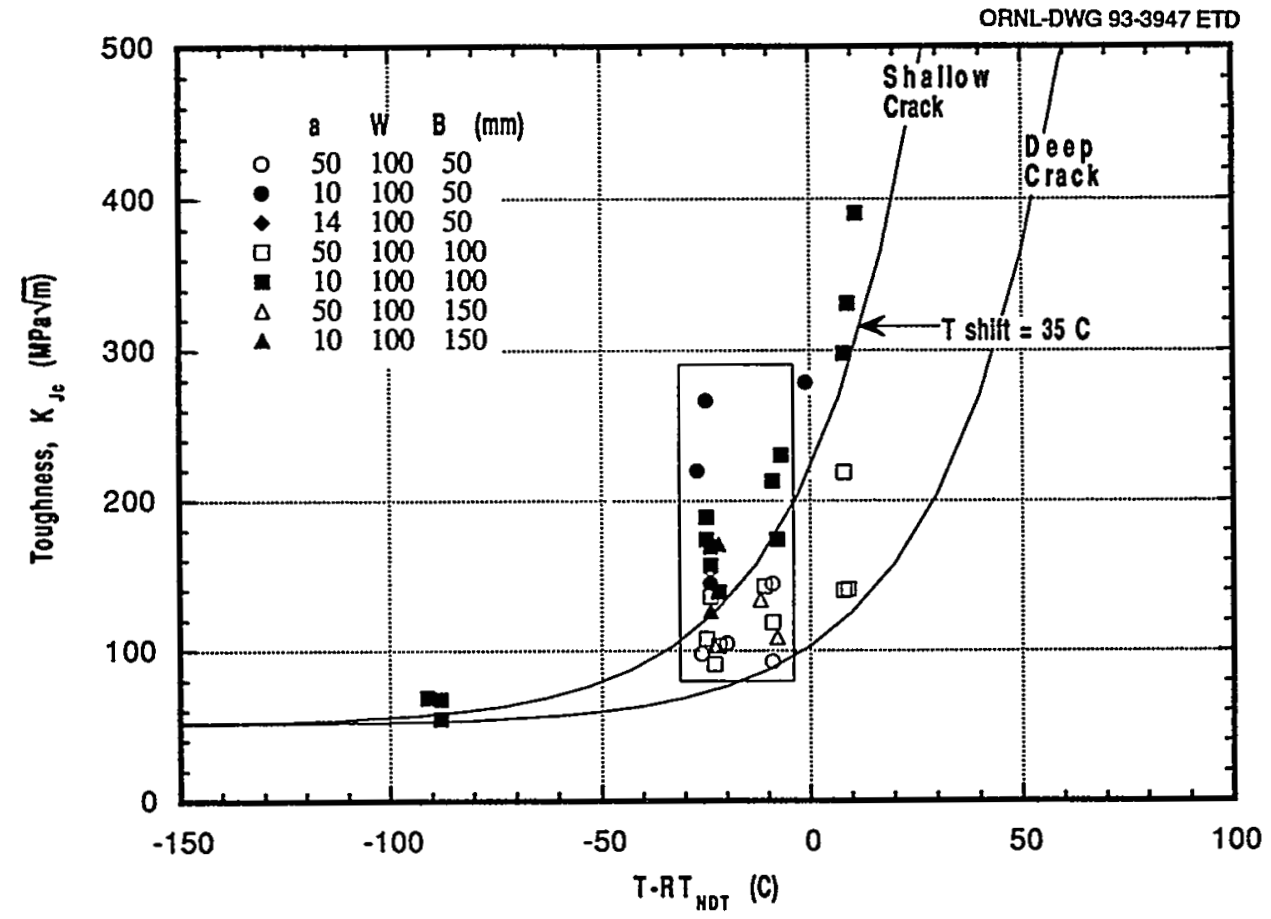

Figure 3.24 HSST shallow-crack fracture toughness results as function of normalized temperature $\mathrm{T}-\mathrm{RT}$ NDT

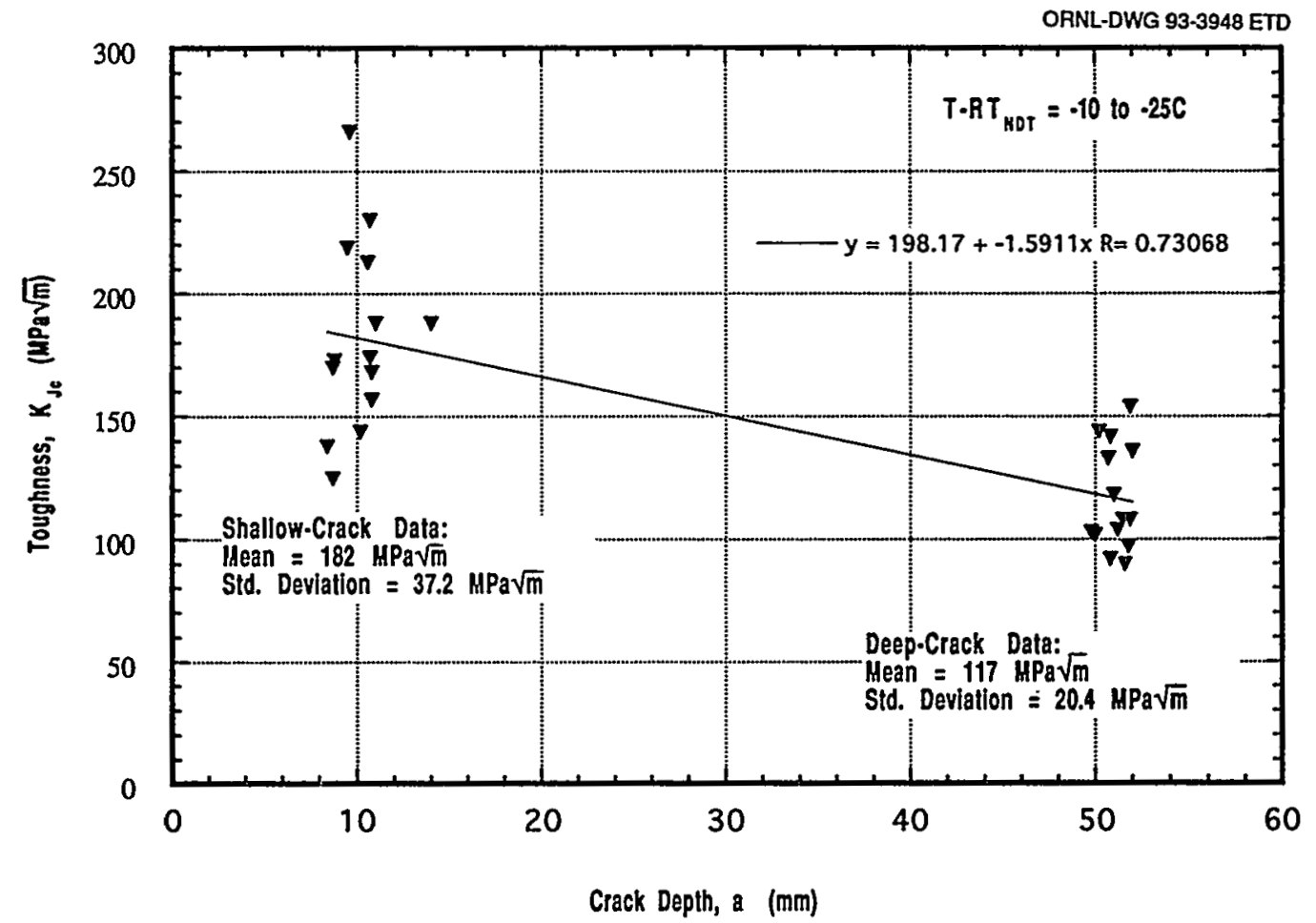

Figure 3.25 Toughness data at $\mathrm{T}-\mathrm{RT}$ NDT $=-25$ to $-10^{\circ} \mathrm{C}$ as function of crack depth 
Constraint

toughness value of about 1.6 times the deep-crack toughness as previously reported. ${ }^{5}$

The following criteria developed by Dodds and Anderson ${ }^{10}$ indicate dimensions in deep-crack ( $2 / W$ > $0.5)$ specimens necessary for SSY:

$$
a, b, B \geq 200 J d \sigma_{f},
$$

where $a$ is the crack depth, $b$ is the remaining ligament, $B$ is the specimen thickness, $J_{c}$ is the cleavage $J$-integral toughness, and $\sigma_{f}$ is the flow stress of the material. Specimens not meeting the criteria are expected to exhibit a toughness increase due to the loss of out-of-plane constraint. The ratio $a \sigma_{f} / J_{c}$ was determined for each specimen and is listed in Table 3.1. As expected, the ratio exceeds 200 for most of the deep-crack specimens and is considerably less than 200 for the shallow-crack specimens.

Using the $D-A^{10}$ analysis results, Wallin ${ }^{21}$ has quantified in-plane constraint loss by the following equation:

Table 3.1 Results of scaling model applied to shallow-crack data

\begin{tabular}{|c|c|c|c|c|c|c|}
\hline $\begin{array}{c}\text { HSST } \\
\text { beam }\end{array}$ & $\underset{\left({ }^{\circ} \mathrm{C}\right)}{\mathbf{T}-\mathbf{R T}_{\mathrm{NDT}}}$ & $\stackrel{a}{(\mathbf{m m})}$ & $\frac{\mathbf{K}_{\mathbf{J c}}}{\left(\mathrm{MPa}_{\mathbf{m}}\right)}$ & $a /\left(J / \sigma_{f}\right)$ & $\mathbf{J}_{\mathrm{FB}} / \mathbf{J}_{\mathrm{o}}$ & $\frac{\mathbf{K}_{\mathbf{o}}}{(\mathrm{MPa} \sqrt{\mathbf{m}})}$ \\
\hline 3 & -1 & 10.0 & 279 & 13 & 6.33 & 111 \\
\hline 4 & -26 & 51.8 & 98 & 579 & 1.03 & 96 \\
\hline 5 & -20 & 51.2 & 105 & 490 & 1.04 & 103 \\
\hline 6 & -24 & 51.9 & 155 & 230 & 1.10 & 147 \\
\hline 7 & -24 & 10.2 & 145 & 51 & 1.80 & 108 \\
\hline 8 & -25 & 9.6 & 267 & 14 & 5.58 & 113 \\
\hline 9 & -27 & 9.5 & 220 & 21 & 3.71 & 114 \\
\hline 10 & -25 & 14.0 & 189 & 42 & 2.05 & 132 \\
\hline 11 & -22 & 8.4 & 139 & 46 & 1.94 & 100 \\
\hline 12 & -22 & 49.8 & 103 & 494 & 1.04 & 101 \\
\hline 13 & -25 & 8.8 & 174 & 31 & 2.60 & 108 \\
\hline 14 & -22 & 8.7 & 171 & 31 & 2.56 & 107 \\
\hline 15 & -24 & 8.7 & 126 & 58 & 1.67 & 97 \\
\hline 16 & -23 & 50.0 & 103 & 501 & 1.04 & 101 \\
\hline $12 \mathrm{~A}$ & -9 & 51.0 & 119 & 369 & 1.05 & 116 \\
\hline $13 \mathrm{~A}$ & -11 & 50.8 & 143 & 255 & 1.09 & 137 \\
\hline $14 \mathrm{A1}$ & -9 & 50.2 & 145 & 244 & 1.09 & 138 \\
\hline $14 \mathrm{A2}$ & -9 & 50.8 & 93 & 601 & 1.03 & 91 \\
\hline $15 \mathrm{~A}$ & -12 & 50.7 & 134 & 289 & 1.07 & 129 \\
\hline $16 \mathrm{~A}$ & -8 & 51.9 & 109 & 445 & 1.04 & 107 \\
\hline 17 & 9 & 52.6 & 141 & 254 & 1.09 & 135 \\
\hline 18 & -9 & 10.6 & 213 & 23 & 3.37 & 116 \\
\hline 20 & 11 & 10.8 & 391 & 7 & 13.68 & 106 \\
\hline 21 & -8 & 10.7 & 174 & 35 & 2.34 & 114 \\
\hline 22 & 8 & 10.9 & 298 & 12 & 6.93 & 113 \\
\hline 24 & 8 & 52.0 & 219 & 105 & 1.30 & 192 \\
\hline 25 & -24 & 52.0 & 136 & 290 & 1.07 & 131 \\
\hline 26 & -25 & 11.0 & 189 & 32 & 2.51 & 119 \\
\hline 27 & -7 & 10.7 & 230 & 20 & 3.92 & 116 \\
\hline 28 & 9 & 10.3 & 331 & 9 & 9.54 & 107 \\
\hline 31 & -25 & 51.5 & 108 & 455 & 1.04 & 106 \\
\hline 32 & -88 & 11.1 & 68 & 327 & 1.06 & 66 \\
\hline 33 & -88 & 10.7 & 55 & 499 & 1.04 & 54 \\
\hline 34 & -91 & 10.4 & 69 & 307 & 1.07 & 67 \\
\hline 35 & $\begin{array}{r}-71 \\
8\end{array}$ & 51.7 & 140 & 255 & 1.09 & 134 \\
\hline 36 & $\begin{array}{l}0 \\
-23\end{array}$ & 51.6 & 91 & 645 & 1.02 & 90 \\
\hline $\begin{array}{l}30 \\
37\end{array}$ & $\begin{array}{l}-23 \\
-24\end{array}$ & 10.8 & 169 & 39 & 2.16 & 115 \\
\hline 38 & -24 & 10.8 & 157 & 45 & 1.95 & 112 \\
\hline
\end{tabular}




$$
\mathrm{J}_{\mathrm{FB}} / \mathrm{J}_{\mathrm{o}}=1+176\left(\mathrm{~J}_{\mathrm{FB}} / \mathrm{a} \sigma_{0}\right)^{1.37}
$$

where $\mathrm{J}_{0}$ is the SSY or reference value of $\mathrm{J}$, and $\mathrm{J}_{F B}$ is the value of $\mathrm{J}$ in the finite body geometry. Equation (4) is applicable to materials with a Ramberg-Osgood hardening exponent of $\sim 10$, such as A 533 B steel. It is recommended in Ref. 10 that results from the above equation not be used in situations in which $J / J_{0}>4$. The SSY value $\left(J_{0}\right)$ was computed from Eq. (4) for each specimen tested as a part of the HSST Shallow-Crack Program. The results are listed in Table 3.1 as $\mathrm{J}_{\mathrm{FB}} / J_{\mathrm{O}}$ and $\mathrm{K}_{\mathrm{O}}$. The plane-strain elastic modulus was used to convert from $\mathrm{J}$ to $\mathrm{K}$. The $\mathrm{K}_{\mathrm{O}}$ results are shown in Fig. 3.26 as a function of normalized temperature. The $K_{0}$ results show no toughness increase associated with the shallow-flaw specimens. As shown in Fig. 3.26, several of the shallow-crack $\mathrm{K}_{0}$ data are below the corresponding deep-crack $\mathrm{K}_{0}$ data at higher temperatures. These specimens exhibited a $\mathrm{J}_{\mathrm{FB}} / \mathrm{J}_{\mathrm{o}}$ adjustment $>4$ and do not represent the SSY toughness value.

The $\mathrm{K}_{\mathrm{o}}$ values as a function of crack depth in the transition region (i.e., the data subset in Fig. 3.26 within the box) are shown in Fig. 3.27. The data in Fig. 3.27 correspond to the uncorrected data in Fig. 3.25. As indicated in Fig. 3.27, the $\mathrm{K}_{\mathrm{o}}$ results are reduced to a toughness level independent of the crack depth of the specimens. Comparing Figs. 3.25 and 3.27, the deep-crack data in Fig. 3.27 experience little to no reduction to their $\mathrm{K}_{0}$ values, while the shallow-crack data are reduced substantially to almost exactly the same toughness level. The regression analysis shown in Fig. 3.27 confirms that the $K_{0}$ data are independent of crack depth. The mean and standard deviation of the shallow- and deepcrack data are included on Fig. 3.27 as well. The mean values are almost identical at $112 \mathrm{MPa} \sqrt{\mathrm{m}}$ for the shallowcrack $K_{0}$ data and $114 \mathrm{MPa} \sqrt{\mathrm{m}}$ for the deep-crack $\mathrm{K}_{\mathrm{o}}$ data. The shallow-crack $\mathrm{K}_{\mathrm{o}}$ also exhibit substantially less scatter than the original shallow-crack data in Fig. 3.25. The standard deviation of the original shallow-crack $\mathrm{K}_{\mathrm{Jc}}$ data was $37.2 \mathrm{MPa} \sqrt{\mathrm{m}}$; the shallow-crack $\mathrm{K}_{\mathrm{o}}$ data had a deviation of only $8.1 \mathrm{MPa} \sqrt{\mathrm{m}}$. All of the data in Fig. 3.27 met the criteria of $\mathrm{J}_{\mathrm{FB}} / \mathrm{J}_{\mathrm{O}} \leq 4$ except one specimen that had a $\mathrm{J}_{\mathrm{FB}} / \mathrm{J}_{\mathrm{O}}$ ratio of $\sim 5.6$. The average $\mathrm{J}_{\mathrm{FB}} / \mathrm{J}_{\mathrm{O}}$ ratio for the shallow-crack specimens in Fig. 3.27 was 2.73; the average deep-crack specimen $\mathrm{J}_{\mathrm{FB}} / \mathrm{J}_{\mathrm{O}}$ value was 1.05 .

Several conclusions can be drawn from the application of the D-A scaling model to the HSST shallow-crack data. First, the scaling model works very well with the shallowcrack data. The model adjusts both shallow- and deepcrack data to the SSY toughness value. In addition, the scatter in the corrected toughness data was also reduced by the application of the scaling model to the original shallow-crack toughness results. Furthermore, the scaling model is very simple to use in this application. The analysis of the data using the scaling model required no additional crack-tip analysis. The constraint corrections were based on specimen geometry and cleavage toughness results. It appears likely that $\mathrm{J}_{\mathrm{c}}$ predictions for shallowcrack geometries could be made from $\mathrm{K}_{\mathrm{o}}$ data obtained from deep-crack specimens.

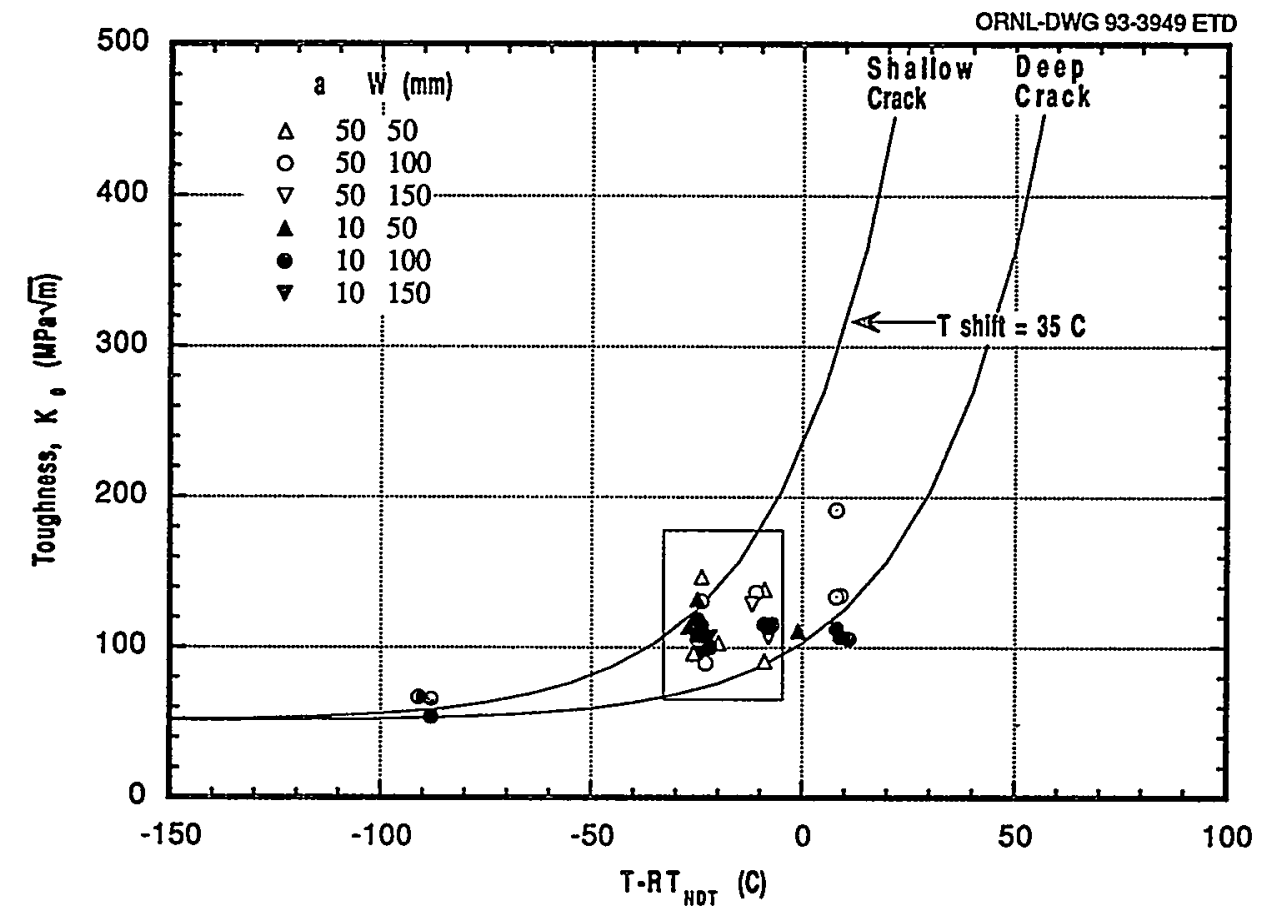

Figure 3.26 SSY toughness $\left(K_{0}\right)$ results as function of normalized temperature 


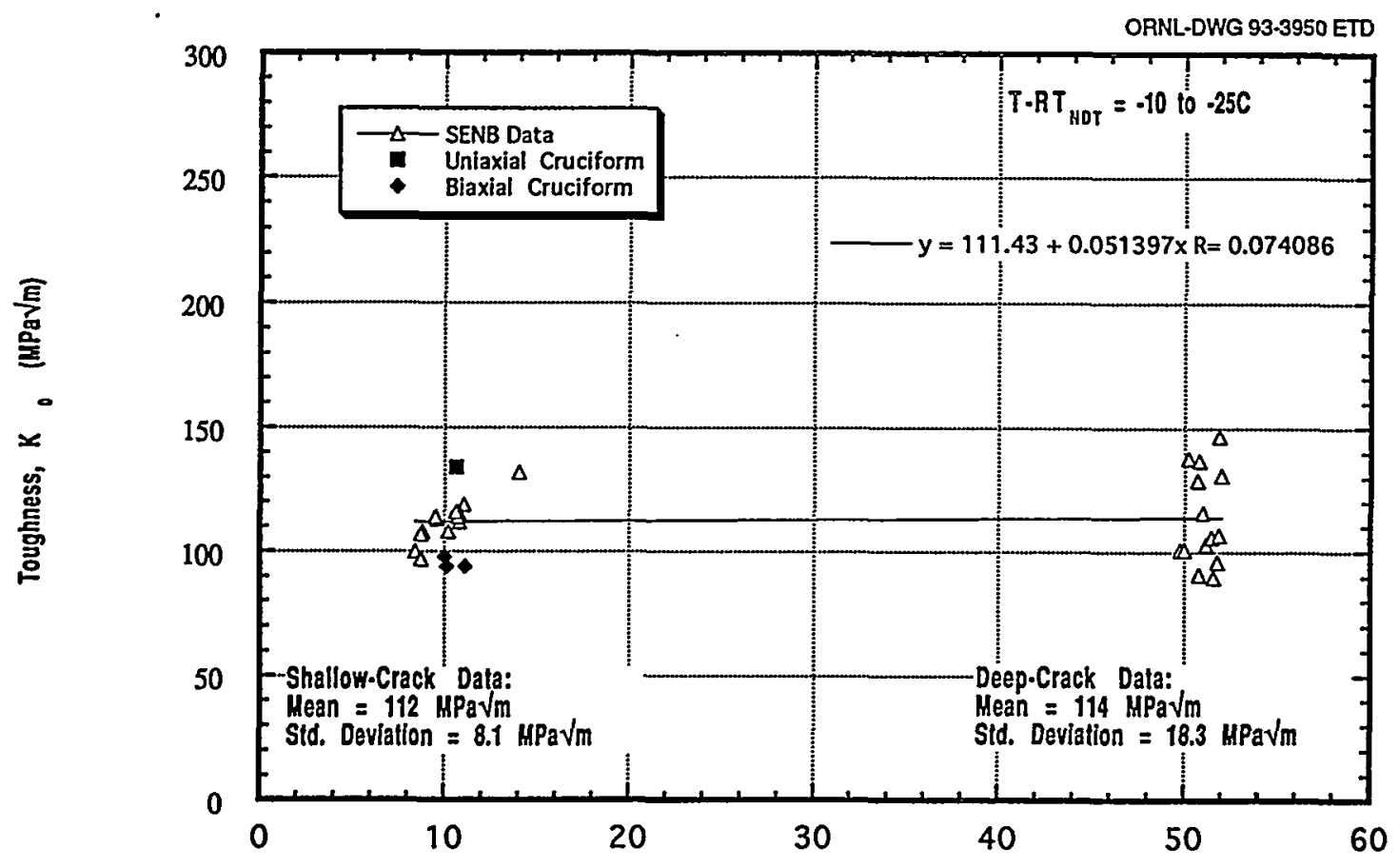

Crack Depth, a (mm)

Figure 3.27 $\mathrm{K}_{\mathrm{o}}$ data at $\mathrm{T}-\mathrm{RT}_{\mathrm{NDT}}=-25$ to $-10^{\circ} \mathrm{C}$ as function of crack depth

\subsubsection{Application of Scaling Model to Cruciform Beam Data}

Dodds et al. ${ }^{11}$ have also developed a methodology for performing constraint adjustments of fracture toughness data from test specimens that utilize a J-Q description of the crack-tip stress fields. This methodology has the advantage of being computationally simpler to apply than the stressed-volume technique for constraint correction previously introduced by Dodds and Anderson. ${ }^{10}$ Applications of this simplified approach to data from the uniaxially and biaxially loaded cruciform specimens, which draw upon the $\mathrm{J}-\mathrm{Q}$ analyses of the previous section, are presented herein.

The modified D-A scaling procedure, like the scaling model previously described, determines the ratio of finitebody toughness to SSY toughness (i.e., $\mathrm{J}_{\mathrm{FB}} / \mathrm{J}_{\mathrm{O}}$ ). The modified D-A scaling procedure is based on the observation ${ }^{11}$ that even under different constraint conditions the shape of the principal stress contour ahead of the crack tip remains the same, with only the size varying. This relationship is maintained until deformation becomes excessive. Critically stressed areas ahead of the crack can be related to critical distances ahead of the crack, which allows the use of the near-tip stress field to determine $\mathrm{J}_{\mathrm{FB}} / \mathrm{J}_{\mathrm{o}}$. Figure 3.28 shows the stresses ahead of the crack tip for the SSY solution and the cruciform specimen under uniaxial and biaxial loading.
The uniaxial and biaxial stresses are at (or near) the critical value of $J$. This allows the determination of the constraint conditions (and $\mathrm{J}_{\mathrm{O}}$ toughness) in these specimens at failure (i.e., critical SSY toughness, $\mathrm{J}_{\mathrm{o}}$ ). The three biaxial specimens yielded toughness values sufficiently close such that only one J value for these specimens is necessary.

Two different methods of applying the D-A scaling procedure were used for these results. ${ }^{*}$ Both methods begin with the ratio of the distance ahead of the crack tip, $\overline{\mathrm{r}}$, for the finite-body and SSY solutions to determine the $\mathrm{J}_{\mathrm{FB}} / \mathrm{J}_{\mathrm{O}}$ ratio. Both methods begin the construction with an $\overline{\mathbf{r}}$ value of about 2 . The first method holds the finite-body stress constant at $\bar{r}=2$ and determines the distance ahead of the crack tip in the SSY solution that corresponds to that stress (see Fig. 3.28). The second method begins with the SSY stress at $\bar{r}=2$ and finds the distance corresponding to that stress in the finite-body solution(s). Both of these methods are outlined in Fig. 3.28. The first method begins with the finite-body stress at $\overline{\mathrm{r}}=2$ or $\mathrm{r}=2 \mathrm{~J}_{\mathrm{FB}} / \sigma_{0}$. The distance in the SSY solution that yields the same critical stress is $\overline{\mathrm{r}}=$ 11.63 or $\mathrm{r}=11.63 \mathrm{~J}_{0} / \sigma_{0}$. Because the critical distances are assumed equal, $\mathrm{J}_{\mathrm{FB}} / \mathrm{J}_{\mathrm{O}}=11.63 / 2.0$ or 5.82 . The second method yields a $\mathrm{J}_{\mathrm{FB}} / \mathrm{J}_{\mathrm{O}}$ of $2.0 / 0.621=3.22$.

*Private conversation with R. H. Dodds, Jr., Sept. 28, 1993. 


\section{Constraint}

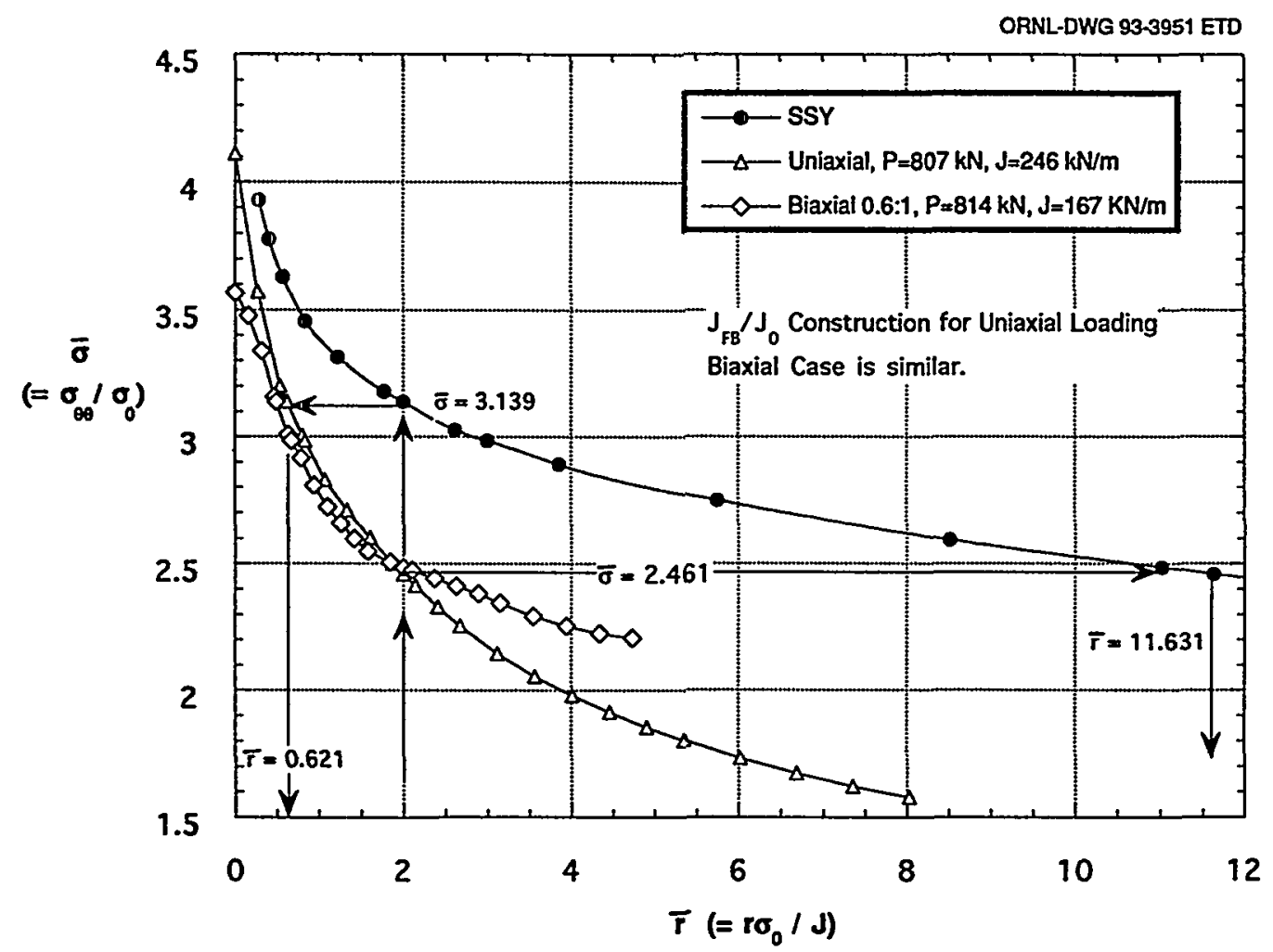

Figure 3.28 Determination of finite-body to SSY toughness ratio from stresses ahead of crack tip

The two methods of applying the D-A scaling model just described yield $\mathrm{J}_{\mathrm{FB}} / \mathrm{J}_{\mathrm{O}}$ ratios that are quite different. Theoretically, as discussed in Ref. 11, both methods should yield identical results. One reason for this problem is that these are numerical approximations to the stresses near the crack tip, which always contain some error. The SSY stress solution tends to flatten as distance from the crack tip increases, which could exaggerate the error in $\mathrm{J}_{\mathrm{FB}} / \mathrm{J}_{\mathrm{O}}$ with increasing distance from the crack tip. Furthermore, the first D-A scaling method used distances greater than $\overline{\mathbf{r}}=$ 10 , which is typically far beyond the process zone for cleavage fracture. (Additional information on the location of the cleavage origin site ahead of the crack tip will be covered in Chap. 4.) For the two reasons just outlined, the second D-A scaling procedure that uses smaller distances ahead of the crack tip is the preferred method in this investigation and will be used to interpret the results.

The $\mathrm{J}_{\mathrm{FB}} / \mathrm{J}_{\mathrm{O}}$ results using the $\mathrm{D}-\mathrm{A}$ scaling procedure for the uniaxial and biaxial cruciform specimens at $\overline{\mathrm{r}}=1.5$ to 4 are included in Table 3.2. These results are plotted as a function of distance ahead of the crack tip in Fig. 3.29. Examination of these results leads to several observations. First, the $\mathrm{J}$ ratios (and subsequently $\mathrm{J}_{0}$ ) vary as a function of distance ahead of the crack tip. For the uniaxial cruciform, the $\mathrm{J}_{\mathrm{FB}} / \mathrm{J}_{\mathrm{O}}$ ratio increases from -3 at $\overline{\mathrm{r}}=1.5$ to $\sim 4$ at $\overrightarrow{\mathbf{r}}=4$. The biaxial cruciform shows a similar increase in
Table 3.2 Scaling model results at distances ahead of crack tip for the uniaxial and biaxial cruciform specimens (at critical load)

\begin{tabular}{cccc}
\hline$\overline{\mathbf{r}}$ & $\sigma_{\mathbf{S S Y}} / \sigma_{\mathbf{o}}$ & $\overline{\mathbf{r}}_{\mathbf{F B}}$ & $\mathbf{J}_{\mathbf{F B}} / \mathbf{J}_{\mathbf{O}}$ \\
\hline \multicolumn{4}{c}{ Uniaxial loading } \\
1.5 & 3.248 & 0.502 & 2.99 \\
2.0 & 3.139 & 0.621 & 3.22 \\
2.5 & 3.048 & 0.744 & 3.36 \\
3.0 & 2.986 & 0.831 & 3.61 \\
3.5 & 2.931 & 0.916 & 3.82 \\
4.0 & 2.881 & 0.994 & 4.02 \\
\multicolumn{4}{c}{ Biaxial loading } \\
1.5 & 3.248 & 0.394 & 3.81 \\
2.0 & 3.139 & 0.493 & 4.06 \\
2.5 & 3.048 & 0.589 & 4.24 \\
3.0 & 2.986 & 0.669 & 4.48 \\
3.5 & 2.931 & 0.765 & 4.58 \\
4.0 & 2.881 & 0.842 & 4.75 \\
\hline
\end{tabular}

$\mathrm{J}_{\mathrm{FB}} / \mathrm{J}_{\mathrm{O}}$ with distance ahead of the crack tip. In Ref. 11, the calculation of $\mathrm{J}_{0}$ is considered valid when values determined at $\bar{r}=1.5$ and at $\bar{r}=4$ differ by $<10 \%$. The variation in $\mathrm{J}_{\mathrm{FB}} / \mathrm{J}_{\mathrm{O}}$ (and subsequently $\mathrm{J}_{\mathrm{O}}$ ) shown in Fig. 3.29 is about $25 \%$ over this range for both the uniaxial and biaxial 


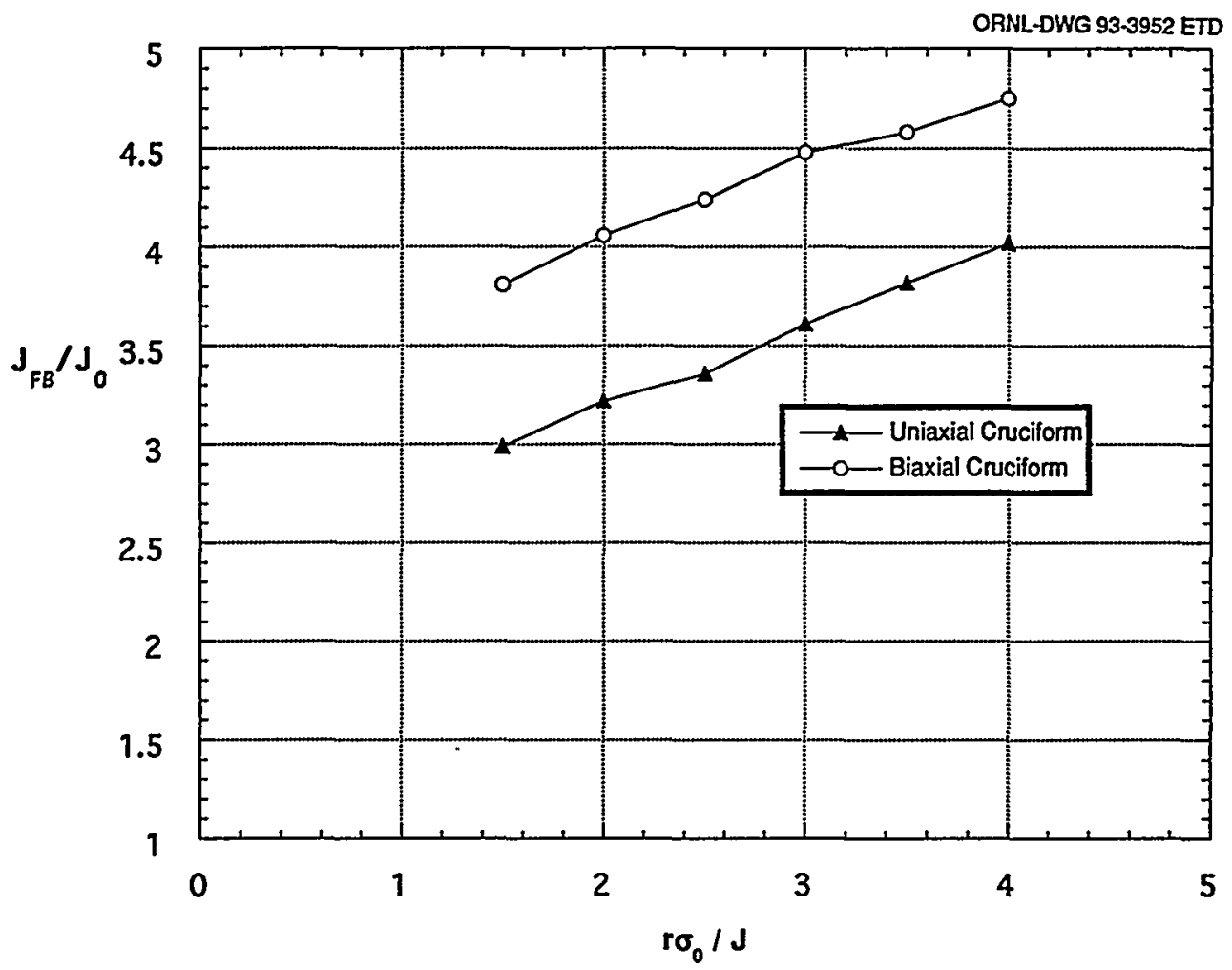

Figure 3.29 Finite-body to SSY toughness ratio as a function of normalized distance ahead of crack tip

cases. The D-A scaling model results do not, therefore, meet the criteria established in Ref. 11.

There are two potential explanations for $\mathrm{J}_{0}$ varying by more than the accepted criteria of $10 \%$. The first is the nature of the cruciform specimen itself, which possesses 3-D stress fields that vary through the thickness (see Fig. 3.8). The D-A scaling model allows the use of critically stressed areas ahead of the crack, assuming a relatively constant field through a specimen thickness. The second explanation is the assumption that the stressed areas in these cases are similarly shaped, allowing the comparison of distances ahead of the crack rather than areas. This assumption could lead to variations in $\mathrm{J}_{0}$ that might not exist had the D-A scaling model used contour areas.

Figure 3.29 indicates that the range of $\mathrm{J}_{\mathrm{FB}} / \mathrm{J}_{\mathrm{O}}$ ratios for the uniaxial cruciform is consistent with previous $\mathrm{J}_{\mathrm{FB}} / \mathrm{J}_{\mathrm{O}}$ values for the shallow-crack SENB specimens. The uniaxial cruciform yields values of $\mathrm{J}_{\mathrm{FB}} / J_{0}$ between 3 and 4 ; the shallow-crack SENB specimens yielded $\mathrm{J}_{\mathrm{FB}} / \mathrm{J}_{\mathrm{O}}$ ratios ranging from 1.8 to 5.6 , averaging 2.7 . Finally, as shown in Fig. 3.29, the biaxial $\mathrm{J}_{\mathrm{FB}} / \mathrm{J}_{\mathrm{O}}$ ratio is $\sim 25 \%$ greater than the uniaxial J-ratio. This implies greater constraint loss for the biaxial specimen than the uniaxial specimen, a result which is inconsistent with the experimental toughness results. However, these ratios have been determined for a very limited number of tests. Additional tests will be necessary to determine if these trends continue.

The $J_{0}$ values were calculated for the uniaxial and biaxial cruciform tests for comparison with SENB $J_{0}$ values using the analytically based $J_{F B}$ values and the $J_{F B} / J_{0}$ ratios determined at $\overline{\mathbf{r}}=2$. The ratio at $\overline{\mathbf{r}}=2$ was chosen because the $Q$-stress is typically determined at that location and the biaxial and uniaxial stresses ahead of the crack tip are almost identical at that location (see Fig. 3.28). The $\mathrm{J}_{0}$ and $\mathrm{K}_{0}$ values for the four cruciform tests are shown in Table 3.3 along with the upper and lower SSY toughness results from the shallow- and deep-crack SENB tests; $\mathrm{K}_{0}$ values are also included in Fig. 3.27. As indicated in Table 3.3, all of the cruciform SSY toughness values are within the range of SSY data from the SENB specimens. The $J_{0}$ values from the biaxial cruciform are near the lower limit of the SENB $J_{0}$ range; the uniaxial $J_{0}$ value was nearer the upper limit. Additional data are necessary to determine the full range of SSY toughness values under uniaxial and biaxial loading.

\subsection{Discussion of Crack-Tip Analyses}

The J-Q method and D-A scaling model have been applied to the shallow- and deep-crack SENB tests and the uniaxial and biaxial cruciform tests. Data sets used in these applications are generated from tests of specimen geometries that 


\section{Constraint}

Table 3.3 SSY toughness results for the uniaxial and biaxial cruciform specimens

\begin{tabular}{cccccc}
\hline $\begin{array}{c}\text { Specimen } \\
\text { No. }\end{array}$ & $\begin{array}{c}\text { Loading } \\
\text { configuration }\end{array}$ & $\begin{array}{c}\mathbf{J}_{\mathbf{F B}} \\
(\mathbf{k N / m})\end{array}$ & $\begin{array}{c}\mathbf{J}_{\mathbf{o}} \\
(\mathbf{k N} / \mathbf{m})\end{array}$ & $\begin{array}{c}\mathbf{K}_{\mathbf{F B}} \\
(\mathbf{M P a} \sqrt{\mathbf{m}})\end{array}$ & $\begin{array}{c}\mathbf{K}_{\mathbf{0}} \\
(\mathbf{M P a} \sqrt{\mathbf{m}})\end{array}$ \\
\hline BB-1 & $0.6: 1$ & 160 & 39.4 & 190 & 94 \\
BB-2 & $0: 1$ & 257 & 79.8 & 241 & 134 \\
BB-4 & $0.6: 1$ & 160 & 39.4 & 190 & 94 \\
BB-5 & $0.6: 1$ & 174 & 42.9 & 198 & 98 \\
\hline
\end{tabular}

Notes: $\mathrm{J}_{\mathrm{FB}} / \mathrm{J}_{\mathrm{O}}$ ratio at $\overline{\mathbf{r}}=2$ was used.

Plane strain relationship between $\mathrm{J}$ and $\mathrm{K}$ was used.

SENB (shallow- and deep-crack) SSY data were $\mathrm{J}_{\mathrm{o}}=35.9-95.8 \mathrm{kN} / \mathrm{m}$ or $\mathrm{K}_{\mathrm{o}}=90$

$147 \mathrm{MPa} \sqrt{\mathrm{m}}$.

provide a contrast in analytical modeling requirements. The SENB specimen is modeled in terms of a 2-D plane strain formulation, while the cruciform specimen exhibits a fully 3-D character that must be considered. Analysis results indicate that both methodologies can be used successfully to interpret experimental results from the deepand shallow-crack SENB specimen tests. Applications of the two methodologies to the cruciform specimen each showed promising features, but they also raised several issues concerning constraint analysis based on near-tip stress fields. These issues have been identified and discussed in the preceding sections. Some additional observations of the limitations of the two methods applied to the cruciform specimen are presented herein.

Figure 3.30 shows the stresses ahead of the crack tip for the SSY solution and the uniaxial and biaxial cruciform specimens at the critical value of J. (Figure 3.30 is identical to Fig. 3.28 except for the distance scale and the construction of $\mathrm{J}_{\mathrm{FB}} / \mathrm{J}_{\mathrm{o}}$.) Because both the J-Q method and the scaling model are based on the stresses ahead of the crack tip, observations about Fig. 3.30 are germane to both techniques. First, the coincidence of the critical crack-tip

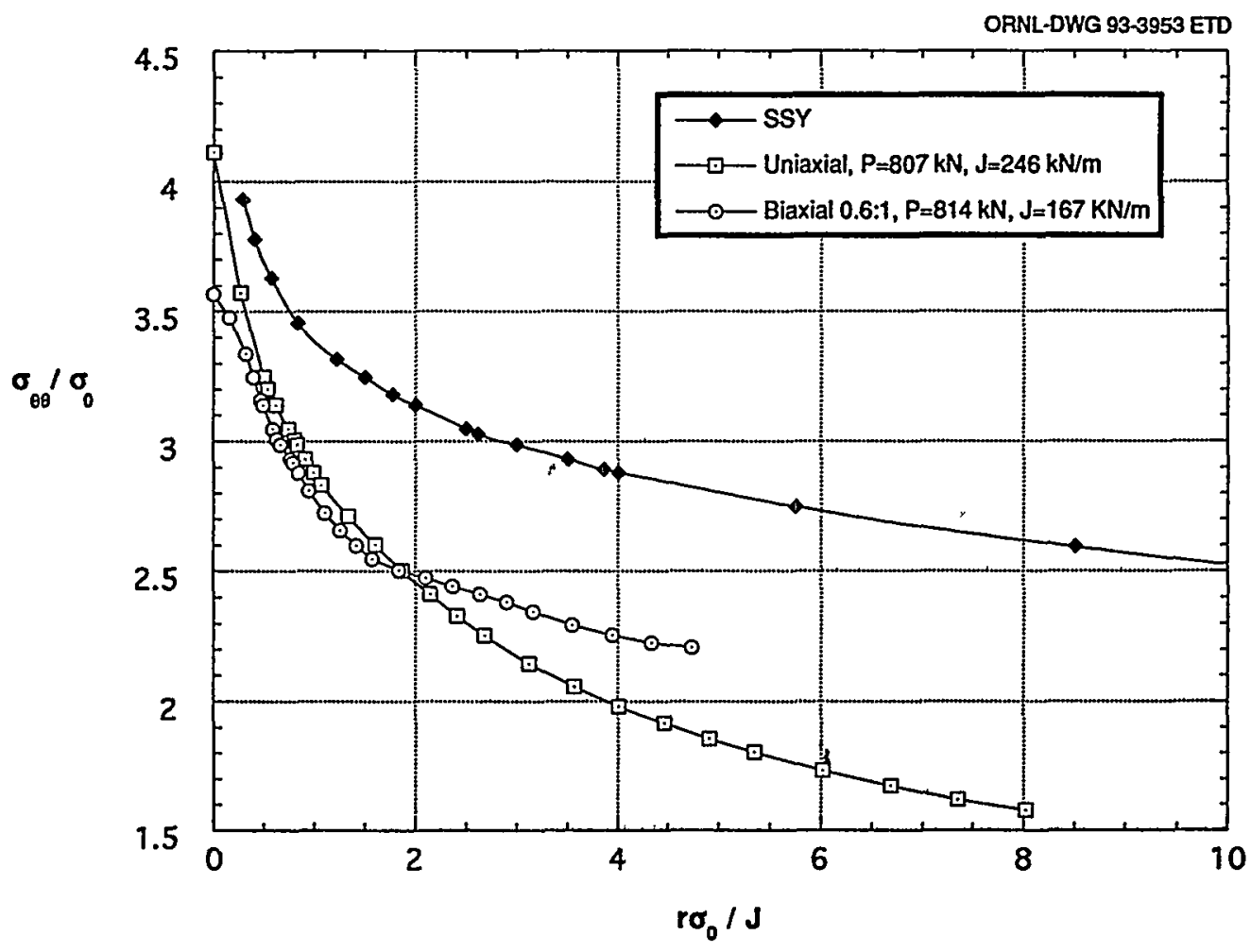

Figure 3.30 Opening-mode stresses ahead of crack tip for the SSY solution and uniaxial and biaxial cruciform specimens at critical values of $\mathbf{J}$ 
stresses near the crack tip $(\tilde{\mathbf{r}} \leq 2)$ is encouraging and indicates the potential applicability of these methods to the uniaxial and biaxial cruciform specimens. Furthermore, both the uniaxial and biaxial stresses deviate significantly from the SSY solution, indicating that the J-integral alone cannot characterize the crack-tip stresses. The crack-tip stresses for the uniaxial and biaxial cruciform specimens begin to diverge at $\overline{\mathbf{r}}=2$, which reflects that the far-field bending stresses are beginning to impinge on the crack-tip stresses in the uniaxial case. In other wo ords, at distances very near the crack tip, $(\overline{\mathrm{r}} \leq 2)$, the stresses are dominated by the crack-tip singularity. At distances satisfying $\overline{\mathrm{r}}>2$, however, the stresses tend to be influenced by the far-field bending stress, resulting in a divergence of the uniaxial and biaxial stresses. Physically, $\overline{\mathrm{r}} \geq 2$ represents a distance ahead of the crack tip of 1.2 and $0.8 \mathrm{~mm}$ for the uniaxial and biaxial cruciform specimens, respectively. These distances are well within the corresponding plastic zone radius that is conservatively estimated, from the plane strain relation, 22 to be 14 and $9.6 \mathrm{~mm}$ for the uniaxial and biaxial case at failure, respectively. In reality, both the uniaxial and biaxial specimens have reached a condition of uncontained yielding at the point of failure.

The difference between the SSY stresses and the uniaxial and biaxial stresses (i.e., the Q-stress) ahead of the crack tip is shown in Fig. 3.31. The Q-stress for the uniaxial specimen is not constant within the range of $\bar{r}=1.5$ to 5 because of the interaction of the bending stresses with the crack-tip singular stresses. In fact, the uniaxial stresses in Fig. 3.30 between $\bar{r}=6$ and 8 appear to be controlled by the far-field bending stress, resulting in a near linear stress distribution. If the identical load were applied to the specimen in a tensile manner rather than through bending loads, the Q-stress for the uniaxial specimen is expected to be more uniform than shown in Fig. 3.31. It is anticipated, however, that the bending stress field will influence the uniaxial and biaxial specimens less as the specimen size increases and/or the load at failure decreases.

In contrast with the uniaxial specimen, the biaxial Q-stress shown in Fig. 3.31 is relatively constant over the distances shown. In fact, the biaxial Q-stress at failure agrees well with the shallow-crack $Q$-stress determined from the SENB specimens. ${ }^{5}$ The reason for the constant biaxial Q-stress appears to be due to offsetting effects. First, the bending stress tends to drive the $Q$-stress more negative with distance from the crack tip as in the uniaxial case. The offsetting effect is the out-of-plane biaxial load itself. The addition of the out-of-plane stress increases the hydrostatic stress, which in turn increases the opening-mode stress. The offsetting nature of the bending stress and the out-ofplane stress cannot be generalized, however, for other biaxially loaded specimens.

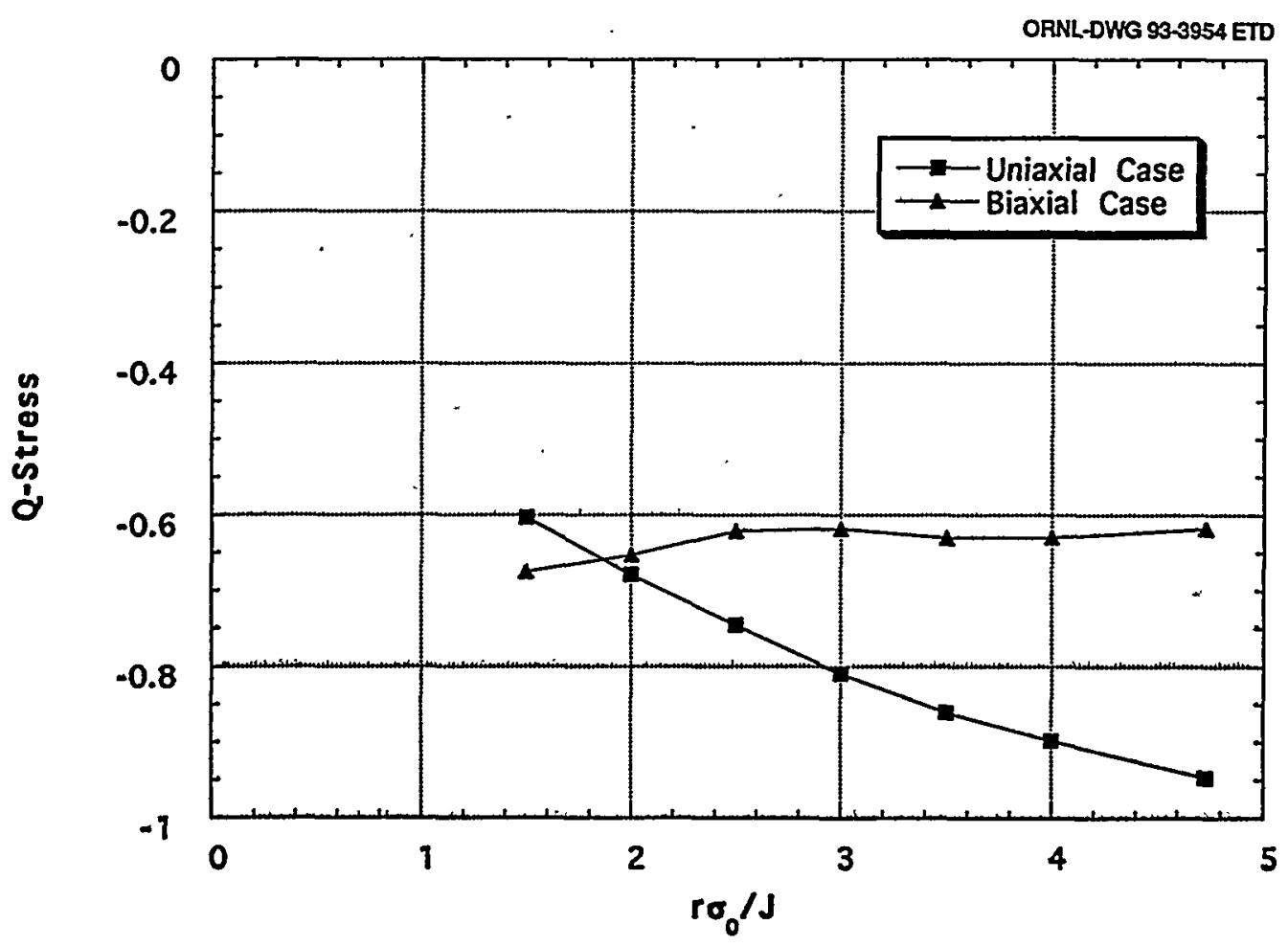

Figure.3.31 Q-stress ahead of crack tip at critical values of $J$ for uniaxial and biaxial cruciform specimens 


\section{Constraint}

The application of crack-tip analysis to a shallow-crack cruciform specimen under biaxial loading such as described in this chapter represents a significant challenge for these techniques. Differences in constraint conditions due to a biaxial load are difficult to quantify because of the absence of an appropriate distance parameter. Out-of-plane constraint (i.e., thickness effects) can be quantified in terms of the specimen thickness B. In-plane constraint loss is similarly related to a shallow-crack depth, a or $\mathrm{a} / \mathrm{W}$. Biaxial loading, however, which impacts the crack-tip stresses substantially, has no appropriate length scale or distance parameter to which the constraint condition can be related. Another way of considering the influence of biaxial loading is that the out-of-plane stress appears to make the specimen behave as a larger uniaxial specimen.

The final impact of out-of-plane biaxial loading is not fully known at this time. It is known, however, that biaxial loading does impact the conditions at the crack tip in a signifi- cant manner under conditions of uncontained yielding. Preliminary estimates from Ref. 23 indicated that under contained yielding, changes in initiation toughness due to biaxial effects would not exceed a few percent. Biaxial effects were exhibited in the cruciform specimen at conditions beyond contained yielding. The analyses confirm previously described experimental trends. As shown in Fig. 3.30, uniaxial and biaxial near-tip stresses $(\overline{\mathrm{r}} \leq 2)$ are coincident at failure loads. The applied load at which failure occurred in the uniaxial and biaxial specimens is almost identical; however, the critical value of toughness ( $\mathrm{J}$ in Fig. 3.30) is quite different. Biaxial loading further alters the way that applied load on a cracked specimen is related to the crack-driving force. Biaxial loading also substantially reduces the ductility of a specimen. Additional crack-tip analysis and additional biaxial tests are necessary before the impact of the biaxial loads on the fracture resistance of an RPV is understood. 


\section{Fractography and Fracture Characterization Issues}

\subsection{Fractographic Examinations}

Fractographic examinations were conducted on the cruciform specimens and several of the shallow- and deep-crack specimens to examine the fracture modes, cleavage origins, and other characteristic surface features. The examinations included optical and scanning electron microscopy (SEM) observations as well as measurement of several key parameters. Previous fractographic results ${ }^{1}$ have focused on the measurement of the fractographic data and a description of the general features of the fracture surface of the specimen(s). This section includes fractographic information reported previously on the cruciform specimens and describes additional fractographic information on these specimens, including the data from additional shallow- and deep-crack beams for comparison. This section also combines pertinent fractographic, analytical, and experimental results from these specimens and provides an interpretation (or reinterpretation) of analytical or experimental results in light of existing fractographic information.

The fractographic information obtained thus far from the cruciform, shallow- and deep-crack specimens is listed in Table 4.1. The information is generally consistent among the different specimen types or loading conditions. Specific details concerning the measurement methods used to compile Table 4.1 are found in Ref. 1. In addition to the fractographic information, Table 4.1 contains a comparison of fractographic and experimental estimates of CTOD for several deep- and shallow-crack specimens. The experimental estimate of CTOD is detailed in Ref. 5. The fractographic estimate of CTOD is calculated using the crack-tip blunting measurement (see Fig. 4.1) assuming an opening angle of $45^{\circ}$ [i.e., CTOD = (2) (sin 45) (blunting)]. Recent fractographic measurements indicate that the opening angle $(\theta$ in Fig. 4.1) seems to vary with fracture toughness but averages about $45^{\circ}$. Future plans include the measurement of the crack-opening angle in different specimens and correlation of the angle with fracture toughness or other parameters. Toughness values shown in Table 4.1 are all based on the area under the P-CMOD curve method described in Chap. 2.

Several observations can be made relative to the information in Table 4.1. Additional data, however, are necessary before these observations can be deemed conclusive. The fractographic data show remarkable similarity in the measurements in all specimens with both ductile crack extension $(\Delta \mathrm{a})$ and cleavage origin distances $(\mathrm{X})$ falling within a narrow range. This is partially explained by the narrow range of toughness values. The data also show a consistent correlation between toughness and $\Delta \mathrm{a}+\mathrm{X}$ values. Next, the estimates of CTOD determined using the crack-tip blunting show good agreement with the experimental estimates of CTOD. This agreement tends to validate the techniques used in these evaluations and provides an independent verification of previously reported CTOD values.

Examining the ductile crack extension $(\Delta \mathrm{a})$ and distance to the cleavage origin $(X)$ reveals that shallow-flaw specimens often show less ductile crack extension $(\Delta a)$ and cleavage origin distances $(\mathrm{X})$ than deep-crack specimens at comparable toughness levels. Additional deep-crack toughness data are necessary, however, to determine if this trend is a function of crack depth or toughness. Finally, the cleavage origin distances $(X)$ tend to be smaller in the specimens tested under 0.6:1 biaxial loading than in the uniaxial specimens. Again, additional data are required to confirm this trend.

\subsection{Cleavage Initiation Sites and Stress- Based Fracture Characterization}

Measured data in Table 4.1 are being used to assess the relevance of stress-based fracture characterizations to conditions at cleavage initiation sites in SENB and cruciform beam test specimens. (Previous studies that seek to interpret fracture toughness results through fractographic observations include those of Heerens et al. ${ }^{24}$ ) The important elements of this study can be summarized through reference to Fig. 4.2. Figure 4.2( $a$ ) and (b) depicts normalized opening-mode, near-crack-tip stress distributions from finite-strain analyses of SENB and biaxially loaded cruciform specimens; the stress distributions are plotted vs normalized distance in front of the crack tip. The finite-strain SSY solutions are shown for reference. In Fig. 4.2(c) and $(d)$, normalized distances $\left[(\mathrm{X}+\Delta \mathrm{a}) \sigma_{0} / J\right]$ to cleavage initiation sites are plotted for SENB and cruciform bend test specimens. Values for the distance $\mathrm{X}+\Delta \mathrm{a}$, measured from the tip of the fatigue precrack to the cleavage initiation site, are taken from Table 4.1.

The central issue here concerns the location of a preponderance of the cleavage initiation sites relative to that region in front of the crack tip where increasing applied J implies increasing opening-mode stress. In Fig. 4.2(a), an effect of progressive loss of stress triaxiality is to shift the stress peak to the left (i.e., toward the crack tip) relative to the SSY stress peak. Given these conditions, the following question is posed: Do the measured cleavage initiation sites tend to fall in a region of the computed stress field where opening-mode stress is increasing with increasing applied $\mathrm{J}$, that is, in Region A of Fig 4.2(a) to the right of the stress 
Table 4.1 Summary of fractographic information

\begin{tabular}{|c|c|c|c|c|c|c|c|c|c|c|}
\hline $\begin{array}{c}\text { Specimen } \\
\text { No. }\end{array}$ & $\begin{array}{c}\text { Specimen } \\
\text { type }\end{array}$ & $\begin{array}{l}\text { Flaw } \\
\text { depth }\end{array}$ & $\frac{\mathbf{K}_{\mathrm{Jc}}}{(\mathrm{MPa} \sqrt{\mathrm{m}})}$ & $\underset{\left({ }^{\circ} \mathrm{C}\right)}{\mathbf{T}-\mathbf{R T}_{\mathbf{N D T}}}$ & $\begin{array}{c}\text { Distance } \\
\text { to origin, } \\
X \\
(\mu \mathrm{m})\end{array}$ & $\begin{array}{c}\text { Ductille } \\
\text { crack } \\
\text { extension, } \\
\Delta \mathbf{a} \\
(\mu \mathrm{m})\end{array}$ & $\begin{array}{l}\text { Distance from } \\
\text { fatigue precrack to } \\
\text { initiation location, } \\
\Delta \mathbf{a}+\mathrm{X} \\
(\mu \mathrm{m})\end{array}$ & $\begin{array}{c}\text { Blunting } \\
(\mu \mathrm{m})\end{array}$ & $\begin{array}{c}\text { Fractographic } \\
\text { CTOD } \\
(\mu \mathrm{m})\end{array}$ & $\begin{array}{l}\text { Experimental } \\
\text { CTOD } \\
(\mu \mathrm{m})\end{array}$ \\
\hline 11 & SENB & Shallow & 139 & -22 & $74-150^{a}$ & 63 & $138-213$ & 80 & 136 & 196 \\
\hline 12 & SENB & Deep & 103 & -22 & $75-120^{a}$ & 24 & $99-144$ & 70 & 119 & 61 \\
\hline 38 & SENB & Shallow & 157 & -24 & 200 & 74 & 274 & 108 & 184 & 206 \\
\hline 31 & SENB & Deep & 108 & -25 & 70 & 11 & 81 & 88 & 150 & 63 \\
\hline 22 & SENB & Shallow & 298 & 8 & 350 & 535 & 885 & 628 & 1069 & 942 \\
\hline 24 & SENB & Deep & 219 & 8 & $550-950^{a}$ & 342 & $892-1292$ & 324 & 551 & 367 \\
\hline 27 & SENB & Shallow & 230 & -7 & 220 & 270 & 490 & 290 & 494 & 559 \\
\hline 28 & SENB & Shallow & 331 & 9 & 750 & 750 & 1500 & $c$ & & \\
\hline BB-1 & Cruciform & Shallow & 175 & -10 & $90-125^{a}$ & 64 & $154-189$ & $c$ & & \\
\hline BB-2 & Cruciform & Shallow & 214 & -4 & $50-100^{a}$ & 77 & $127-177$ & $c$ & & \\
\hline BB-3 & Cruciform & Shallow & $c$ & -12 & $b$ & 45 & $b$ & $c$ & & \\
\hline BB-4 & Cruciform & Shallow & 178 & -11 & 140 & 83 & 223 & $c$ & & \\
\hline BB-5 & Cruciform & Shallow & 178 & -9 & 90 & 87 & 177 & $c$ & & \\
\hline
\end{tabular}

$a_{\text {Location of origin unclear. }}$

$b_{\text {Origin in corner. }}$

Not measured. 


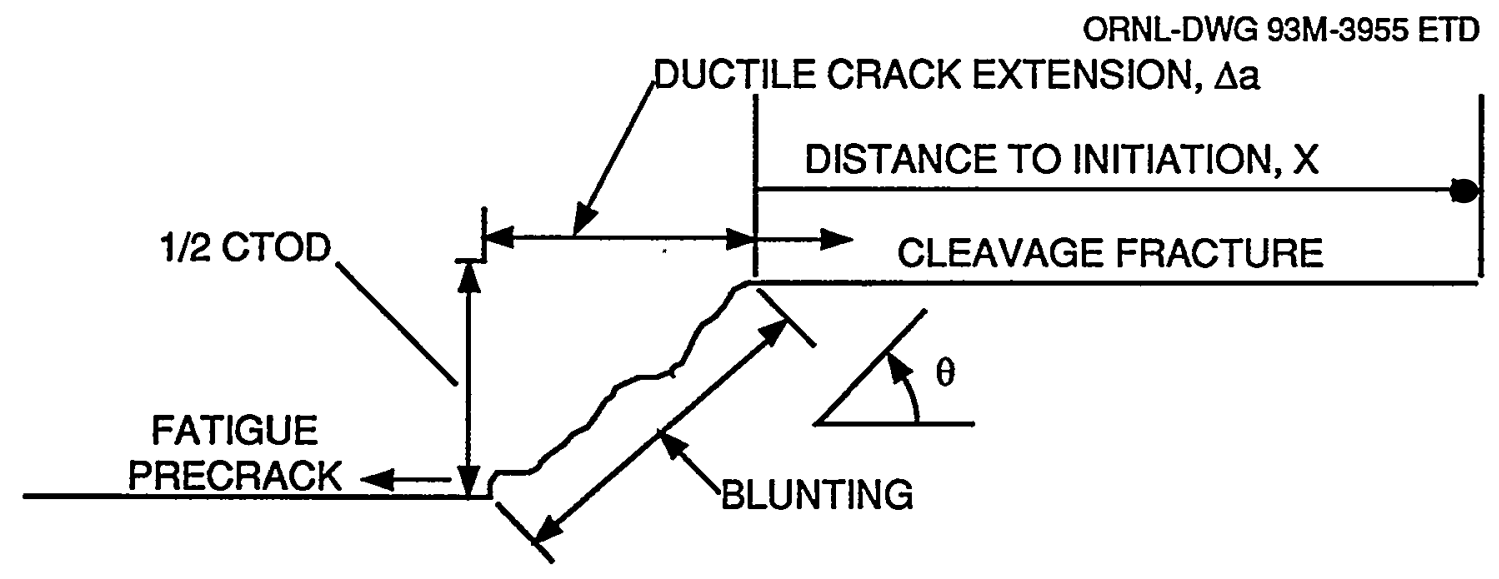

Figure 4.1 Schematic defining fractographic variables

peak? (Material points to the left of the stress peak experience a stress field that decreases in magnitude with increasing J). The expectation* is that a cleavage initiation event governed by a stress-based criterion will occur in a rising near-tip stress field under increasing applied load.

Results depicted in Fig. 4.2 permit comparisons of normalized distances from the crack tip to opening-mode stress peaks at failure and to measured cleavage initiation sites. For the SENB shallow-crack specimens, the initiation sites appear to fall in the region experiencing a rising stress field, that is, to the right of the stress peak in Fig.4.2(a). The cruciform specimens present a contrasting result, with the sites located in a falling stress field with increasing $\mathrm{J}$, that is, to the left of the stress peak in Fig. 4.2(b). Thus, fractographic data from the SENB shallow-crack specimens [Fig. 4.2(c)] tend to support the expectation for a critical stress-based fracture criterion discussed above, while data from the cruciform specimens [Fig. 4.2(d)] require further study for reasons discussed below.

Results of this comparison between locations of the stress peak and the cleavage initiation sites for the cruciform specimens must be evaluated in the context of several factors. The fractographic data in Table 4.1 reflect that the process leading to cleavage fracture involves ductile extension of the crack tip before unstable cleavage. The finite-element models employed in analyses of the specimens in Table 4.1 do not incorporate the micromechanical processes that lead to generation of new fracture surfaces before the onset of cleavage instability. The 3-D finiteelement model of the cruciform specimen described herein utilizes centered-fan crack-tip elements that allow a simpli-

\footnotetext{
*W. E. Pennell et al., Martin Marietta Energy Systems, Inc., Oak Ridge Natl. Lab., "Biaxial Loading and Shallow-Flaw Effects on Crack-Tip Constraint and Fracture-Toughness," presented at the Twenty-First Water Reactor Safety Information Meeting, Bethesda, Md., Oct. 25, 1993.
}

fied blunting and translation of the tip without considering the complexities of the actual process. Inclusion of model refinements associated with these crack-tip processes can potentially influence the near-crack-tip stress fields and, consequently, interpretations of any comparisons between analytical predictions and measured fractographic data.

The opening-mode stress distributions in Fig. 4.2(a) and (b) are plotted vs normalized distance from the crack tip based on the initial undeformed configuration of the model. Of necessity, measurements taken on the fracture surfaces and compiled in Table 4.1 are given in terms of deformed points in the broken specimen. To compensate for these differences, adjustments of the material reference configuration have been proposed for the analytical and experimental plots of Fig. 4.2. One option is to plot the opening-mode stress distribution in terms of the deformed coordinates of the finite-element model and compare this directly with distance $\mathrm{X}$ measured from the tip of the blunted crack to the cleavage initiation site.

The proposed adjustment for results given in Fig. 4.2 is based partly on a hypothesis describing micromechanical processes leading to cleavage fracture in the test specimens of Table 4.1. Studies to effectively validate such adjustments or hypotheses have been initiated but not completed. Motivation for such adjustments is derived primarily from recognized limitations of the analytical models in representing the micromechanics of fracture processes. It ${ }^{*}$ has been proposed that development and application of a micromechanical model based on void formation and strain softening concepts (e.g., see Ref. 25) could potentially resolve issues related to representation of crack-tip stress fields. 

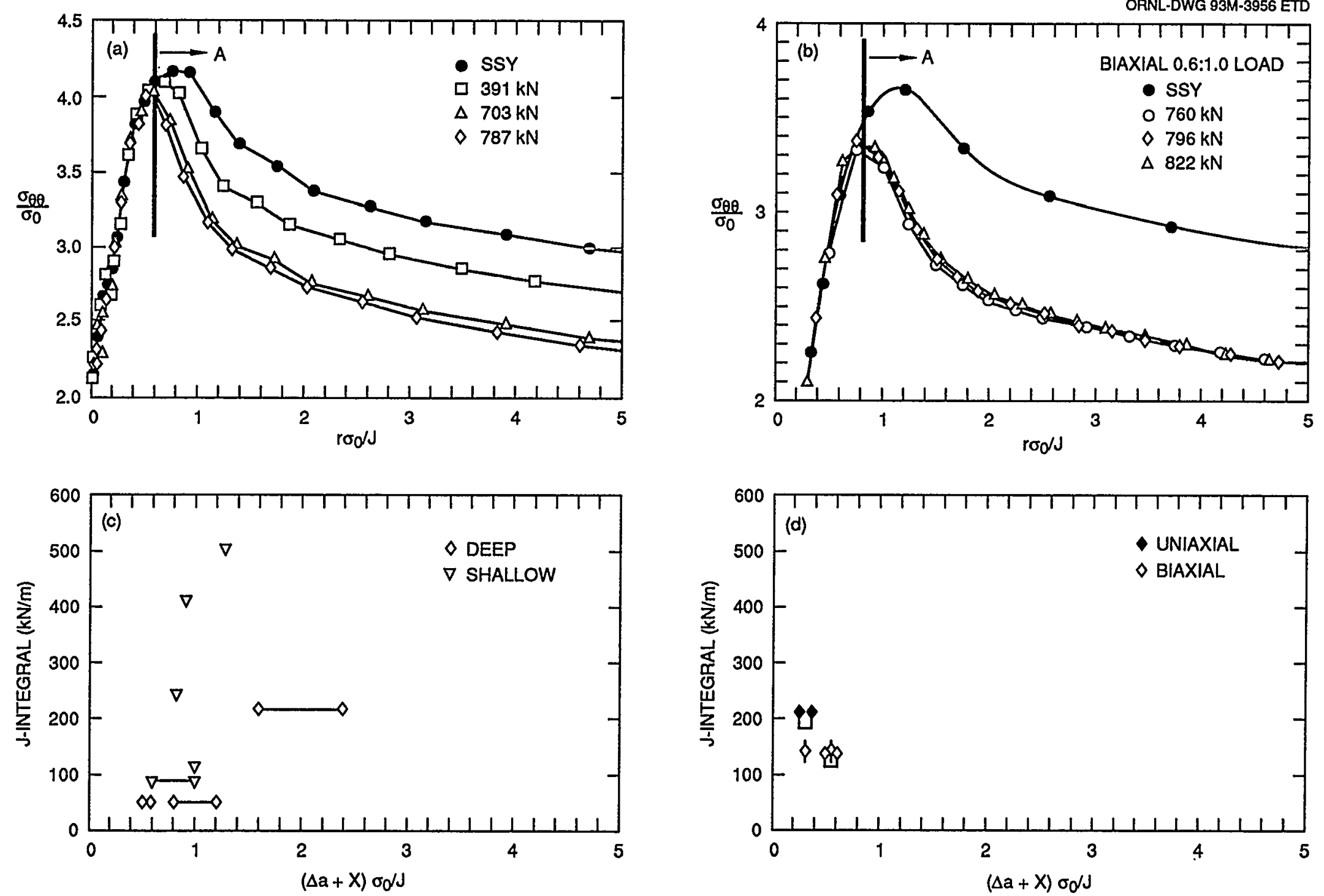

Figure 4.2 (a) Distributions of opening-mode stress component for SENB specimen with $a / W=0.1$ as function of applied load up to crack initiation; $(b)$ distribution of opening-mode stress component for biaxial shallowcrack cruciform specimen; $(c)$ toughness vs normalized distance to initiation site for shallow- and deepcrack SENB specimens; and $(d)$ toughness vs normalized distance to initiation site for uniaxial and biaxial shallow-crack cruciform specimens 


\subsection{3-D Interpretation of Toughness}

One of the functional criteria of a satisfactory biaxial cruciform specimen design was that "the crack-driving forces be relatively uniform over a substantial portion of the crack distance with no significant edge effects."1 The criteria were satisfied for the initial phase of the biaxial testing program by showing that the cruciform specimen did not have a propensity for crack initiation at the intersection of the diffusion slots and the crack tip. One specimen (BB-3) did initiate at the corner, and as a consequence the toughness result was considered suspect and was not determined. Due to the concern over edge effects in the cruciform specimens, the initiation site location along the crack front for all of the cruciform specimens and for several of the shallow- and deep-crack beam specimens was measured.

Conventionally, the position of the initiation site within the thickness of the specimen is not important because of the consistency of crack-driving force through the specimen thickness. For example, analysis of a 4T compact-tension specimen reveals that at the limit of plane strain validity determined by ASTM E399, the crack-driving force is within $5 \%$ of the centerline value over the central $90 \%$ of the specimen thickness. ${ }^{*}$ Obviously, as the load level

*D. K. M. Shum, "Preliminary Investigation on the Inclusion of Warm Prestress Effects in Fracture-Margin Assessment of Reactor Pressure Vessels," NUREG/CR-5946 (ORNL/M-12236), to be issued. increases into the elastic-plastic domain, thickness variation in the crack-driving force will take place. The point remains, however, that conventional specimens have fairly uniform crack-driving forces over their thickness, making the toughness interpretation a 2-D calculation without regard to the actual location of the initiation site along the crack front.

As discussed previously in this report and in Ref. 1, the variation of crack-driving forces through the thickness of the cruciform specimen is greater than that for conventional specimens. In fact, through-thickness variation is estimated to be as large as the toughness difference between biaxial and uniaxial loading conditions being determined in these studies. These observations have led to consideration of initiation site locations along the crack front and to the 3-D interpretation of fracture toughness described herein.

All experimental measurements used to measure fracture toughness are taken at the specimen centerline, and additional measurements through thickness are impractical. Analytical results provide the best estimate of the variation of the crack-driving force and, subsequently, 3-D toughness values. The calculated variation of crack-driving forces through the thickness for specimens BB- 4 and -5 is shown in Fig. 4.3 along with the location of the initiation sites for these two tests. As shown in Fig. 4.3, specimen

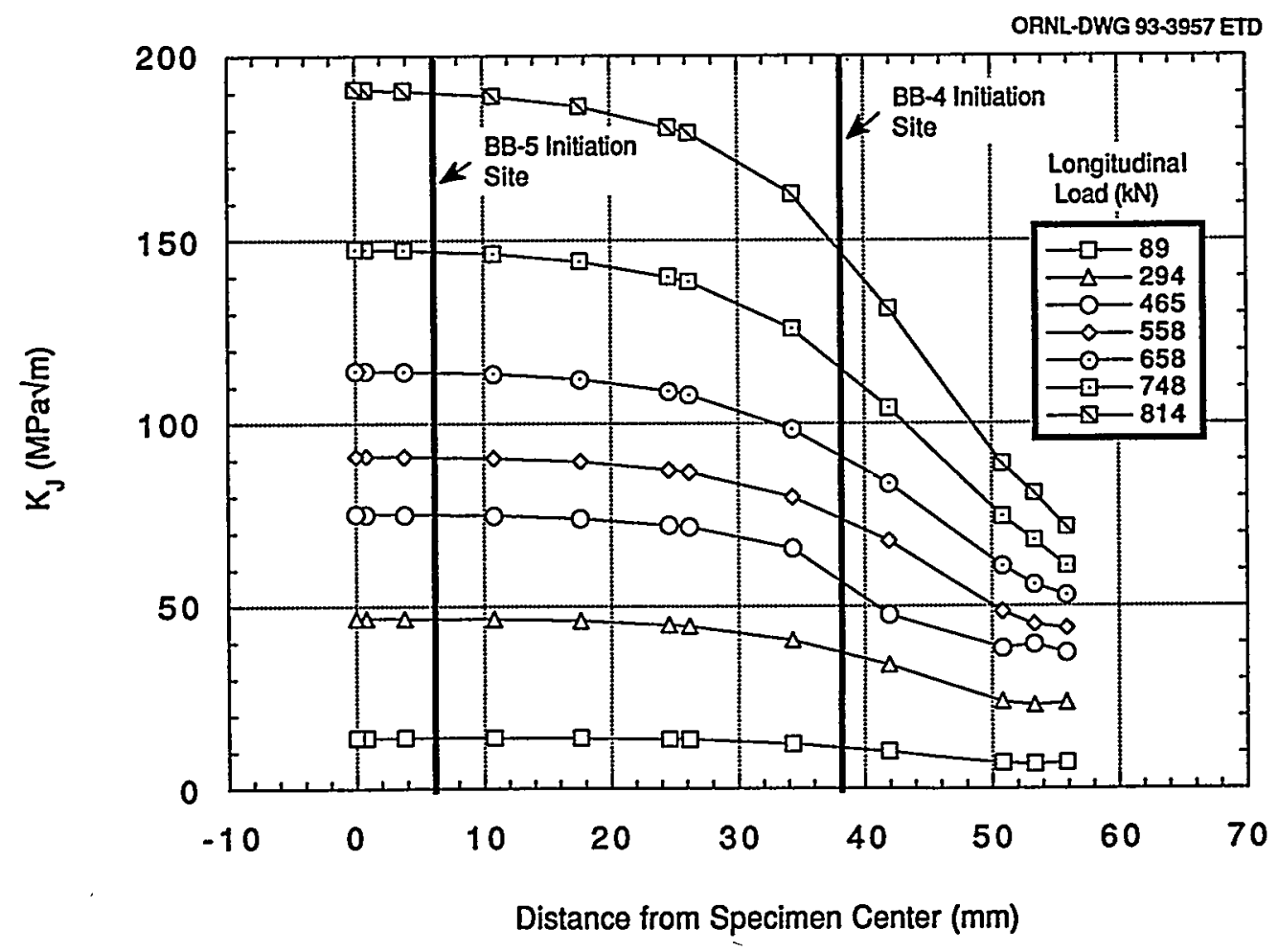

Figure 4.3 Crack-driving force through-thickness for BB-4 and -5 


\section{Fractography}

BB-5 initiated sufficiently close to the specimen centerline that the 3-D toughness value is the same as 2-D toughness value. Specimen BB-4 initiated about $38 \mathrm{~mm}$ from the centerline. The crack-driving force at this position is $\sim 20 \%$ less than at the center. The 3-D toughness values are computed by decreasing the 2-D toughness values as determined analytically from the variation of crack-driving force at the center and the position of crack initiation.

The 3-D toughness values were determined for all the cruciform specimens (except BB-3) and the shallow- and deep-crack SENB specimens tested at the same normalized temperature $\left(\mathrm{T}-\mathrm{RT} \mathrm{NDT}=-10^{\circ} \mathrm{C}\right)$. The 3-D toughness data for these specimens and the information needed to compute the 3-D toughness, such as initiation location and analytical raiio of 3-D/2-D toughness values, are included in Table 4.2. Table 4.2 indicates that few of the specimens initiated directly at the specimen center or close to the edge. Most specimens initiated at about the $1 / 4 \mathrm{t}$ location through the specimen thickness. As expected, the 3-D toughness values for the deep-crack specimens are indistinguishable from the 2-D values. The shallow-crack specimens, however, exhibit a small increase in toughness at the $1 / 4 \mathrm{t}$ location over the centerline value. The cruciform specimens $\mathrm{BB}-1,-2$, and -4 show a reduction in toughness of about 20 to $25 \%$. The toughness for specimen BB-5 remains unchanged. The 3-D toughness results for all specimens tested at $\mathrm{T}-\mathrm{RT}$ NDT $=-10^{\circ} \mathrm{C}$ are plotted as a function of load ratio in Fig. 4.4. The comparable 2-D toughness plot is shown in Fig. 2.5. A comparison of Figs. 4.4 and 2.5 indicates that both interpretations of toughness are reasonable. The uniaxial cruciform specimen (BB-2) has a 2-D toughness toward the mean of the shallow-crack specimens but a 3-D toughness near the lower bound of the shallow-crack beam data. The average of biaxial cruciform data is decreased about $15 \%$ from 177 to $149 \mathrm{MPa} \sqrt{\mathrm{m}}$ by considering the initiation site location. The scatter of the biaxial data is increased when the 3-D toughness interpretation is considered. The primary observation, however, that biaxial loading reduces some but not all of the shallow-crack toughness increase appears accurate for both toughness interpretations.

The 3-D interpretation of toughness is not being recommended or proposed for all testing applications. The analytical and fractographic effort to interpret the 3-D toughness is not justified for most specimens. The cruciform specimen tests are sufficiently unconventional and novel to warrant this type of treatment. These results should be considered tentative because the entire concept of considering the initiation point in toughness determinations is new and not well understood.

Table 4.2 3-D interpretation of toughness

\begin{tabular}{|c|c|c|c|c|c|c|}
\hline Specimen & $B(\mathbf{m m})$ & Initiation location & $\% t(1 / 4 t \ldots)$ & $\begin{array}{l}\text { Ratio of 3-D K } \\
\text { to 2-D KJ }\end{array}$ & $\begin{array}{c}2-D K_{J c} \\
(\mathrm{MPa} \sqrt{\mathrm{m}})\end{array}$ & $\begin{array}{c}\text { 3-D K } K_{\mathrm{Jc}} \\
(\mathrm{MPa} \sqrt{\mathbf{m}})\end{array}$ \\
\hline \multicolumn{7}{|c|}{ Deep-crack beams at $\mathrm{T}-\mathrm{RT}$ NDT $=-10^{\circ} \mathrm{C}$ [CE material $]$} \\
\hline $12 \mathrm{~A}$ & 100 & $31 \mathrm{~mm}$ from edge & 0.31 & 1 & 119 & 119 \\
\hline $13 \mathrm{~A}$ & 100 & $12 \mathrm{~mm}$ from edge? & 0.12 & 0.95 & 143 & 136 \\
\hline $14 \mathrm{~A} 1$ & 50 & $15 \mathrm{~mm}$ from edge & 0.30 & 1 & 145 & 145 \\
\hline $14 \mathrm{Al}$ & 50 & Center? & 0.50 & 1 & 93 & 93 \\
\hline $15 \mathrm{~A}$ & 150 & Center? & 0.50 & 1 & 134 & 134 \\
\hline $16 \mathrm{~A}$ & 150 & Center? & 0.50 & 1 & 109 & 109 \\
\hline \multicolumn{7}{|c|}{ Shallow-crack beams at $\mathrm{T}-\mathrm{RT}_{\mathrm{NDT}}=-10^{\circ} \mathrm{C}[13 \mathrm{~B}$ material $]$} \\
\hline 18 & 100 & $12 \mathrm{~mm}$ from edge & 0.12 & 1.06 & 213 & 226 \\
\hline 21 & 100 & $29 \mathrm{~mm}$ from edge & 0.29 & 1.03 & 174 & 179 \\
\hline 27 & 100 & $26 \mathrm{~mm}$ from edge & 0.26 & 1.03 & 230 & 237 \\
\hline \multicolumn{7}{|c|}{ Shallow-crack cruciforms at $\mathrm{T}-\mathrm{RT}_{\mathrm{NDT}}=-10^{\circ} \mathrm{C}$ [CE material] } \\
\hline BB-1 & 100 & $2.5 \mathrm{~mm}$ from edge & 0.03 & 0.76 & 175 & 133 \\
\hline BB-2 & 110 & $20 \mathrm{~mm}$ from edge & 0.18 & 0.82 & 214 & 175 \\
\hline $\mathrm{BB}-3$ & 110 & Corner & 0.00 & N/A & N/A & N/A \\
\hline $\mathrm{BB}-4$ & 110 & $18 \mathrm{~mm}$ from edge & 0.16 & 0.76 & 178 & 135 \\
\hline BB-5 & 110 & $50 \mathrm{~mm}$ from edge & 0.45 & 1 & 178 & 178 \\
\hline
\end{tabular}


Fractography

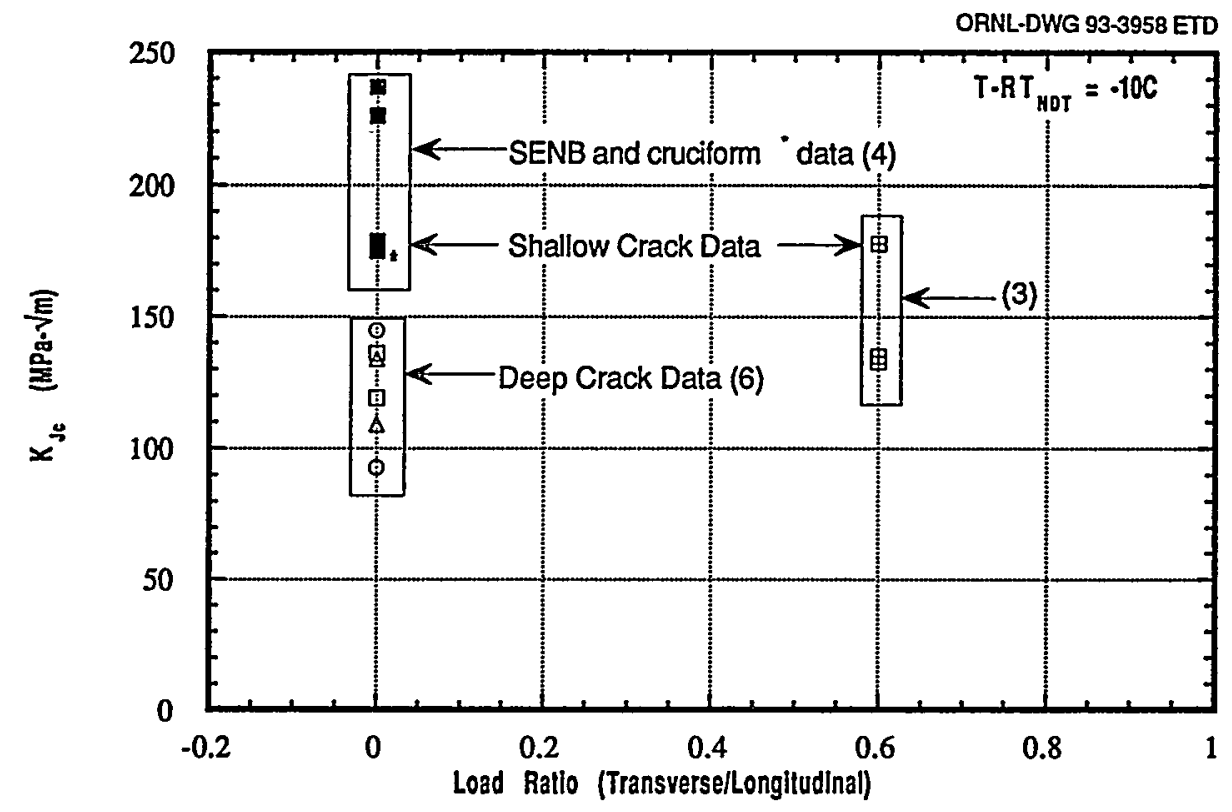

Figure 4.4 3-D toughness results as function of load ratio for data at $\mathrm{RT}_{\mathrm{NDT}}=-10^{\circ} \mathrm{C}$ 
- 


\section{Summary and Conclusions}

Crack-tip constraint is an issue that significantly impacts fracture mechanics technologies employed in failure predictions for commercially licensed nuclear RPVs. A validated technology that incorporates constraint effects is essential to the transfer of fracture toughness data from, for example, miniature fracture toughness surveillance specimens to RPVs. This capability could have a substantial impact on the outcome of probabilistic PTS analyses and assessments of startup/cooldown transients of aging nuclear plants. This report has provided interim results from a program to evaluate selected fracture methodologies for the quantitative assessment of crack-tip constraint effects on fracture toughness of RPV steels.

Far-field tensile out-of-plane biaxial loading and shallowcrack effects have been identified as constraint issues that influence both fracture toughness and the extent of the fracture toughness scatter band. Relevance of these issues to RPV failure predictions is supported by several observations. First, PTS loading produces biaxial stress fields in an RPV wall that have no counterpart in conventional laboratory specimens used to generate fracture toughness data. Limited data indicate that a decrease in toughness is associated with biaxial loading. Second, the probability of RPV vessel failure in PTS analyses is dominated by initiations from shallow cracks. Recent testing has demonstrated an effective increase in fracture toughness of shallow cracks compared to deep-cracked specimens. Determining the extent of the interaction between this toughness elevation associated with shallow cracks and toughness reduction due to biaxial loading effects is one of the main goals of the HSST biaxial testing program.

The focus of the studies described herein has been on evaluations of stress-based fracture methodologies (i.e., the $J-Q$ model of O'Dowd and Shih and the D-A constraint correction model) through applications to experimental and fractographic data. These methodologies were selected for the initial evaluations because of their previously demonstrated promise as practical means for incorporating effects of crack-tip constraint into fracture assessments. Data for these assessments were obtained primarily from the HSST shallow-crack and biaxial testing programs. Shallow- and deep-crack SENB specimens and uniaxially and biaxially loaded cruciform specimens from these testing programs were analyzed using both the J-Q methodology and the D-A constraint scaling model. The SENB data set consists of 14 deep-crack and 14 shallow-crack specimens; the biaxial cruciform data set included one uniaxially loaded and three biaxially loaded specimens.
The J-Q methodology was first applied to a subset of shallow- and deep-crack SENB specimens. The J-Q analysis of the SENB specimens indicated a significant loss of constraint for the shallow-crack specimens with the Q-stress saturating at about -0.7 . The deep-crack specimens had negligible constraint loss with $Q \sim 0$. Both specimens developed spatially inđependent $Q$-stress fields ahead of the crack.

The J-Q analyses of the cruciform specimens yielded results that are not as straightforward to interpret as the SENB specimens. The uniaxial cruciform specimen failed at a sufficiently high load that the far-field bending stress began to impinge on the near-tip stress field in the annulus $2<\overline{\mathbf{r}}<5$. This near-tip and far-field stress interaction produces Q-stresses that decrease linearly with distance from the crack tip. The $Q^{\prime}$ function was introduced to quantify this spatial dependence of the Q-stress field over the cracktip annulus. The criterion $\left|Q^{\prime}\right|<0.1$ is not satisfied in the uniaxial cruciform specimen as failure is approached. However, this criterion (from O'Dowd and Shih $^{8}$ ) permits a relatively large variation in Q-stress over the crack-tip annulus. In the present application, the variation in Q-stress over the annulus is greater than the difference between Q-stress values calculated for the uniform and biaxial loading cases. Biaxial loading of the cruciform specimen produces a higher stress triaxiality ahead of the crack tip at failure than the uniaxial case; also, it generates essentially a uniform hydrostatic stress field (i.e., a very low value of $Q^{\prime}$ ) in front of the crack tip.

The J-Q loading trajectories were computed for the uniaxial and biaxial cruciform specimens at normalized distances $\bar{r}$ ahead of the crack tip of $2,3,4$ and 5 . At distances farther from the crack tip ( $\bar{r}=4$ and 5), the uniaxial and biaxial trajectories followed the same path up to relatively high load levels. The expectation was that the $\mathrm{J}-\mathrm{Q}$ trajectories would exhibit this behavior at least up to intermediate loads, given the similarity of the P-CMOD responses. The $\mathrm{J}-\mathrm{Q}$ trajectories at $\overline{\mathrm{r}}=2$ and 3 were not so well behaved. The trajectories for the uniaxial case exhibited a higher constraint condition (i.e., higher Q-stress) than the biaxial case for almost the entire loading path. This result conflicts with experimental results which imply that the biaxially loaded specimen is the more highly constrained specimen. However, there is no rationale for quantifying constraint at distances farther removed from the crack tip (i.e., at distances $\bar{r}>2$ ), where far-field stresses were observed to have a strong influence in the uniaxially loaded specimen. Fractographic data from the cruciform specimens showed no evidence of cleavage initiation sites in the annulus $\overline{\mathrm{r}}>2$. Thus, despite the 


\section{Summary}

observed inconsistencies, the cruciform specimens were interpreted in terms of J-Q trajectories computed at $\bar{r}=2$. From the J-Q trajectories at $\overline{\mathbf{r}}=2$, critical $Q$-stress values of -0.69 and -0.66 were determined for the uniaxial and biaxial loading conditions, respectively. These failure points fall within the scatter of a J-Q failure locus generated from deep- and shallow-crack SENB and wideplate results at the same normalized temperature.

Applications of the D-A scaling model to data obtained from shallow- and deep-crack SENB specimens produced very good results. The scaling model provided adjusted SSY toughness values in the transition region that were virtually identical for deep- and shallow-crack data. In addition to removing the influence of crack depth in the toughness data, the scaling model reduced the scatter associated with the shallow-crack data.

When the scaling model was applied to the cruciform data, the results were again more difficult to interpret than the SENB application. In the original formulation of the scaling model, toughness data are adjusted to SSY values based on ratios of areas (or volumes) within stress contours around the crack tip. The engineering model applied to the cruciform specimens approximates these ratios from the stress distribution directly ahead of the crack tip. Stresses very close to the crack tip $(\overline{\mathrm{r}}<2)$ were used to determine the $\mathrm{J}_{\mathrm{FB}} / \mathrm{J}_{\mathrm{o}}$ ratios for the cruciform specimens. These ratios were found to vary $\sim 25 \%$ over the annulus $1.5<\overline{\mathrm{I}}<4$ for both uniaxial and biaxial load cases. This difference exceeds the maximum of $10 \%$ recommended in Ref. 11 for a valid calculation of $\mathrm{J}_{0}$. Also, the biaxial $\mathrm{J}_{\mathrm{FB}} / \mathrm{J}_{0}$ ratio was $\sim 25 \%$ greater than the uniaxial ratio, which implies a greater constraint loss for the biaxial specimen than the uniaxial specimen. The latter result is inconsistent with toughness results determined from experimental data. All of the cruciform SSY toughness values determined from these ratios, however, were within the range of SSY data from the SENB specimens.

Fractographic examinations were conducted on several of the fracture surfaces from the shallow- and deep-crack SENB specimens and the cruciform specimens. Fractographic information included crack-tip blunting (which can be related to CTOD), ductile crack extension $\Delta a$, and distance to the cleavage initiation site $X$. The total distance to the initiation site $(\Delta \mathrm{a}+\mathrm{X})$ appears to increase with increasing toughness, but shallow-crack specimens seem to have lower $\Delta a+X$ values than deep-crack specimens at the same toughness level. However, additional data are necessary to confirm this trend.
Comparisons were performed between measured data describing total distance to cleavage initiation sites $(\Delta \mathrm{a}+\mathrm{X})$ and distance to opening-mode stress peaks in near crack-tip stress fields. The central question can be stated as follows: Are the cleavage initiation sites concentrated in a region where the computed opening-mode stress field is increasing with increasing applied J? The expectation is that cleavage initiation would occur for a condition of increasing stress at the measured initiation site. The initiation sites for the SENB shallow-crack specimens appear to fall in a region experiencing a rising stress field, and those for the cruciform specimens are located in a falling stress field. Thus, fractographic data from the SENB shallow-crack specimens tend to support the expectation for a critical-stress-based fracture criterion posed above, while data from the cruciform specimens require further study for reasons discussed previously. The preponderance of initiation sites at $\overline{\mathbf{r}} \sim 1$ supports crack-tip constraint methods that are based on stresses very close to the crack tip (i.e., $\overline{\mathbf{r}} \leq 2$ ). Incorporation of selected micromechanical features of the fracture process into the analytical models are planned and may provide some resolution of the issues related to representation of cracktip stress fields in the cruciform specimen.

Toughness data for the uniaxial and biaxial cruciform specimens were reinterpreted taking into account the position of the initiation site through the thickness of the specimen. This exercise was performed because the cruciform specimens experienced a substantial decrease in crack-driving force toward the intersection of the crack and the load-diffusion control slot. This through-thickness variation is estimated to be as large as the toughness difference between biaxial and uniaxial loading conditions being determined in these studies. This decrease is more pronounced and influences a greater portion of the thickness than either deep- or shallow-crack specimens. The 3-D toughness reinterpretation lowered the average toughness of the biaxial specimens but increased the scatter of the data. This concept of taking into account the initiation site for toughness determination is unique and will require further examination.

Applications of the J-Q and D-A constraint methodologies presented herein utilized data sets generated from tests of specimen geometries that provide a contrast in analytical modeling requirements. The shallow- and deep-crack SENB specimen is modeled in terms of a 2-D plane-strain formulation, while the fully 3-D character of the uniaxially and biaxially loaded cruciform specimen must be considered. Analysis results from applications indicate that both methodologies can be used successfully to interpret experimental data from the shallow- and deep-crack SENB specimen tests. The two methodologies showed some promising features in applications to the cruciform 
specimen, but also raised a number of questions concerning the interpretation of constraint conditions in the specimen from near-tip stress fields. The more successful interpretations of these methodologies applied to the SENB data are partially explained by the greater number of available data points. Crack-tip constraint analyses of the shallow-crack cruciform specimen subjected to uniaxial or biaxial loading conditions represent a significant challenge for these methodologies. Unresolved issues identified from these analyses and summarized in the foregoing discussion require resolution as part of a validation process for biaxial loading applications. Additional cruciform specimens need to be tested before any conclusion can be reached concerning the application of these methods to the cruciform data.

Some additional observations concerning applications to the cruciform specimen are presented herein. The near-tip stresses ahead of the crack are the focal point of the stressbased fracture methodologies applied in this study. The uniaxial cruciform specimen exhibited a substantial interaction of the near-tip and far-field bending stresses, which provided a contrast to a relatively uniform hydrostatic (i.e., Q-stress) field ahead of the crack tip in the SENB specimen. The biaxial specimen appears to be influenced by offsetting effects that also result in a spatially independent Q-stress field ahead of the crack. The far-field stresses, which tend to lower the near-tip stresses, are almost exactly offset by the out-of-plane stress component that increases the opening-mode stress in the biaxial specimen. This offsetting effect, however, cannot be generalized to biaxial specimens having different dimensions or load ratios. In addition, the impact of the far-field bending stress on the near-tip stresses would be reduced in specimens having larger dimensions. Testing of a limited number of larger biaxial cruciform specimens, such as currently planned within the HSST Program, would provide additional data to quantify these effects.

The primary problem with using techniques described herein to examine the influence of biaxial loading is the absence of an appropriate length scale with which to quantify constraint. Differences in out-of-plane constraint are quantified by the specimen thickness; in-plane constraint is related to crack depth, but biaxial loading cannot be related to a similar length parameter.

Examination of analytical results from this study indicates that biaxial loading produces a near-tip stress pattern similar to that expected of a larger specimen under uniaxial loading (i.e., biaxial loading increases the "effective" size of the specimen). However, additional data and analyses are necessary to substantiate this observation. 


\section{References}

1. T. J. Theiss et al., Martin Marietta Energy Systems, Inc., Oak Ridge Natl. Lab., "Initial Results of the Influence of Biaxial Loading on Fracture Toughness," USNRC Report NUREG/CR-6036 (ORNL/ TM-12349), June 1993.*

2. R. D. Cheverton and D. G. Ball, Martin Marietta Energy Systems, Inc., Oak Ridge Natl. Lab., "Pressurized-Thermal-Shock Evaluation of the H. B. Robinson Nuclear Power Plant," pp. 263-306, USNRC Report NUREG/CR-4183 (ORNL/TM95657/V1), September 1985.*

3. R. D. Cheverton and D. G. Ball, Martin Marietta Energy Systems, Inc., Oak Ridge Natl. Lab., "Pressurized-Thermal-Shock Evaluations of the Calvert Cliffs Nuclear Power Plant," pp. 201-244, USNRC Report NUREG/CR-4022 (ORNL/TM-9408), September 1985.*

4. R. D. Cheverton and D. G. Ball, Martin Marietta Energy Systems, Inc., Oak Ridge Natl. Lab., "Preliminary Development of an Integrated Approach to the Evaluation of Pressurized Thermal-Shock as Applied to the Oconee 1 Nuclear Power Plant," pp. 5.1-5.51, USNRC Report NUREG/CR-3770 (ORNL/TM-9176), May 1986.

5. T. J. Theiss, D. K. M. Shum, and S. T. Rolfe, Martin Marietta Energy Systems, Inc., Oak Ridge Natl. Lab., "Experimental and Analytical Investigation of the Shallow-Flaw Effect to Reactor Pressure Vessels," USNRC Report NUREG/CR-5886 (ORNL/ TM-12115), July 1992.*

6. N. P. O'Dowd and C. F. Shih, "Family of Crack-Tip Fields Characterized by a Triaxiality Parameter: Part I-Structure of Fields," J. Mech. Phys. Solids 39, 989-1015 (1991). $\dagger$

7. N. P. O'Dowd and C. F. Shih, "Family of Crack-Tip Fields Characterized by a Triaxiality Parameter: Part II-Fracture Applications," J. Mech. Phys. Solids 40, 939-963 (1992). ${ }^{\dagger}$

8. N. P. O'Dowd and C. F. Shih, Naval Surface Warfare Center, "Two Parameter Fracture Mechanics: Theory and Applications," USNRC Report NUREG/CR-5958 (CDNSWC/SME-CR-16-92), February 1993.
9. R. H. Dodds, T. L. Anderson, and M. T. Kirk, "A Framework to Correlate a/W Ratio Effects on ElasticPlastic Fracture Toughness $\left(J_{\mathrm{c}}\right)$," Int. J. Frac. 48, 1-22 (1991) ${ }^{\dagger}$

10. T. L. Anderson and R. H. Dodds, "Specimen Size Requirements for Fracture Toughness Testing in the Ductile-Brittle Transition Region," J. Test. Eval. 19, 123-134 (1991). ${ }^{\dagger}$

11. R. H. Dodds, C. F. Shih, and T. L. Anderson, Department of Civil Engineering, University of Illinois, "Continuum and Micromechanics Treatment of Constraint in Fracture," Report UILU-ENG-92-2014, November 1992.*

12. R. O. Ritchie, J. F. Knott, and J. R. Rice, "On the Relationship Between Critical Tensile Stress and Fracture Toughness in Mild Steel," J. Mech. Phys. Solids 21, 395-410 (1973) ${ }^{\dagger}$

13. D. P. Clausing, "Effect of Plastic Strain State on Ductility and Toughness," Int. J. Frac. Mech. 6(1), 71-85 (March 1970). ${ }^{\dagger}$

14. J. M. Barsom, "Relationship Between Plane-Strain Ductility and $\mathrm{K}_{\mathrm{Ic}}$ for Various Steels," Paper No. 71-PVP-13 presented at the First National Congress on Pressure Vessels and Piping, San Francisco, California, May 10-12, 1971. $\dagger$

15. J. G. Merkle, Union Carbide Corp. Nuclear Div., Oak Ridge Natl. Lab., "An Elastic-Plastic ThickWalled Hollow Cylinder Analogy for Analyzing the Strains in the Plastic Zone Just Ahead of a Notch Tip," ORNL-TM-4071, January 1973."

16. D. J. Naus et al., Martin Marietta Energy Systems, Inc., Oak Ridge Natl. Lab., "Crack-Arrest Behavior in SEN Wide Plates of Quenched and Tempered A 533 Grade B Steel Tested Under Nonisothermal Conditions," USNRC Report NUREG/CR-4930 (ORNL6388), August 1987."

17. D. J. Naus et al., Martin Marietta Energy Systems, Inc., Oak Ridge Natl. Lab., "High-Temperature CrackArrest Behavior in 152-mm-Thick SEN Wide Plates of Quenched and Tempered A 533 Grade B Class 1 


\section{References}

Steel," USNRC Report NUREG/CR-5330

(ORNL/TM-11083), April 1989.*

18. T. J. Theiss et al., Martin Marietta Energy Systems, Inc., Oak Ridge Natl. Lab., "Preliminary Results from Biaxial Shallow-Flaw Fracture Toughness Tests on Reactor Pressure Vessel Steel," ASME Pressure Vessel \& Piping Conference, Denver, Colorado, July 25-29, 1993. ${ }^{\dagger}$

19. ABAQUS Theory Manual, Version 4-8, Hibbith, Karlson, and Sorensen, Inc., Providence, R.I., 1989.*

20. B. R. Bass, D. K. M. Shum, and J. Keeney-Walker, Martin Marietta Energy Systems, Inc., Oak Ridge Natl. Lab., "Constraint Effects on Fracture Toughness for Circumferentially Oriented Cracks in Reactor Pressure Vessels," USNRC Report NUREG/CR-6008 (ORNL/ TM-12131), 1992.*

21. K. Wallin, "Statistical Aspects of Constraint with Emphasis on Testing and Analysis of Laboratory Specimens in the Transition Region," pp. 264-288 in Constraint Effects in Fracture, ASTM STP 1171, E. M. Hackett, K. H. Schwalbe, and R. H. Dodds, Eds., American Society for Testing and Materials, 1993 . $^{\dagger}$

22. J. M. Barsom and S. T. Rolfe, Fracture and Fatigue Control in Structures-Applications in Fracture
Mechanics, 2nd Ed., Prentice-Hall, Englewood Cliffs, New Jersey, 1987. ${ }^{\dagger}$

23. D. K. M. Shum et al., Martin Marietta Energy Systems, Inc., Oak Ridge Natl. Lab., "Analytical Studies of Transverse Strain Effects on Fracture Toughness for Circumferemtially Oriented Cracks," USNRC Report NUREG/CR-5592 (ORNL/ TM-11581), April 1991.*

24. J. Heerens et al., "Interpretations of Fracture Toughness in the Ductile-to-Brittle Transition Region by Fractographical Observations," in Defect Assessment in Components-Fundamentals and Applications, ESIS/EGF9, J. G. Blauel and K.-H. Schwalbe, Eds. (Mechanical Engineering Publications, London, 1991), pp. 659-678. ${ }^{\dagger}$

25. J.-C. Devaux et al., "Experimental and Numerical Validation of Ductile Fracture Local Criterion Based on a Simulation of Cavity Growth," pp. 7-23 in Nonlinear Fracture Mechanics: Volume II-Elastic Plastic-Fracture, ASTM STP 995, J. D. Landes, A. Saxena, and J. G. Merkle, Eds., American Society for Testing and Materials, Philadelphia, 1989. $\dagger$

\footnotetext{
* Available for purchase from the National Technical Information Service, Springfield, VA 22161.

${ }^{\dagger}$ Available in public technical libraries.
} 


\section{Appendix A}

\section{Small-Scale Yielding Solution}

The SSY reference solution is determined using a boundary layer model (BLM) and a uniaxial stress-strain curve appropriate for the material under consideration. Figure A.1(a) depicts a semicircular finite-element model of the near-crack-tip region used in the boundary layer approach. The model incorporates a highly refined cracktip region [Fig. A.1(b)] with an initial root radius at the tip $10^{-6}$ times the outer radius of the mesh. The mesh is defined by 1977 nodes and 624 eight-noded isoparametric plane strain elements. A linear-elastic $\mathrm{K}_{I}$ field is imposed on the model through the appropriate displacement boundary conditions. To ensure SSY conditions in the model, the maximum extent of plastic zone is limited to $<10 \%$ of the outer radial dimension.

The material properties used for all calculations presented herein include Young's modulus $E=205,170 \mathrm{MPa}$, Poisson's ratio $v=0.25$, and the piecewise-linear uniaxial stress-strain curve depicted in Fig. 3.3.

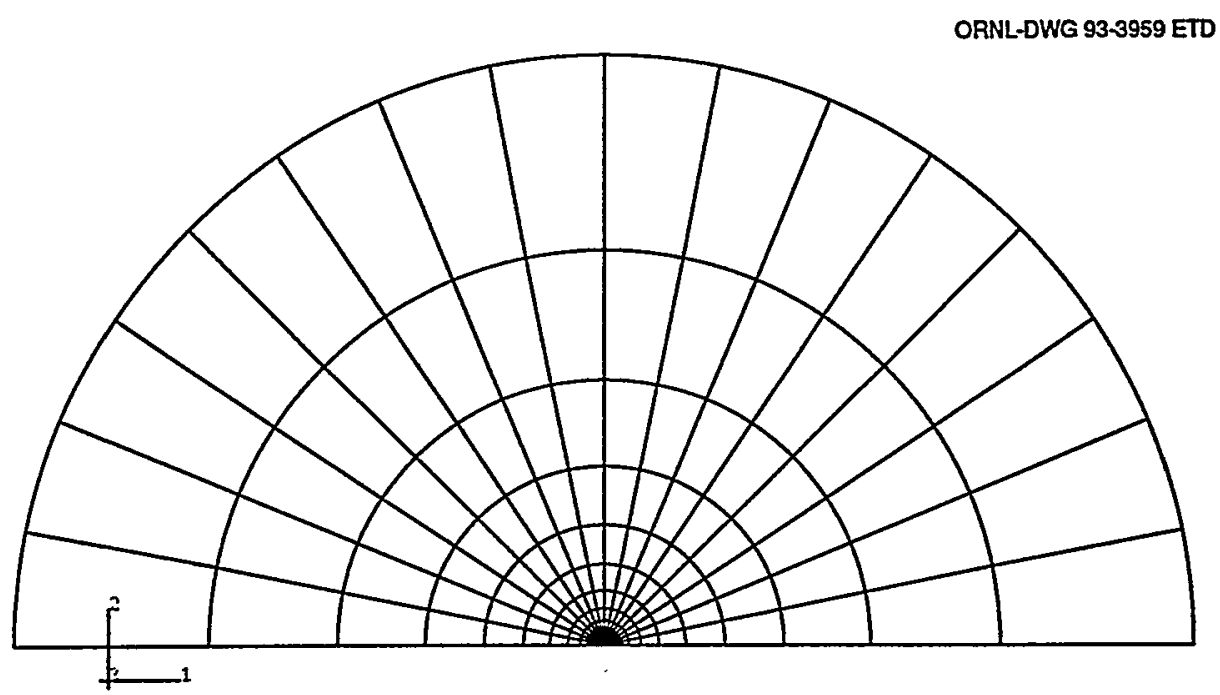

(a)

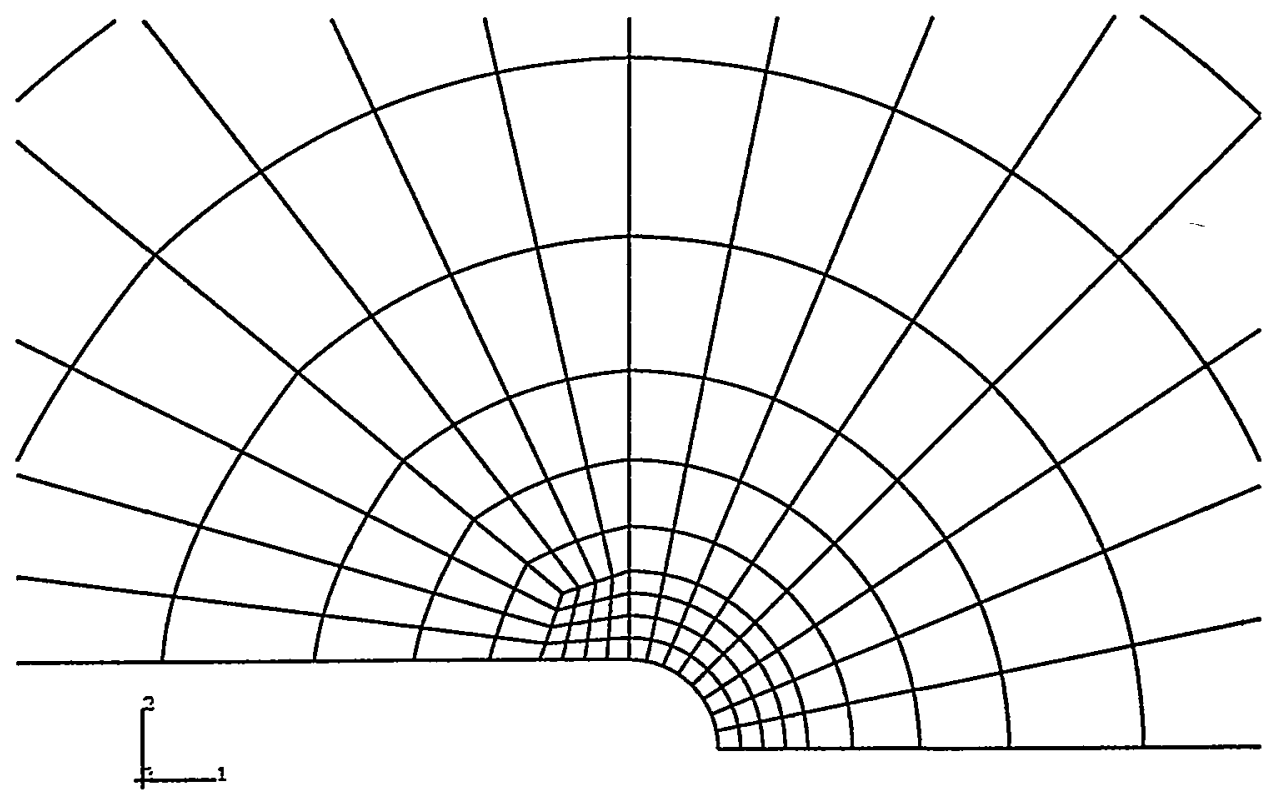

(b)

Figure A.1 (a) Finite-element model employed to obtain SSY reference solution; (b) crack-tip region of SSY finiteelement model 


\section{Appendix A}

The plane strain reference fields determined from the BLM are shown in Fig. A.2 for both finite strain and small strain formulations. In Fig. A.2, the normalized opening-mode stress is plotted vs normalized distance in front of the crack tip. A typical feature of these fields is that the finite strain and small strain solutions are essentially the same for values of $r \sigma_{0} / \mathrm{J}>2$.

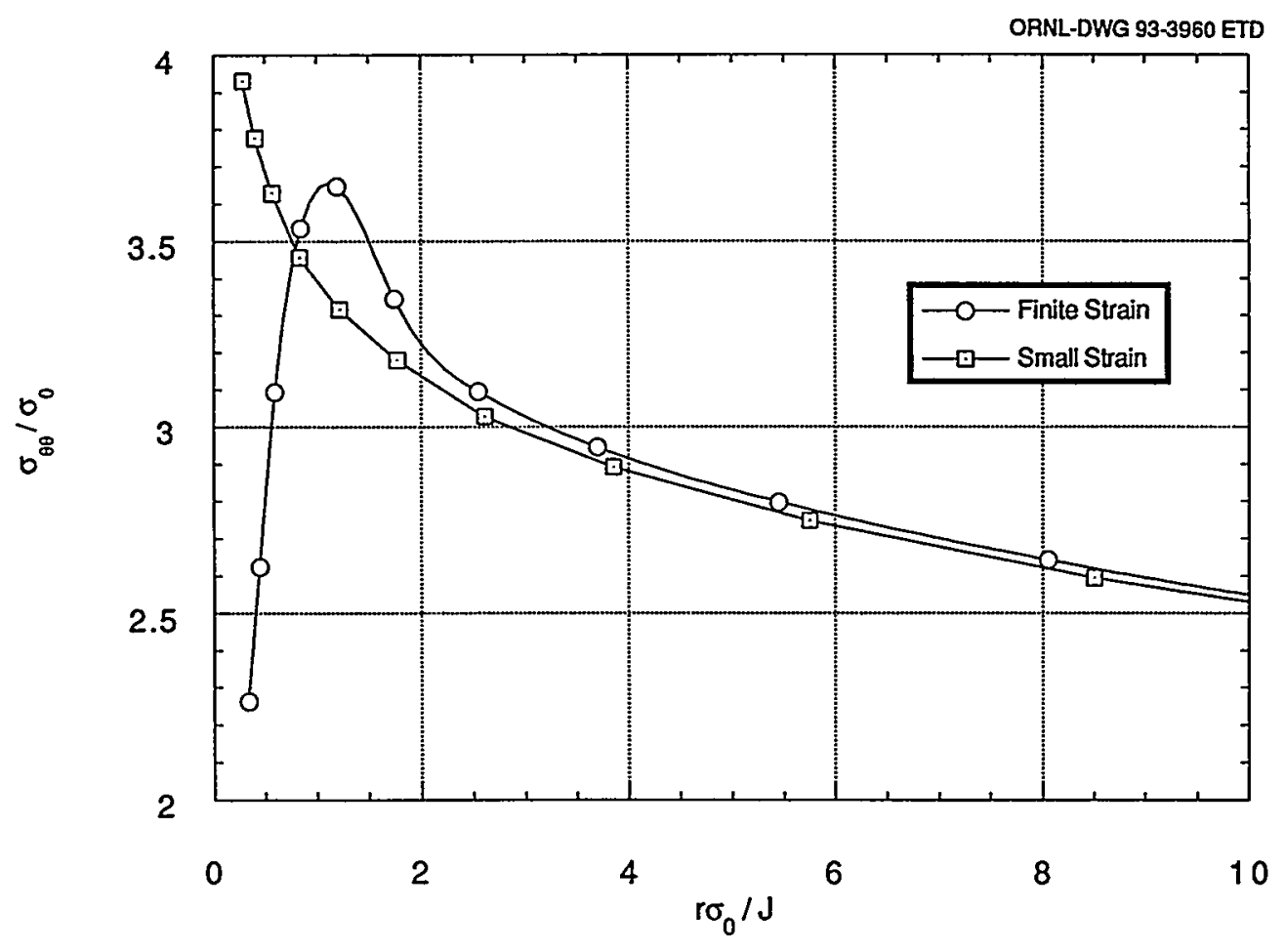

Figure A.2 SSY plane strain reference fields for cruciform bend specimen 


\section{Appendix B}

\section{Finite Strain Calculations}

The crack-tip constraint analyses presented in the main body of this report were computed using a small strain, finite-element formulation. Finite strain calculations are provided here for completeness. The finite strain calculations presented in Figs. B.1-B.11 can be directly compared with the small strain calculations given in Chap. 3. Interpretations of biaxial loading effects on stress triaxiality are unchanged from those presented earlier for a small strain formulation.

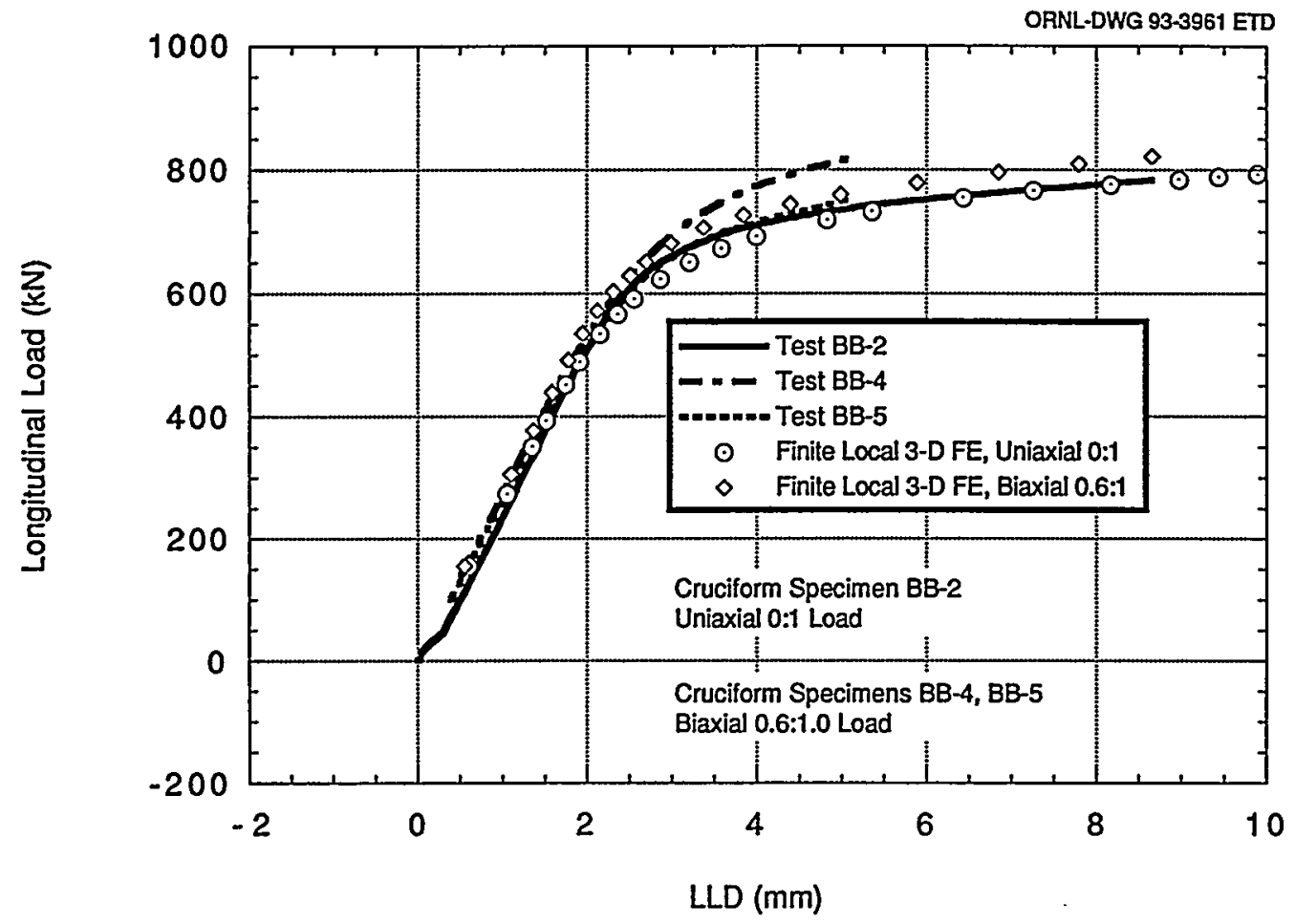

Figure B.1 Comparison of calculated (finite strain) and measured LLD for cruciform bend specimens 


\section{Appendix B}

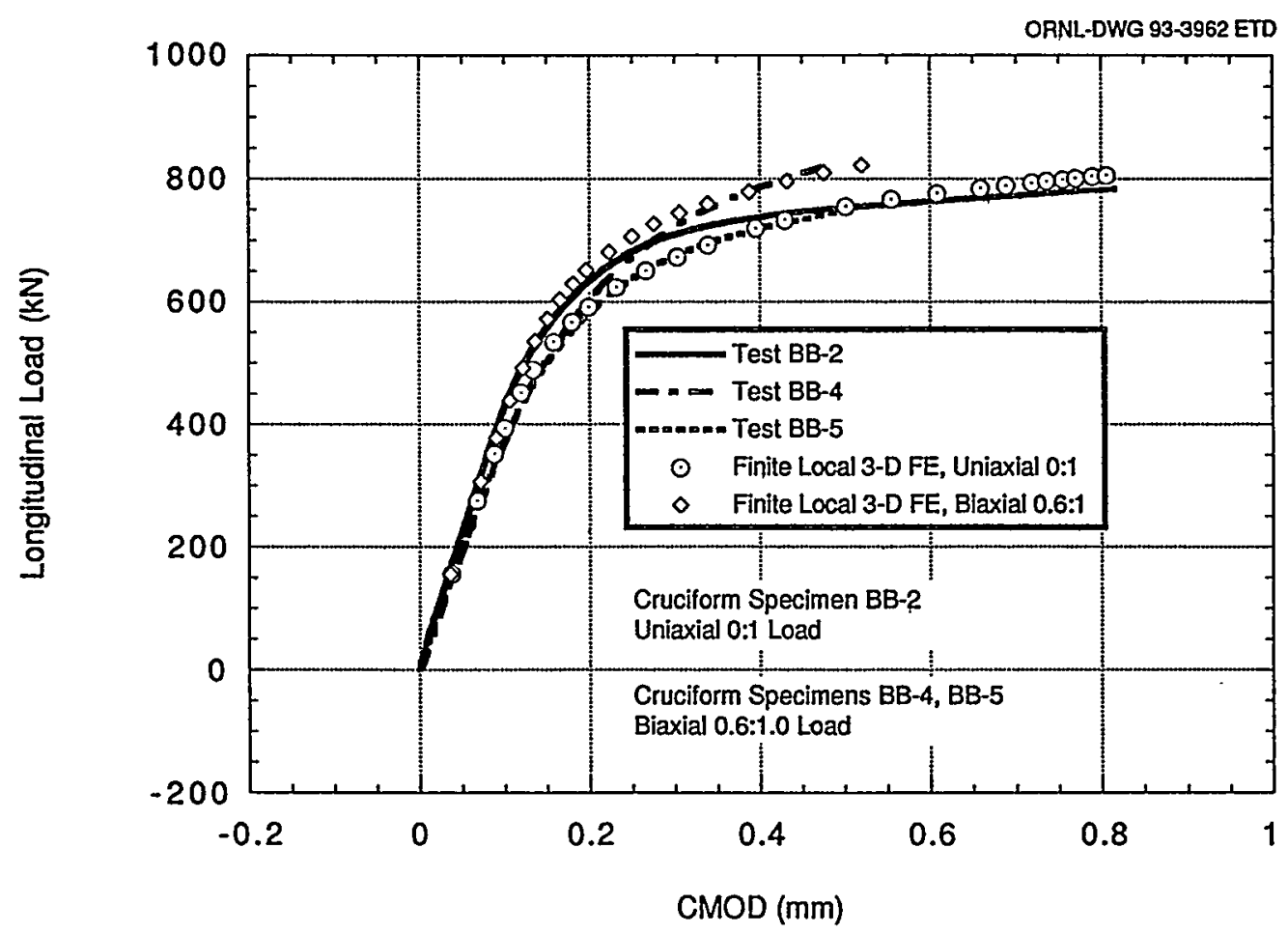

Figure B.2 Comparison of calculated (finite strain) and measured CMOD for cruciform bend specimens

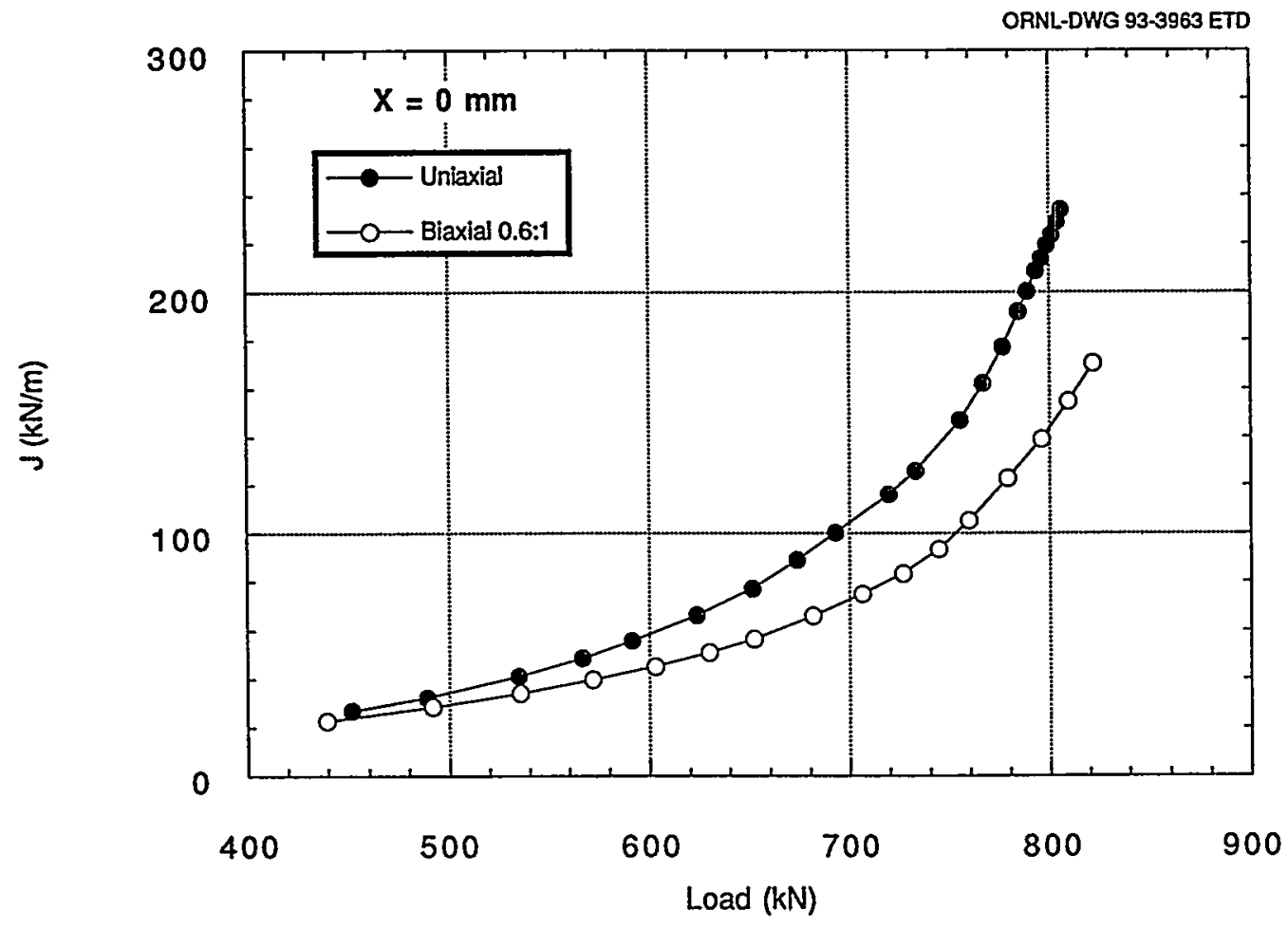

Figure B.3 Applied J at specimen midplane (X=0 mm) (finite strain) 
ORNL-DWG 93-3964 ETD

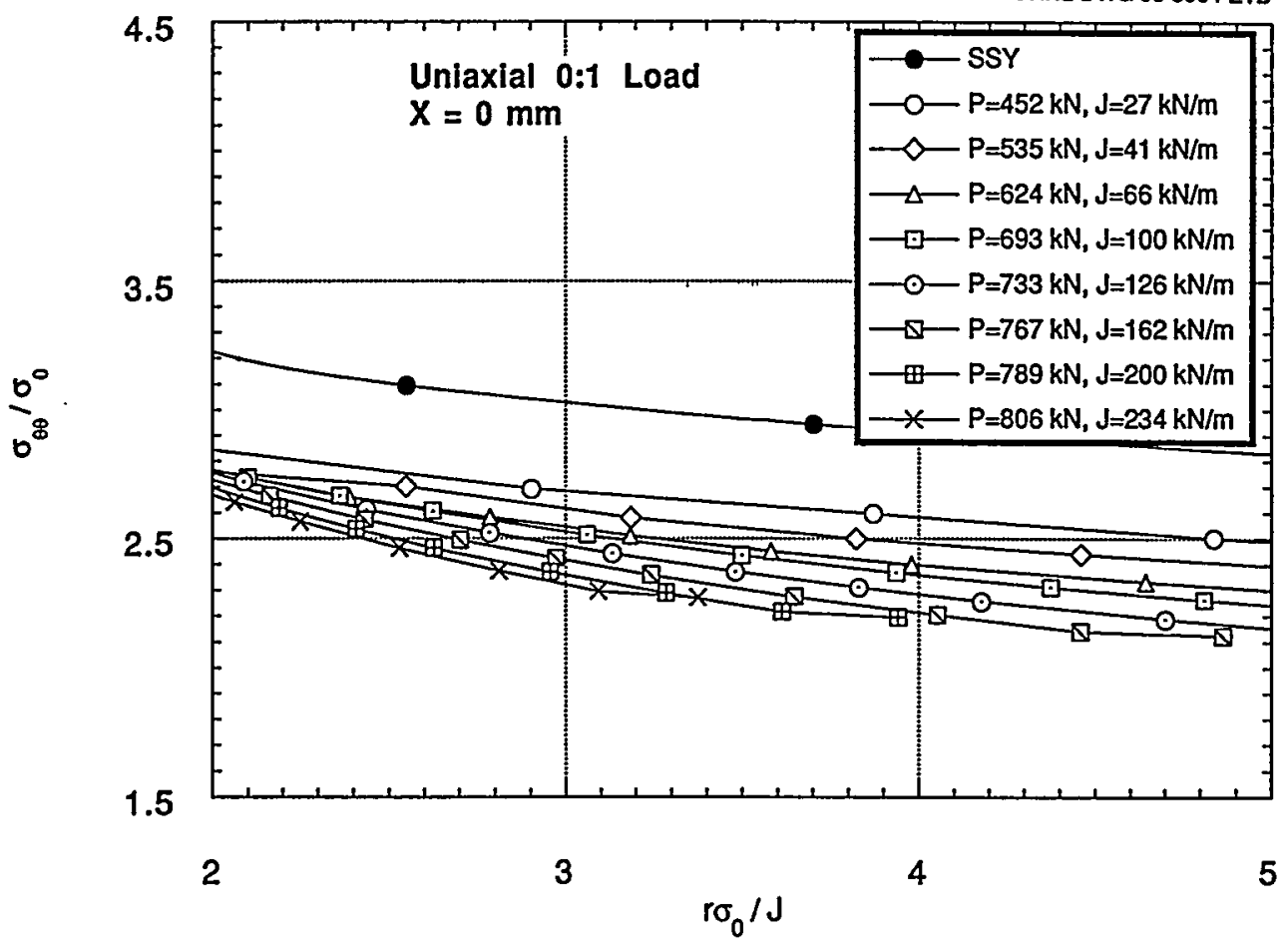

Figure B.4 Normalized opening-mode stress ahead of crack tip, $X=0 \mathrm{~mm}$, uniaxial loading (finite strain)

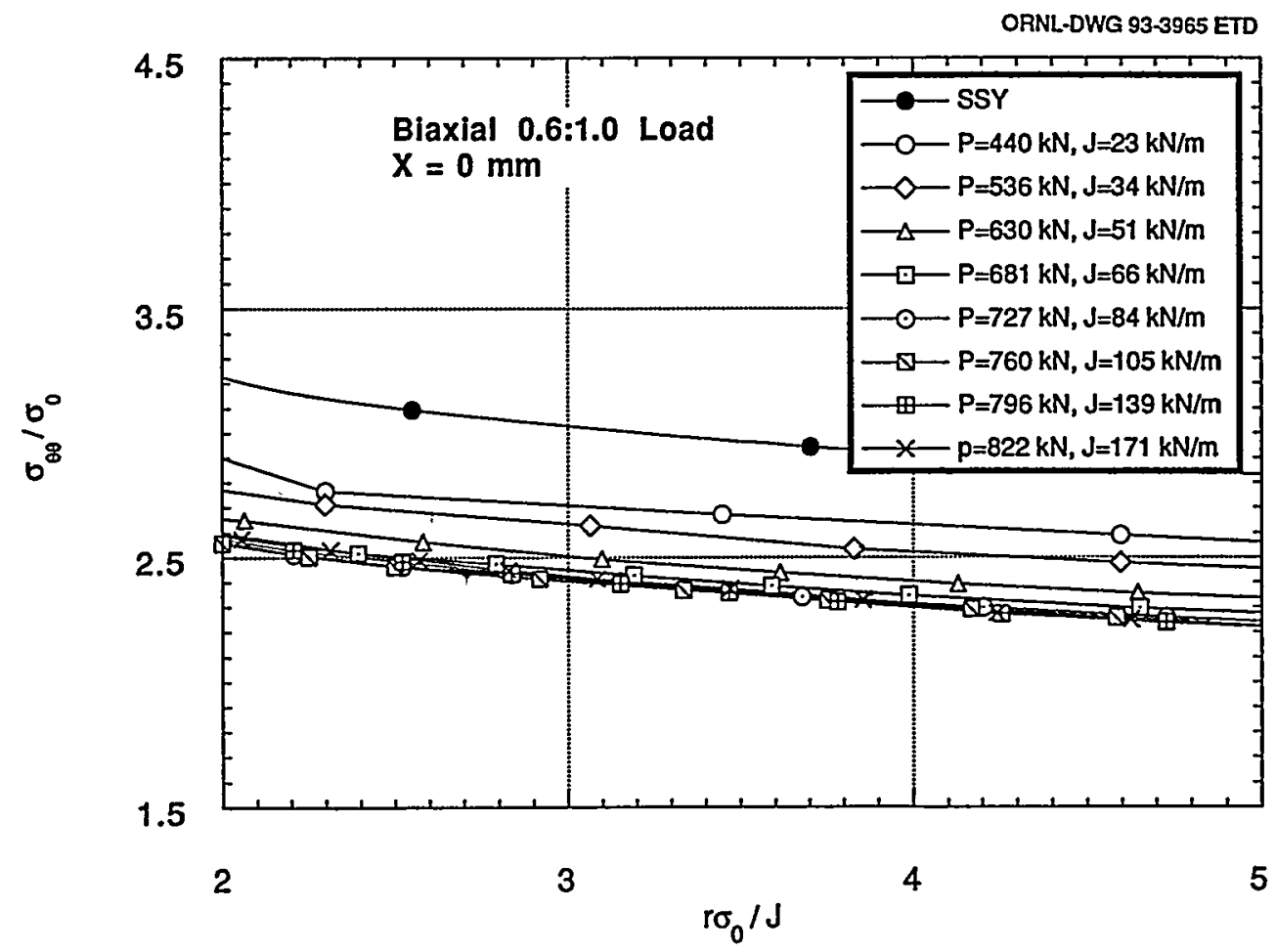

Figure B.5 Normalized opening-mode stress ahead of crack tip, $X=0 \mathrm{~mm}$, biaxial 0.6:1 loading (finite strain) 
Appendix B

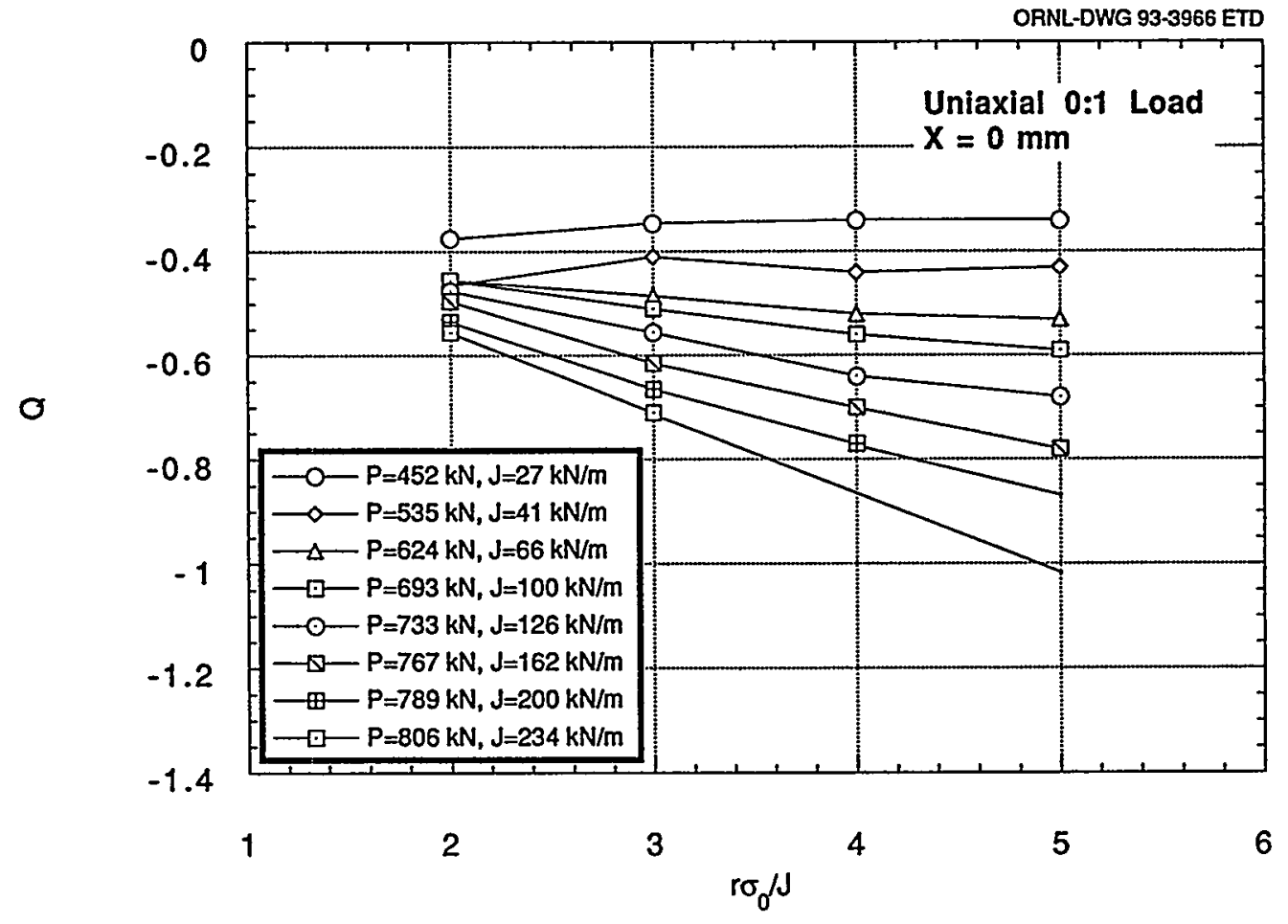

Figure B.6 Variation of $Q$ with normalized distance ahead of crack tip, $X=0 \mathrm{~mm}$, uniaxial loading (finite strain)

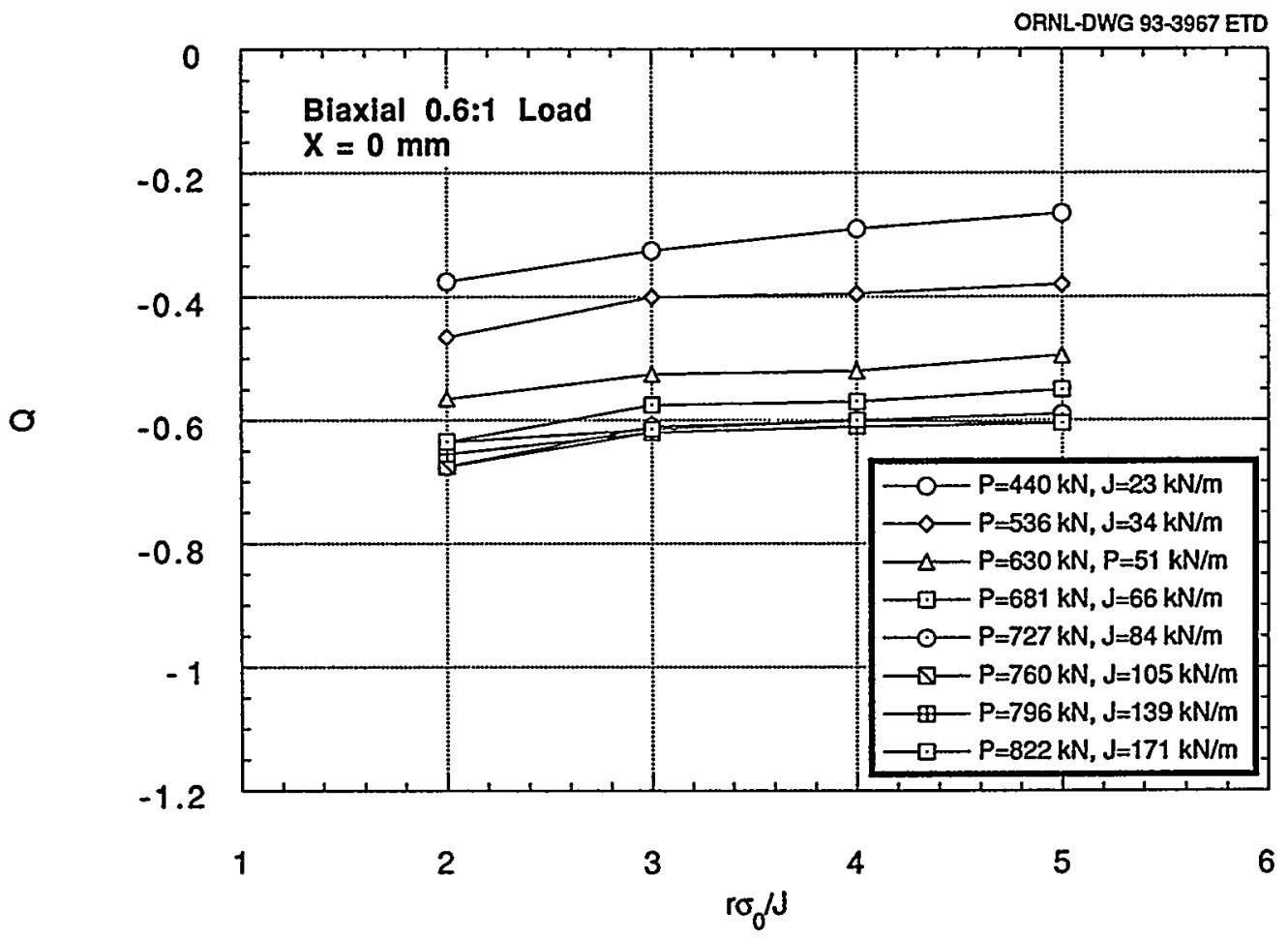

Figure B.7 Variation of $Q$ with normalized distance ahead of crack tip, $X=0 \mathrm{~mm}$, biaxial 0.6:1 loading (finite strain) 


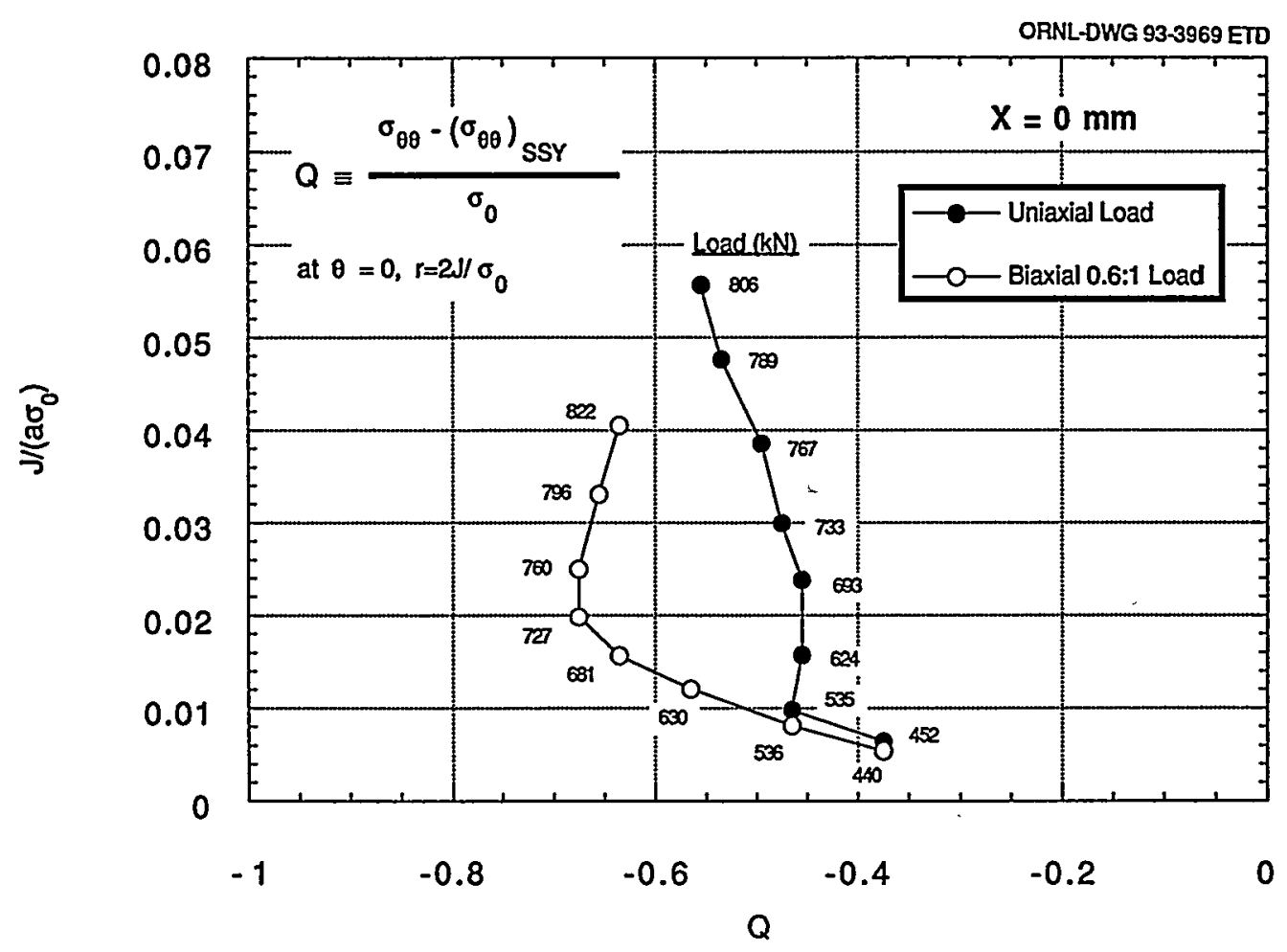

Figure B.8 J-Q trajectories at $X=0 \mathrm{~mm}$ for normalized distance $r \sigma_{0} / \mathrm{J}=2$ (finite strain)

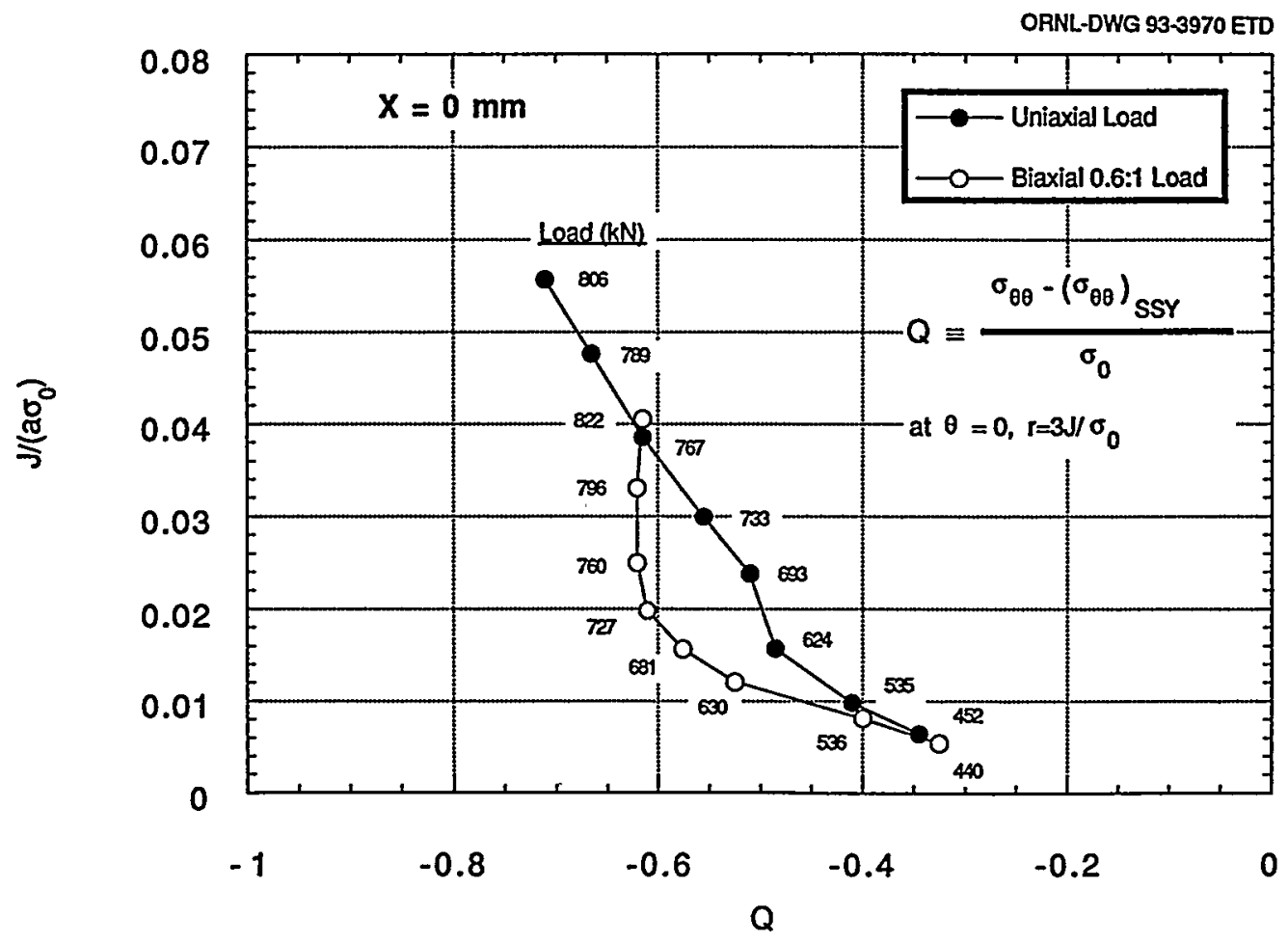

Figure B.9 J-Q trajectories at $X=0 \mathrm{~mm}$ for normalized distance $r \sigma_{0} / J=3$ (finite strain) 


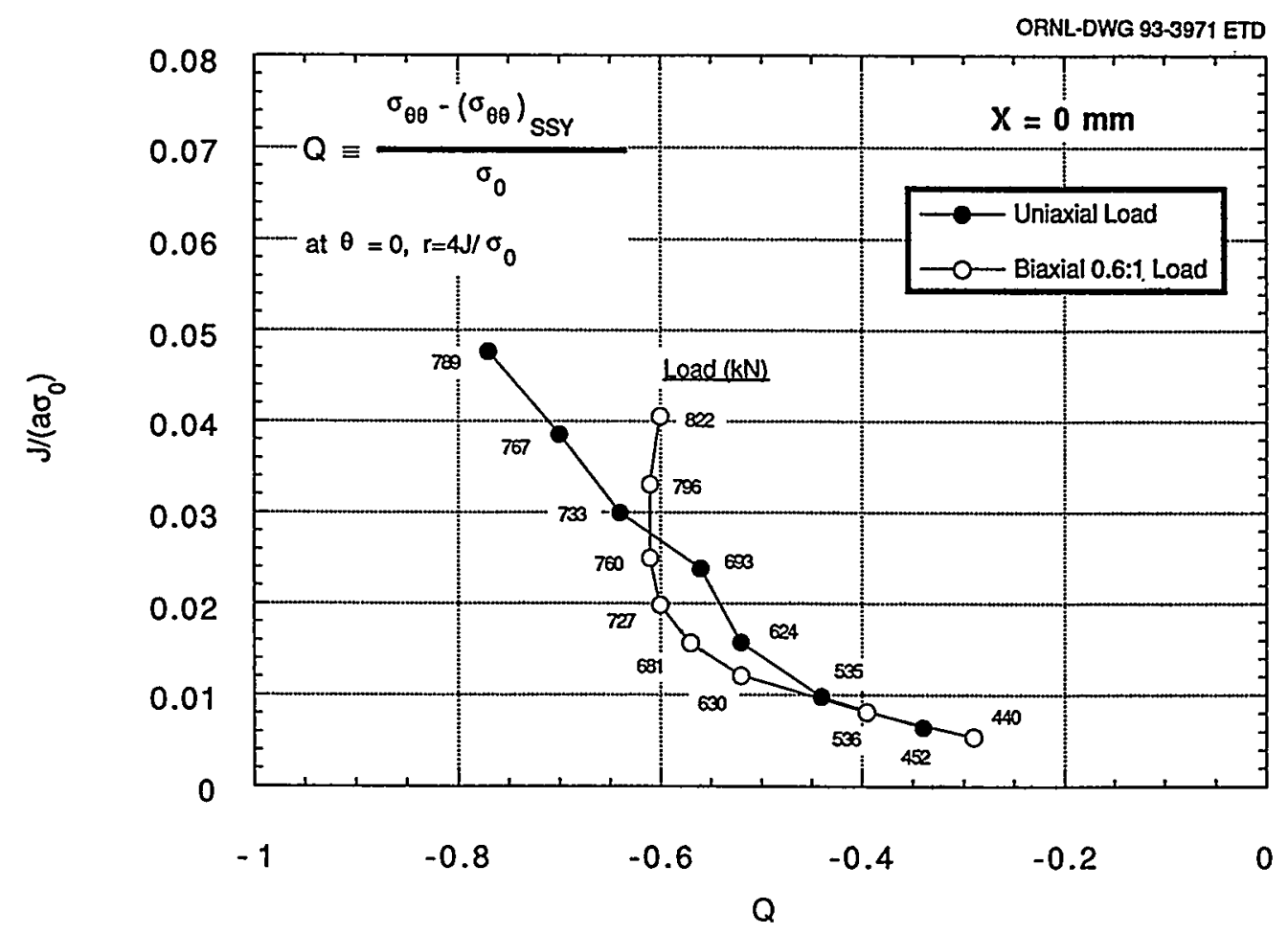

Figure B.10 $\mathrm{J}-\mathrm{Q}$ trajectories at $\mathrm{X}=0 \mathrm{~mm}$ for normalized distance $r \sigma_{0} \mathrm{~J}=4$ (finite strain)

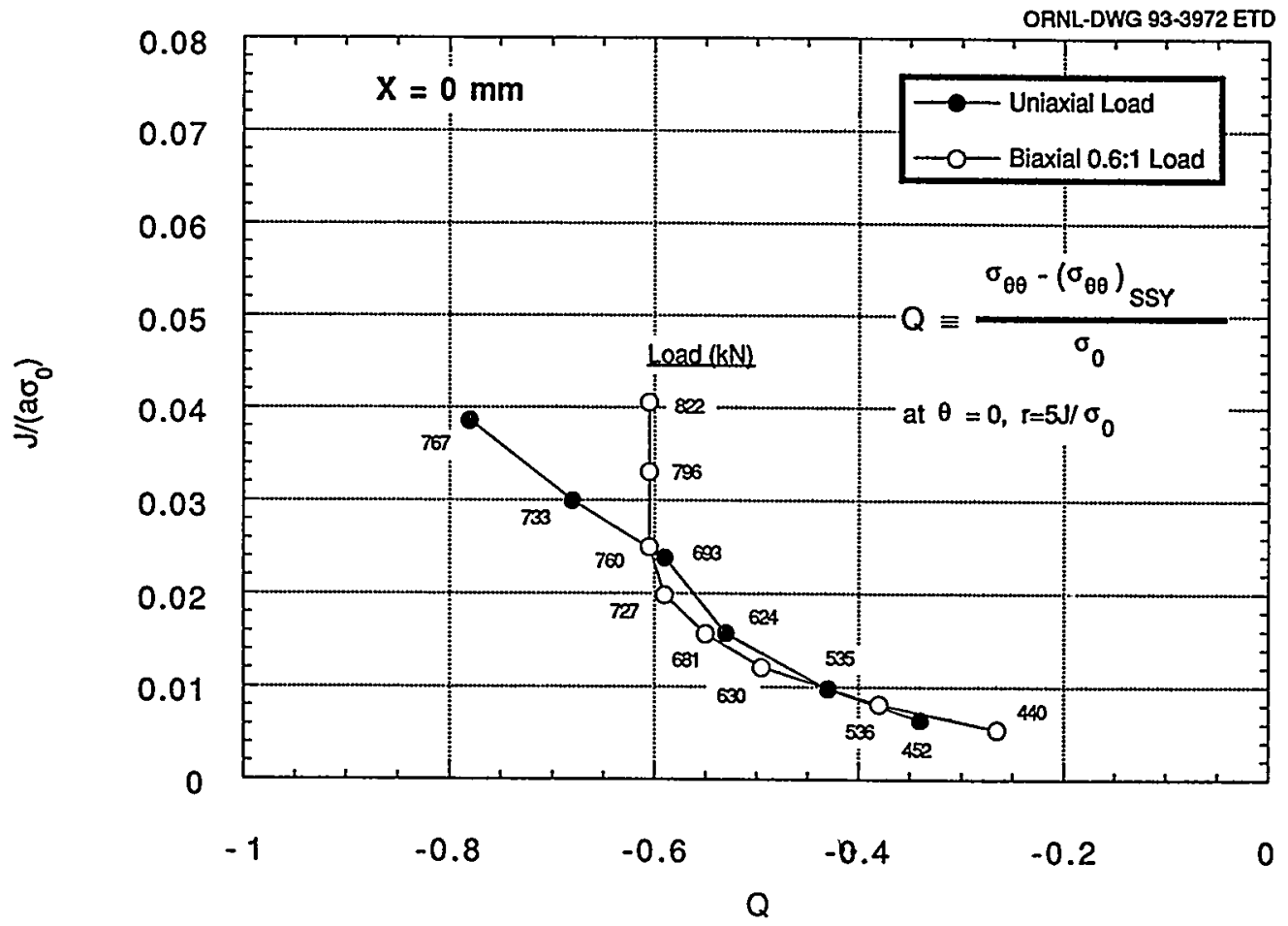

Figure B.11 J-Q trajectories at $X=0 \mathrm{~mm}$ for normalized distance $r \sigma_{0} / J=5$ (finite strain) 
NUREG/CR-6132

ORNL/TM-12498

Dist. Category RF

\section{Internal Distribution}

1. D. J. Alexander

2-5. B. R. Bass

6. J. W. Bryson

7. R. D. Cheverton

8. J. M. Corum

9. W. R. Corwin

10. T. L. Dickson

11-12. R. G. Gilliland

13. F. M. Haggag

14. D. M. Hetrick

15. W. F. Jackson

16. S. K. Iskander

17. J. A. Keeney

18. W. J. McAfee
19. D. E. McCabe

20. J. G. Merkle

21. R. K. Nanstad

22-26. W. E. Pennell

27. C. E. Pugh

28. M. C. Rao

29. C. C. Southmayd

30-35. T. J. Theiss

36. G. E. Whitesides

37. ORNL Patent Section

38. Central Research Library

39. Document Reference Section

40-41. Laboratory Records

42. Laboratory Records (RC)

\section{External Distribution}

43. L. C. Shao, Director, Division of Engineering, RES, U.S. Nuclear Regulatory Commission, Washington, DC 20555

44. J. R. Strosnider, Materials and Chemical Engineering Branch, NRR, U.S. Nuclear Regulatory Commission, Washington, DC 20555

45-47. S. N. M. Malik, Division of Engineering, U.S. Nuclear Regulatory Commission, Washington, DC 20555

48. M. E. Mayfield, Division of Engineering, U.S. Nuclear Regulatory Commission, Washington, DC 20555

49. G. R. Irwin, Department of Mechanical Engineering, University of Maryland, College Park, MD 20742

50. L. James, Westinghouse Bettis Lab., P.O. Box 79, ZAP 13A, 814 Pittsburgh McKeesport Blvd., West Mifflin, PA 15122

51. C. F. Shih, Box D, Division of Engineering, Brown University, Providence, RI 02912

52. R. Dodds, 3140 Newmark Laboratory, 205 North Matthews, Urbana, IL 61801

53. R. Fields, National Institute of Standards and Technology, Bldg. 223, B144, Gaithersburg, MD 20899

54. W. L. Fourney, Department of Mechanical Engineering, University of Maryland, College Park, MD 20742

55. J. D. Landes, The University of Tennessee, Knoxville, TN 37996-2030

56. S. T. Rolfe, The University of Kansas, Lawrence, KS 66045-2235

57. G. M. Wilkowsky, Battelle Columbus Division, Columbus, $\mathrm{OH} 43201$

58. C. W. Schwartz, Department of Civil Engineering, University of Maryland, College Park, MD 20742

59. E. T. Wessel, 312 Wolverine, Haines City, FL 33844

60. Office of Assistant Manager for Energy Research and Development, DOE-ORO, Oak Ridge, TN 37831

61. Commander and Director USAE Waterways Experiment Station, Attn: CEWES-IM-MI-R, Alfrieda S. Clark, CD Dept./\#1072, 3909 Halls Ferry Road, Vicksburg, MS 39180-6199

62-63. Office of Scientific and Technical Information, P. O. Box 62, Oak Riuge, TN 37831

64. Y. J. Chao, Mechanical Engineering, The University of South Carolina, Columbia Campus, Columbia, SC 29208

65. T. L. Anderson, Department of Mechanical Engineering, Texas A\&M University, College Station, TX 77843

66. J. M. Joyce, U.S. Naval Academy, Annapolis, MD 21402 
Biaxial Loading and Shallow-Flaw Effects on Crack-Tip Constraint and Fracture Toughness

3. DATE REPORT PUBLISHED \begin{tabular}{l|r} 
MDNTH & YEAR \\
January & 1994
\end{tabular}

4. FIN OR GRANT NUMBER $\mathrm{B} 0119$

6. TYPE OF REPORT

B0119

7. PERIOD COVERED (Ine/uUu Oates)

Technical

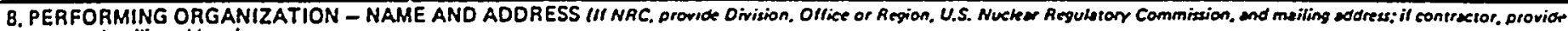
name and mailing adorets

Oak Ridge National Laboratory

Oak Ridge, Tennessee 37831-6285

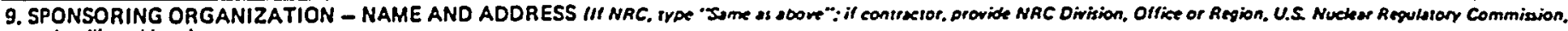
end malling eddreat

Division of Engineering

Office of Nuclear Regulatory Research

U.S. Nuclear Regulatory Commission

Washington, DC 20555 -0001

10. SUPPLEMENTARY NOTES

11. ABSTRACT (200 words or lest)

A program to develop and evaluate fracture methodologies for the assessment of crack-tip constraint effects on fracture toughness of reactor pressure vessel (RPV) steels has been initiated in the Heavy-Section Steel Technology (HSST) Program. Crack-tip constraint is an issue that significantly impacts fracture mechanics technologies employed in safety assessment procedures for commercially licensed nuclear RPVs. The focus of studies described herein is on the evaluation of two stressed-based methodologies for quantifying crack-tip constraint (i.e., J-Q theory and a micromechanical scaling model based on critical stressed volumes) through applications to experimental and fractographic data. Data were utilized from single-edge notch bend (SENB) specimens and HSST-developed cruciform beam specimens that were tested in HSST shallow-crack and biaxial testing programs. Results from applications indicate that both the J-Q methodology and the micromechanical scaling model can be used successfully to interpret experimental data from the shallow- and deep-crack SENB specimen tests. When applied to the uniaxially and biaxially loaded cruciform specimens, the two methodologies showed some promising features, but also raised several questions concerning the interpretation of constraint conditions in the specimen based on near-tip stress fields. Fractographic data taken from the fracture surfaces of the SENB and cruciform specimens are used to assess the relevance of stress-based fracture characterizations to conditions at cleavage initiation sites. Unresolved issues identified from these analyses require resolution as part of a validation process for biaxial loading applications. This report is designated as HSST Report No. 142.

12. KEY WORDS/DESCR!PTORS (List words or phreses that will estist retearthers in loceling ine report.)

13. AVAILABILITY STATEMENT

Unlimited

A533 Grade B class 1 steel

Shallow-crack beam

Constraint Analysis

Biaxial loading

Factography
Elastic-plastic fracture mechanics

Fracture toughness data

J-Q Methodology

Constraint Adjustment model

Cruciform beam
14. SECURITY CLASSIFICATION

(This Pagl

Unclassified

Tran Reporil

Unclassified

15. NUMBEA OF PAGES 